\title{
Crop residue decomposition and stabilization in soil organic matter
}

\author{
Dissertation \\ to attain the doctoral degree (Dr. sc. agr.) \\ of the Faculty of Agricultural Sciences \\ Georg-August-Universität Göttingen, Germany
}

Submitted by

Muhammad Shahbaz

born in Narowal, Pakistan

Göttingen, Dec 2016 
Thesis committee

1) Prof. Dr. Yakov Kuzyakov. Department of Soil Science of Temperate Ecosystems, and Department of Agricultural Soil Science, Georg-August-University of Göttingen

2) Prof. Dr. Andrea Carminati. Department of Soil Hydrology, Georg-August-University of Göttingen

3) PD Dr. Evgenia Blagodatskaya. Department of Soil Science of Temperate Ecosystems, Georg-August-University of Göttingen

4) Dr. Felix Heitkamp. Department of Physical Geography, Georg-August-University of Göttingen

Date of oral examination: $.02 \mathrm{Feb} 2017$ 
To my parents

$$
\text { and my son }
$$

Arham Shahbaz 


\section{Preface}

The German Academic Exchange Service (DAAD) provided a scholarship for the doctoral study at the Georg-August University of Göttignen. Subsequent research work was funded by Deutsche Forschungsgemeinschaft (DFG). The dissertation is being submitted to the Faculty of Agricultural Sciences under the doctoral degree program of Graduate School in Forest and Agriculture Sciences (GFA), to fulfill the requirements for the acquisition of the doctoral degree of agricultural sciences 'Doctor scientiarum agrariarum' (Dr. sc. agr.).

The presented dissertation is cumulative based on three papers as the first author, which are published in the international refereed journals, and on an additional study (study 4, in preparation). The published manuscripts are included in chapters 3 .

The focus of the general introduction (chapter 1) is on the theoretical background of the soil organic matter and the need of work. Chapter 2 presents the objectives, study site, methods and summary of the main results. Whereas specific introductions on the effects of crop residue decomposition and stabilization in soil organic matter are given in chapter 3 comprising following manuscripts.

Chapter 3.1

Shahbaz M, Kuzyakov Y, Heitkamp F: Decrease of soil organic matter stabilization with increasing inputs: Mechanisms and controls. Geoderma (2016). doi: org/10.1016/j.geoderma.2016.05.019

\section{Chapter 3.2}

Shahbaz M, Kuzyakov Y, Sanaullah M, Heitkamp F, Zelenev V, Kumar A, Blagodatskaya E (2016) Microbial decomposition of soil organic matter is mediated by quality and quantity of crop residues: mechanisms and thresholds. Biology and Fertility of Soils (2016). doi: 10.1007/s00374-016-1174-9

\section{Chapter 3.3}

Shahbaz M, Kuzyakov Y, Maqsood M, Wendland M, Heitkamp F: Decadal nitrogen fertilization decreases mineral-associated and subsoil carbon: a 32 years study. Land degradation and development (2016). doi: 10.1002/1dr.2667 


\section{Table of contents}

\section{Contents}

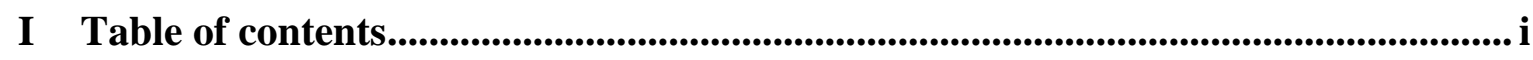

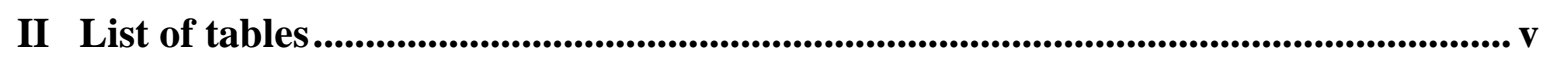

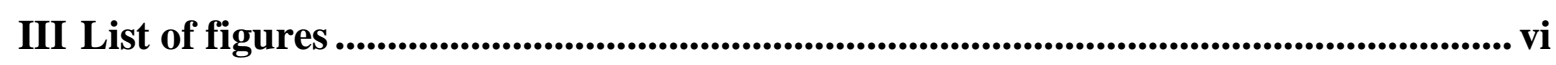

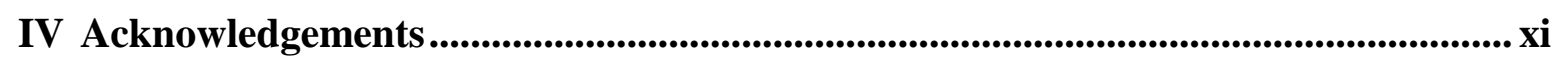

V List of abbreviations..................................................................................................

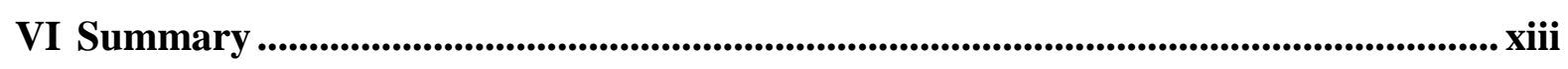

1 General introduction............................................................................................ 1

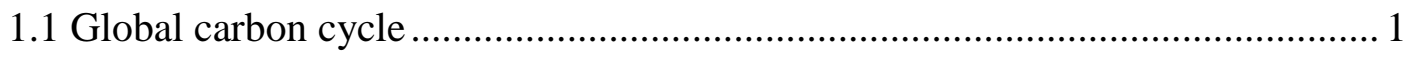

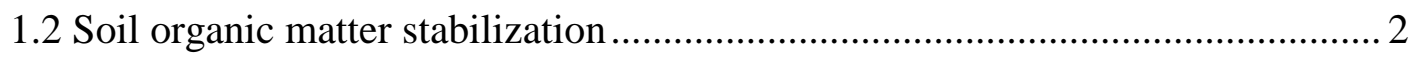

1.3 Impact of long-term C inputs on SOM .......................................................... 3

1.3.1 Alteration of soil physical properties.......................................... 5

1.3.2 Change in crop residue quality ................................................... 6

1.3.3 Residue partitioning with SOM fractions ................................... 7

1.3.4 Stabilization in subsoil.......................................................... 7

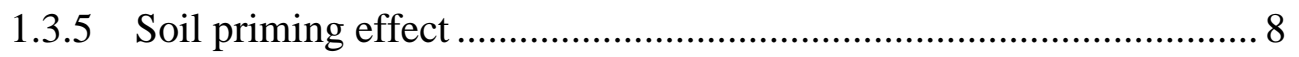

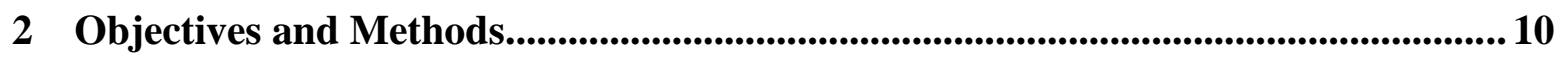

2.1 Objectives ........................................................................................................................ 10

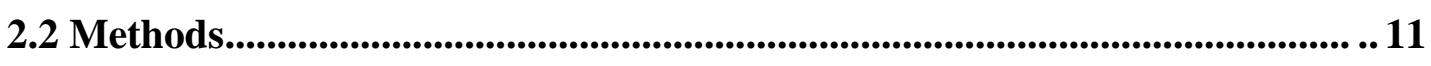

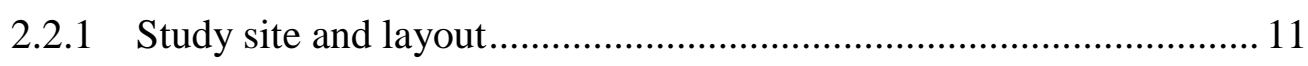

2.2.2 Soil sampling ................................................................. 13

2.3 Summary of experiments and main results.......................................................... 14

3 Publications and Manuscripts.............................................................................................. 16

3.1 Study 1: Decrease of soil organic matter stabilization with increasing

inputs: mechanisms and controls ............................................................................. 16

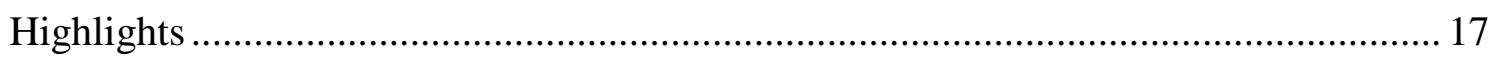

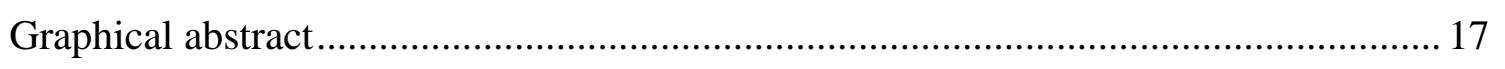

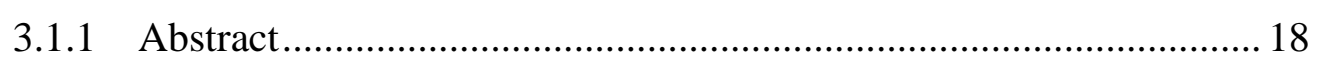

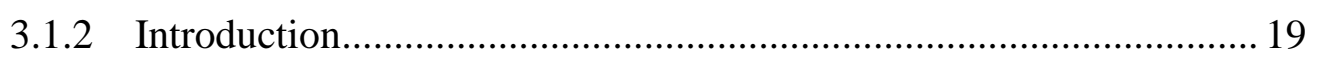

3.1.3 Materials and methods ............................................................. 21 


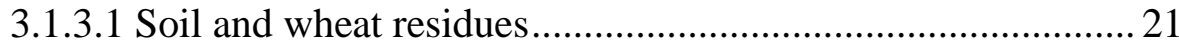

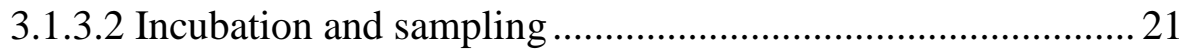

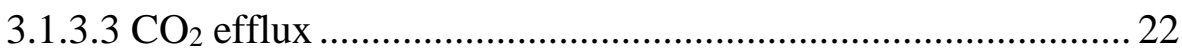

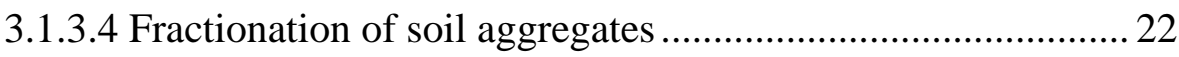

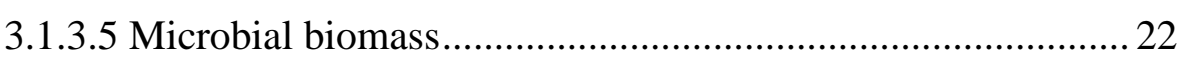

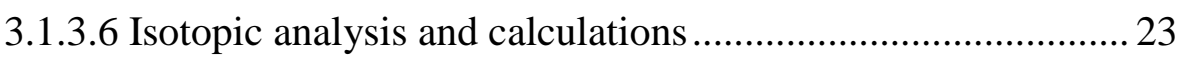

3.1.3.7 Statistical analysis ......................................................... 24

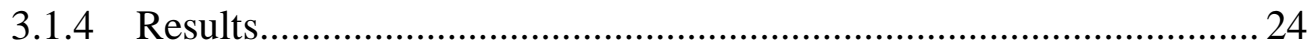

3.1.4.1 Effect of residue addition on aggregates and $\mathrm{C}$ distribution.. 24

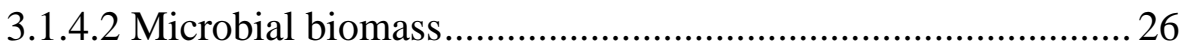

3.1.4.3 Mineralization ................................................................. 26

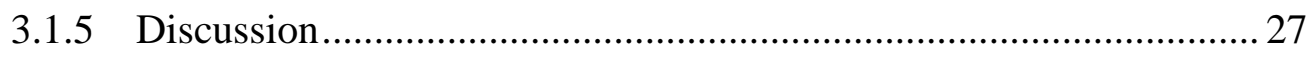

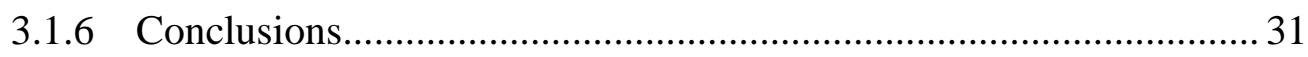

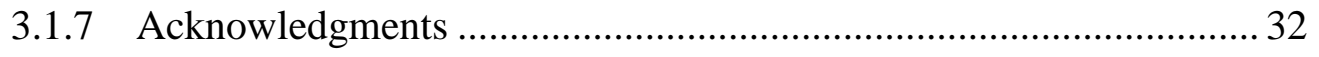

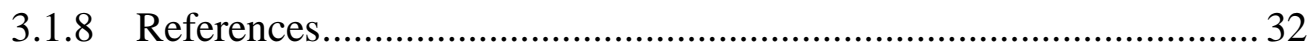

3.2 Study 2: Microbial decomposition of soil organic matter is mediated by quality and quantity of crop residues: mechanisms and thresholds.............. 37

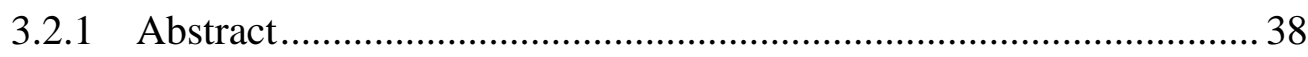

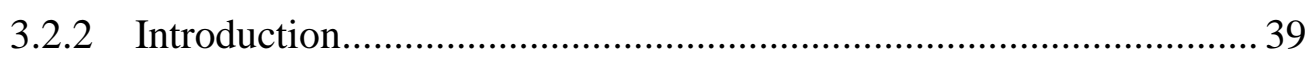

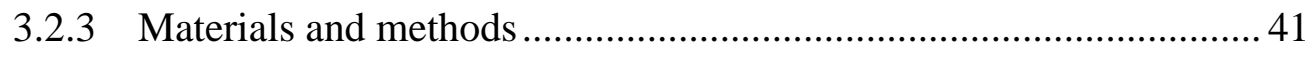

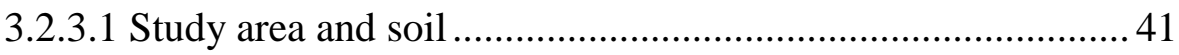

3.2.3.2 Production of ${ }^{13} \mathrm{C}$-labeled plant residues ............................ 41

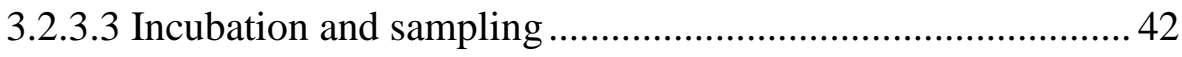

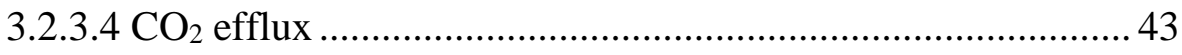

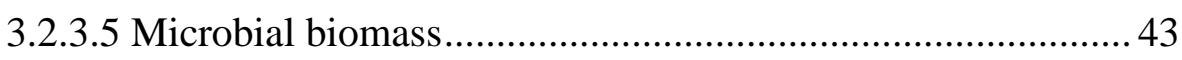

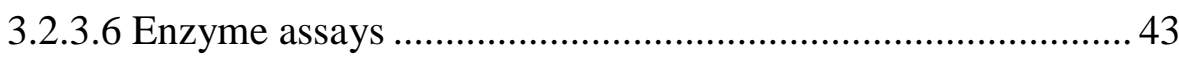

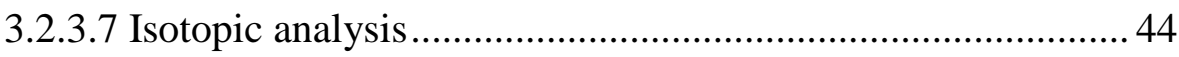

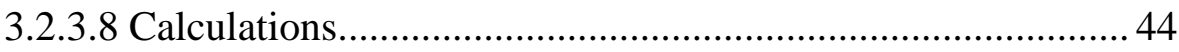

3.2.3.9 Threshold values for PE increase ......................................... 45

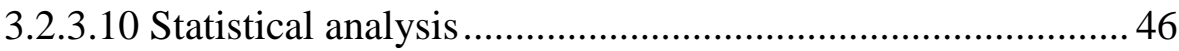

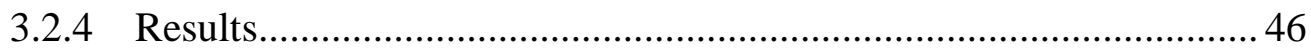

3.2.4.1 ${ }^{13} \mathrm{C}$ in plant residues during incubation............................... 46 
3.2.4.2 Residue and soil organic matter mineralization.................... 47

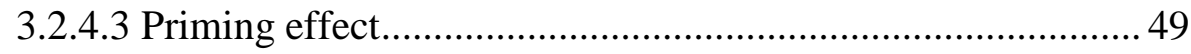

3.2.4.4 Microbial biomass................................................................. 51

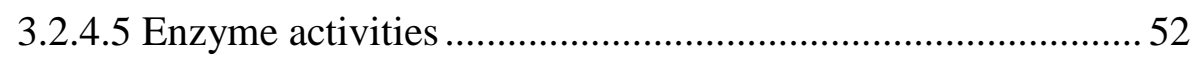

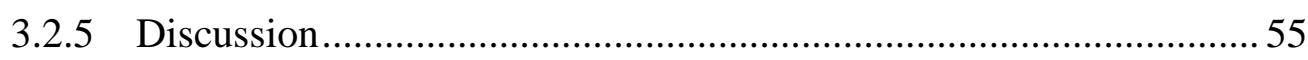

3.2.5.1 Residue and soil organic matter decomposition .................... 55

3.2.5.1.1 Residue quality effects ....................................... 55

3.2.5.1.2 Priming effect as a function of residue mineralization

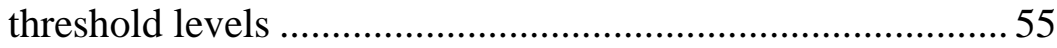

3.2.5.2 Mechanisms of priming effect ............................................ 56

3.2.5.2.1 Apparent and real priming effect in relation to residue

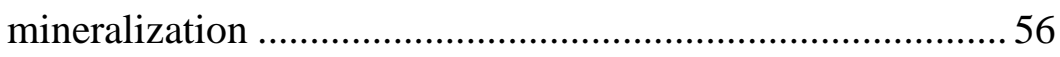

3.2.5.2.2 Priming effect mechanisms in relation to microbial

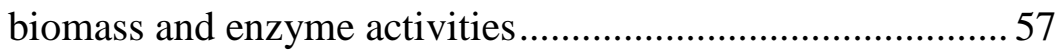

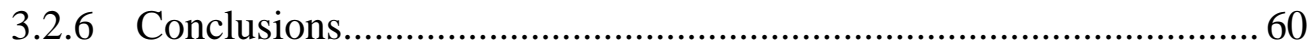

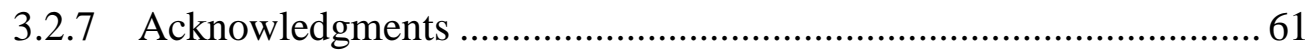

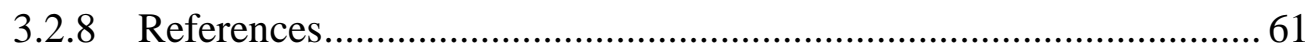

3.3 Study 3: Decadal nitrogen fertilization decreases mineral-associated and subsoil carbon: a 32 year study ................................................................................ 68

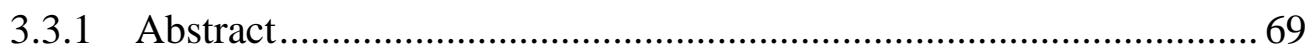

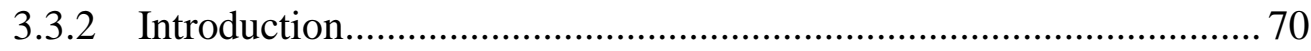

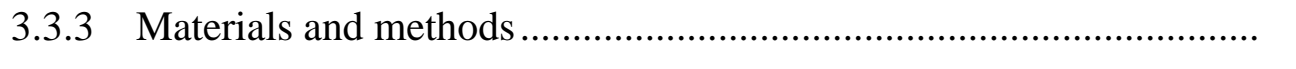

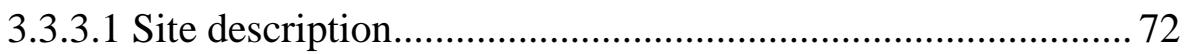

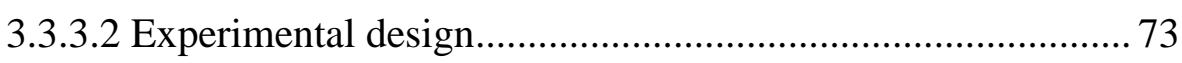

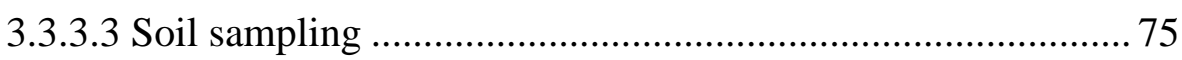

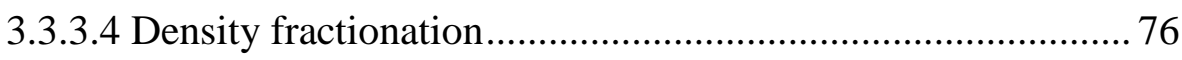

3.3.3.5 Analysis of total carbon contents ....................................... 77

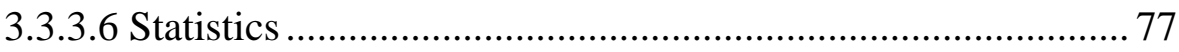

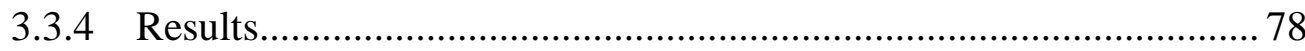

3.3.4.1 Soil organic matter contents depending on $\mathrm{C}$ inputs and $\mathrm{N}$

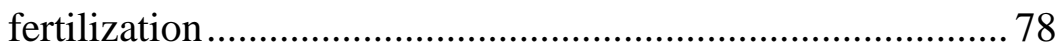

3.3.4.2 Effect of $\mathrm{C}$ inputs and $\mathrm{N}$ fertilization on SOM fractions ....... 79

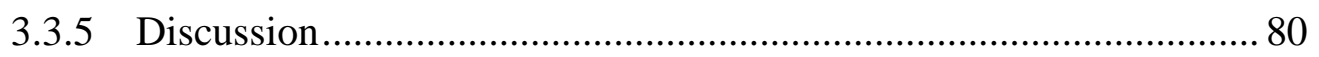


3.3.5.1 Effect of $\mathrm{C}$ inputs and $\mathrm{N}$ fertilization on top- and subsoil SOM. 80

3.3.5.2 Distribution of organic matter in density fractions ............... 82

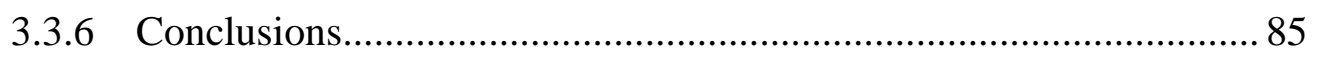

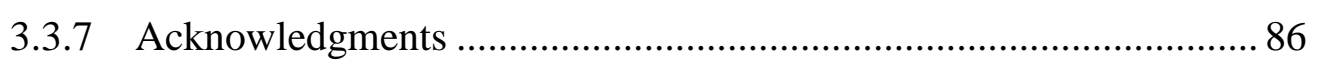

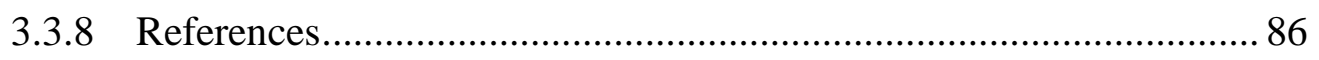

4 Additional study ....................................................................................................................... 95

Study 4: Interactive effect of glucose and partially decomposed plant residues priming: A three source partitioning study .......................................95

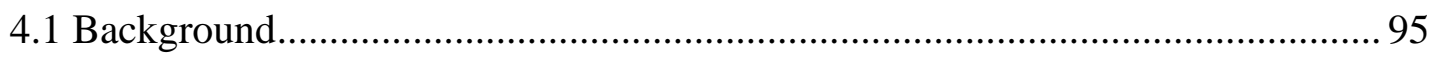

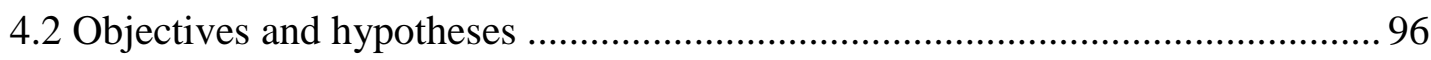

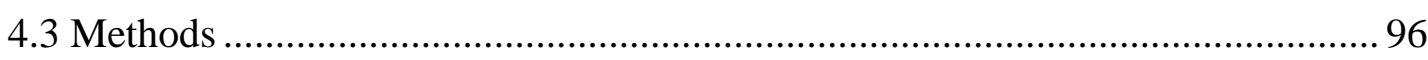

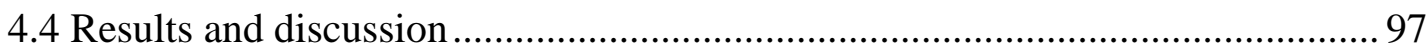

4.4.1 Glucose and residue mineralization ................................................ 97

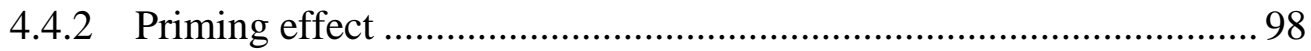

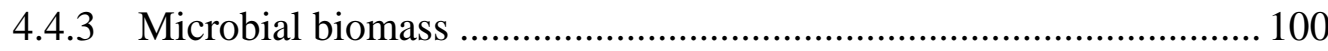

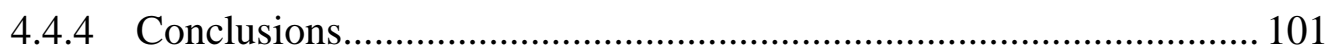

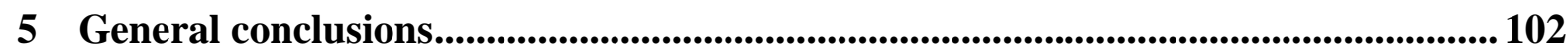

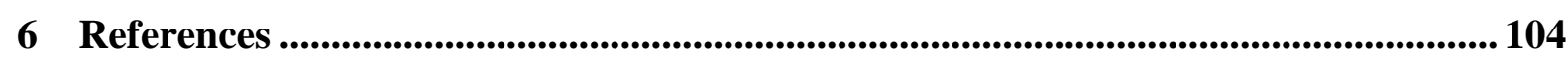

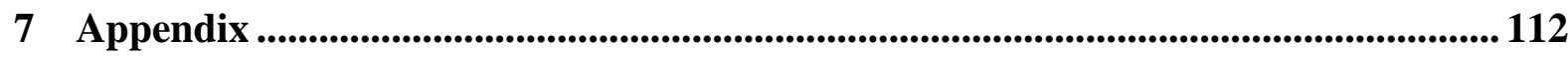

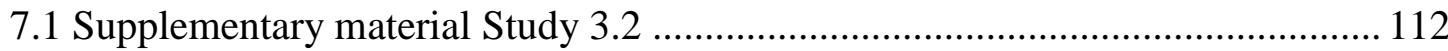

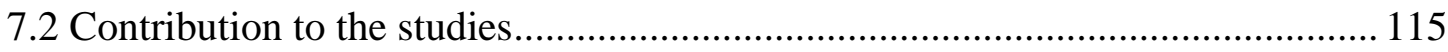

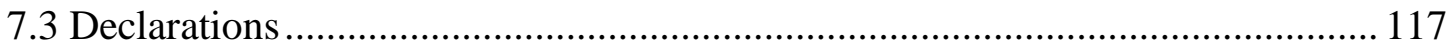

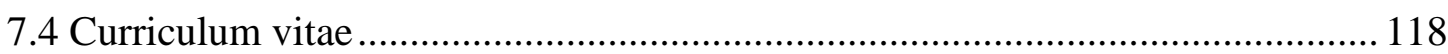




\section{List of tables}

\section{Objectives and methods}

Table 2-1. Rates of $\mathrm{N}$-fertilizer application and annual $\mathrm{C}$ additions ................................... 13

Table 2-2. Summary of the experiments: objectives, methods and main results .................. 14

\section{Study 1 (chapter 3.1)}

Table S1-1. The contribution of residue-C (as \% of initial input) protected in different soil aggregate fractions (macroaggregates $>250 \mu \mathrm{m}$, microaggregates $53-250 \mu \mathrm{m}$ and silt plus clay $<53 \mu \mathrm{m}$ ), and mineralized as $\mathrm{CO}_{2}$, in total recovery of added residue after 64 days of incubation, depending on the level and type of addition. Unrecovered plant residues were not incorporated into aggregates and removed from samples. Numbers in the brackets represent SE $(n=3)$

\section{Study 2 (chapter 3.2)}

Table S2-1. The ${ }^{13} \mathrm{C}$ values (atom\%) of leaves, stems and roots of wheat residues at different decomposition stages over the incubation period at days 0, 15, 30, 60 and 120. Numbers in brackets: \pm SE of mean 47

Table S2-2. The Pearson correlations (r) between specific priming effect and values of specific enzyme activities at days 15, 30, 60 and 120 of incubation in soils amended with residues

\section{Study 3 (chapter 3.3)}

Table S3-1. Mineral N fertilization rates 


\section{List of figures}

\section{Introduction}

Figure 1-1. Hypothetical relationship between annual carbon inputs and measured (diamond symbols) or modeled (round symbols) long-term changes in soil organic matter (SOM) contents as proposed by Heitkamp et al. (2012a), Powlson et al. (2011) and Stewart et al. (2007) 4

Figure 1-2. Schematic diagram of the influence of organic substrate addition on soil organic matter (SOM) mineralization, i.e. priming effect (PE). The increase of SOM mineralization represents positive $\mathrm{PE}$, while decrease of SOM mineralization reflects negative PE (modified after Kuzyakov et al., 2000)

\section{Objectives and methods}

Figure 2-3. An aerial view of the study site located at Puch, close to Munich 12

\section{Study 1 (chapter 3.1)}

Figure S1-1. The relative distribution of aggregate size classes (Macro $>250 \mu \mathrm{m}$, Micro 53-250 $\mu \mathrm{m}$ and silt plus clay $<53 \mu \mathrm{m}$ ) after 64 days of incubation depending on type and level of crop residue additions. Means and standard errors $(n=4)$. The probability levels of the ANOVA for accepting the null hypothesis that the factors have no effect are as follows: macroaggregates (type $<0.001$; level $<0.001$; type $\times$ level $=0.068$ ), microaggregates (type $<0.001 ;$ level $=0.001 ;$ type $\times$ level $=0.349),<53 \mathrm{~mm}($ type $=0.034 ;$ level $=$ 0.116 ; type $\times$ level $=0.003$ ) 25

Figure S1-2. Residue-derived $\mathrm{C}$ in the soil aggregate size classes (Macro $>250 \mu \mathrm{m}$, Micro 53-250 $\mu \mathrm{m}$ and silt plus clay $<53 \mu \mathrm{m}$ ). Upper subfigures present total aggregate protected $\mathrm{C}$ in soil and lower subfigures show protected $\mathrm{C}$ portion of initially added residue-C. Means and standard errors $(n=3)$. The $\mathrm{p}$-values calculated by an ANOVA show probability levels for accepting the null hypothesis that the factors have no effect

Figure S1-3. The contribution of residue derived and soil organic matter (SOM) derived C to microbial biomass (left) and the amount of primed $\mathrm{C}$ due to low and high level of crop residue addition (right). Means with standard errors $(n=3)$. The probability levels of the ANOVA for accepting the null hypothesis that the factors have no effect are as follows: SOM derived C (type $<0.001$; level $=0.001$; level $\times$ type $=0.001)$, residue derived $\mathrm{C}$ (type $=0.001$; level $<0.001$; level $\times$ type $=0.118)$, primed C $($ type $=0.413$; level $<0.001$; level $\times$ type $=0.613$ ) 29

Figure S1-4. Cumulative $\mathrm{CO}_{2}-\mathrm{C}$ release during 64 days of incubation depending on type and level of crop residue additions. Left: release from crop residues; right: release from soil organic matter $(\mathrm{SOM})$. Mean values with standard errors $(n=3)$. The p-values 
calculated by an ANOVA show probability levels for accepting the null hypothesis that the factors have no effect 30

\section{Study 2 (chapter 3.2)}

Figure $\mathrm{S} 2$-1. Cumulative $\mathrm{CO}_{2}$ release originated from soil organic matter (SOM, a), crop residue decomposition (\% of initial addition, b), total priming effect (PE, c), and specific PE (d) over 120 days of incubation, depending on the residue type and addition level. Mean values with standard errors $(n=3)$. The $\mathrm{p}$-values of the ANOVA showing the effect of different factors for all; cumulative $\mathrm{CO}_{2}$ release originated from SOM (a); residue decomposition (\% of initial addition, b); total PE (c) and; specific PE (d) are as follows: type $<0.001$, level $<0.001$ and their interactions; level $\times$ type $<0.001$ 48

Figure S2-2. The relationship between the fraction of mineralized residue, $x$ (as $\%$ of initial input) and soil specific priming effect (PE), was best explained and fitted by a unifying model (combined with logistic and power functions): $P E(x)=a \cdot x^{2}+b /[1+$ $\exp (-c \cdot(x-d))]+e$. Means and standard error $(\mathrm{n}=3)$

Figure S2-3. The relative contribution (\%) of carbon (C) sources from basal respiration, priming effect and residue mineralization) to their corresponding total soil $\mathrm{CO}_{2}$ efflux after 120 days of incubation, depending on the residue type and addition level. Basal respiration (without addition) was assumed to be constant for all residue treated soils. Means and standard errors $(n=3)$. The $p$-values from the ANOVA showing the factors effect is as: basal respiration (type $<0.001$; level $<0.001$; and their interactions: type $\times$ level $=$ 0.081 ), and for both; priming effect and residue mineralization is as (type $<0.001$; level $<0.001$; and their interactions: type $\times$ level $<0.001$ ) 50

Figure S2-4. The contribution of soil organic matter (SOM) and crop residues originated C (Res_C $\mathrm{C}_{\mathrm{MB}}$ ) to total microbial biomass (a); and the amount of priming effect per unit of Res_C $\mathrm{C}_{\mathrm{MB}},(\mathrm{b})$, depending on the residue type, addition level and time of sampling. The inset (a) shows amount of total SOM derived $\mathrm{CO}_{2}$ during the period of 15-30 days. Means with standard errors $(n=3)$. The $p$-values from the ANOVA showing the factors effect on SOM originated microbial biomass (type $=0.043$, level $=0.174$, time $<0.001$, type $\times$ level $=0.042$, type $\times$ time $<0.001$, level $\times$ time $=0.661$, and level $\times$ type $\times$ time $=0.546$ ); and on Res_ $\mathrm{C}_{\mathrm{MB}}$ (for all factors i.e. type, level, time and their interactions, $\mathrm{p}$ $<0.001$ ). Similarly p-values for Priming effect per unit Res_C $C_{M B}$ (b) are as, for all factors and interactions $\leq 0.001$ (except the interaction of type $\times$ time, $p=0.307$ ) ..

Figure S2-5. Specific enzyme activities (enzyme activities per unit of residue originated microbial biomass (Res_CMB)), depending on the residue type, addition level and time of incubation. Mean values with standard errors $(n=3)$. The presented $p$-values are from the ANOVA of the data (residue type, addition level, time of sampling and their interactions). 
Figure S2-6. Conceptual scheme of apparent and real priming effect (PE) in soil after residue addition, explained by three main mechanisms: pool substitution, re-utilization and commensal use. Threshold values represents the strong increase of PE (which mainly represented by real PE) after $\sim 20 \%$ (roots), $\sim 44 \%$ (stems) and $\sim 51 \%$ mineralization of added residues

\section{Study 3 (chapter 3.3)}

Figure S3-1. Aerial view of the study site $\left(48^{\circ} 11^{\prime} 37.85^{\prime \prime} \mathrm{N}, 9^{\circ} 13^{\prime} 04.55^{\prime \prime} \mathrm{E}\right)$, located at Puch close to Munich (Germany), showing the field experimental design which consists of two factors: organic additions (1 - control, 2 - manure, 3 - straw, 4 - slurry, 5 straw+slurry) and N fertilization rates (N0, N2 and N4 represents; no, medium and high $\mathrm{N}$ fertilization, respectively). The expanded box shows random soil sampling points (3 sample which were bulked) for both top- and subsoil of individual plot............. 73

Figure S3-2. The contribution of organic carbon (C) sources to total annual C additions ( $\mathrm{Mg} \mathrm{C}$ ha-1) starting from 1984. The $\mathrm{C}$ input by manure, slurry, straw and crop roots (stubbles) was measured and calculated (see detail Heitkamp et al., 2012a). N0, N2 and N4 represents; no, medium and high $\mathrm{N}$ fertilization, respectively. Control: without organic additions; Manure: straw removed, farmyard manure applied every third year; Slurry: cattle slurry application, straw removed; Straw: straw incorporated; Straw+Slurry: straw incorporated combined with slurry application 74

Figure S3-3. The curve represents the exponential relationship between the mean annual C additions and changes of topsoil soil organic matter (SOM) contents (\%, between 1983 and 2015) over 32 years. 0-line corresponds to $\mathrm{C}$ content in soil at the start of the experiment (32 years ago). Control: without organic additions; Manure: straw removed, farmyard manure applied every third year; Slurry: cattle slurry application, straw removed; Straw: straw incorporated; Straw+Slurry: straw incorporated combined with slurry application. Bars represent the \pm standard error of the mean $(n=3)$. The probability levels of the linear mixed model describing the effects $(\mathrm{C}$ addition, $\mathrm{N}$ fertilization, interaction) for accepting the null hypothesis that the factors have no effect on the change of total SOM $(\%)$ are as follows, $\mathrm{C}$ addition $\leq 0.001$; $\mathrm{N}$ fertilization $\leq 0.001$ and interactions: $\mathrm{C}$ addition $\times \mathrm{N}$ fertilization $=0.409$ 79

Figure S3-4. Contents of soil organic matter $(\mathrm{SOM})$ in topsoil $(0-25 \mathrm{~cm})$, subsoil $(25-60 \mathrm{~cm})$ and initial topsoil (32 years ago, crossed circle) (a); and the ratio of sub- to topsoil SOM contents (b). N0, N2 and N4 represents; no, medium and high $\mathrm{N}$ fertilization, respectively. Control: without organic additions; Manure: straw removed, farmyard manure applied every third year; Slurry: cattle slurry application, straw removed; Straw: straw incorporated; Straw+Slurry: straw incorporated combined with slurry application. Bars represent the \pm standard error of the mean $(n=3)$. The probability levels of the linear mixed model for accepting the null hypothesis that the factors have no effect are as follows: topsoil SOM (organic addition $\leq 0.001 ; \mathrm{N}$ fertilization $\leq 0.001$; and interactions: organic addition $\times \mathrm{N}$ fertilization $=0.750$ ), subsoil SOM (organic addition 
$=0.002 ; \mathrm{N}$ fertilization $\leq 0.001$; and interactions: organic addition $\times \mathrm{N}$ fertilization $=$ 0.323 ), sub-to- topsoil SOM ratio (organic addition $\leq 0.001$; $\mathrm{N}$ fertilization $\leq 0.001$; and interactions: organic addition $\times \mathrm{N}$-fertilization $=0.691)$

Figure S3-5. Soil organic matter (SOM) contents and their relationships with mean annual C addition over 32 years. The slopes of the linear regressions ( \pm standard errors) either of the total dataset $(n=45)$ or within individual treatment (organic additions $n=9)$ along $\mathrm{N}$ fertilization rates are given. Free light fractions (f-LF) (a) and their slopes (b), occluded light fractions (o-LF) (c) and their slopes (d), heavy fractions (HF) (e) and their slopes (f). Control: without organic additions; Manure: straw removed, farmyard manure applied every third year; Slurry: cattle slurry application, straw removed; Straw: straw incorporated; Straw+Slurry: straw incorporated combined with slurry application. $* * *: p \leq 0.001 ; * *: p \leq 0.01 ; *: p \leq 0.05 ;+: p \leq 0.1$; ns: $p>0.1$. The probability levels of the linear mixed model for accepting the null hypothesis that the factors have no effect on $\mathrm{C}$ contents are as follows: $\mathrm{f}-\mathrm{LF}(\mathrm{C}$ addition $\leq 0.001$; $\mathrm{N}$ fertilization $\leq 0.001$; and interaction: $\mathrm{C}$ addition $\times \mathrm{N}$ fertilization $=0.010)$, o-LF $(\mathrm{C}$ addition $\leq 0.001 ; \mathrm{N}$ fertilization $=0.428$; and interaction: $\mathrm{C}$ addition $\times \mathrm{N}$ fertilization $=0.005), \mathrm{HF}(\mathrm{C}$ addition $\leq 0.001 ; \mathrm{N}$ fertilization $=0.0109$; and interaction: $\mathrm{C}$ addition $\times \mathrm{N}$ fertilization $=0.326)$

Figure S3-6. The stabilization of top- and subsoil soil organic matter (SOM) under long-term organic $\mathrm{C}$ inputs and $\mathrm{N}$ fertilization rates (lower part). The upper part represents the partitioning and stabilization (by different mechanisms) of added organic $\mathrm{C}$ into topsoil SOM fractions. The inset on free light fraction and heavy fraction shows the contribution of root dominated ( $\mathrm{R}$ in circle) or straw dominated ( $\mathrm{S}$ in circle) $\mathrm{C}$ inputs in $\mathrm{C}$ storage within $\mathrm{SOM}$ fraction along $\mathrm{N}$ fertilization rates. 84

\section{Additional Study (chapter 4)}

Figure 4-1. Mineralization rate of total soil $\mathrm{CO}_{2}$ efflux, before (during 30 day pre-incubation period) and after glucose additions. The inset represent the mineralization rate of wheat residues (leaves and stems). Error bar represents standard error of mean $(\mathrm{n}=3)$.

Figure 4-2. Cumulative glucose mineralization over the incubation period depending on plant residue type. The inset shows cumulative residue derived $\mathrm{CO}_{2}$ with or without glucose additions. Error bar represents standard error of mean $(n=3)$ 98

Figure 4-3. Cumulative soil organic matter (SOM) priming effect at different time intervals, depending on: time, glucose and residue addition, type of residue and combination of glucose and residues. Error bar represents standard error of mean $(n=3)$.

Figure 4-4. Priming effects of glucose on the mineralization of residues (leaves and roots) versus soil organic matter (SOM) in soil-residue mixtures. The priming effects are 
differences in SOM mineralization between the Soil+residue+glucose and soil+residue amendments. Error bars represent standard error of mean $(n=3)$. 100

Figure 4-5. Microbial biomass carbon originating from three sources: soil organic matter $(\mathrm{SOM})$, residue and glucose following incubation. Error bars represent standard error of mean $(n=3)$ 101 


\section{Acknowledgements}

First and foremost, in particular I offer my sincerest gratitude to my supervisors Prof. Yakov Kuzyakov and Dr. Felix Heitkamp for allowing me to peruse doctoral studies in July 2014 under a precise time-bound circumstances. Their perpetual support and guidance, however, enabled me to finish my PhD studies gracefully within 2.5 years.

I spent a good time of my life in an excellent research group under the supervision of Prof. Kuyakov. Aside from his support and knowledge I gained from him during my PhD studies, I especially appreciate the flexibility and the extent of independence he gave me to conduct my $\mathrm{PhD}$ work and his reactivity to provide valuable feedback on short notice. At the same time, I would like to express my sincere and profound gratitude to Dr. Heitkamp (Department of Physical Geography) for providing me unusual, perpetual help in conducting and planning experiments and in writing papers. Furthermore, I am very thankful Prof. Andrea Carminati and Dr. Evgenia Blagodatskaya (also for helping in study 3.2) for evaluating my work.

Sincere thanks to a special group of friends, office fellows - all my fellow $\mathrm{PhD}$ candidates in the department for the memorable moments we shared together. I especially thank Dr. Sahfique Maqsood (Department of Physical Geography) for first time introducing me to Dr. Heitkamp and Josh Bostic and Kyle Mason-jones for proof reading this dissertation. I am also highly thankful to Dr Abdul Wakeel (UAF, Faisalabad, Pakistan) for his positive guidance and support whenever I need it. I would like to appreciate the technical staff for their assistance and guidance in the laboratory. Special thanks go out to Karin Schmidt and Anita Kriegel - Vielen Dank!

I am very thankful to the German academic exchange service (DAAD) for providing me a scholarship for PhD studies. I also acknowledge the financial support given by the International Office of the university and the Agriculture Faculty (GFA) for completion of the dissertation.

I thank almighty who blessed me with a charming Son at the start of my $\mathrm{PhD}$ studies. However, I apologize to my Son "Arham Shahbaz" and wife "Saamra Manzoor" for my frequent absence during PhD. I am greatly indebted to my family for making my life happy at home. Finally, I sincerely appreciate my parents, brother and sisters, their continued spiritual support during my entire stay in Germany, which successfully pushed me to the finish line. 


\section{List of abbreviations}

\begin{tabular}{|c|c|}
\hline ANOVA & Analysis of variance \\
\hline $\mathrm{At} \%$ & Atom $\%$ \\
\hline $\mathrm{C}$ & Carbon \\
\hline${ }^{13} \mathrm{C}$ & Stable carbon isotope with atomic mass 13 \\
\hline${ }^{14} \mathrm{C}$ & Radioactive carbon isotope with atomic mass 14 \\
\hline $\mathrm{CO}_{2}$ & Carbon dioxide \\
\hline $\mathrm{C} / \mathrm{N}$ & Carbon to nitrogen ratio \\
\hline EA-IRMS & Elemental analysis - isotope ratio mass spectrometry \\
\hline f-LF & Free light fraction $\left(\rho<1.6 \mathrm{~g} \mathrm{~cm}^{-3}\right)$ \\
\hline ha & Hectare \\
\hline $\mathrm{HF}$ & Mineral-associated heavy fraction $\left(\rho>1.6 \mathrm{~g} \mathrm{~cm}^{-3}\right)$ \\
\hline IUSS-WRB & International Union of Soil Sciences-World Reference Base \\
\hline K & Potassium \\
\hline LAP & Leucine aminopeptidase \\
\hline MB & Microbial biomass \\
\hline $\mathrm{N}$ & Nitrogen \\
\hline o-LF & Occluded light fraction $\left(\rho<1.6 \mathrm{~g} \mathrm{~cm}^{-3}\right)$ \\
\hline $\mathrm{P}$ & Phosphorus \\
\hline PE & Priming effect \\
\hline Res_C ${ }_{M B}$ & Residue originated microbial biomass carbon \\
\hline rpm & rotation per minute \\
\hline $\mathrm{SE}$ & Standard error \\
\hline $\mathrm{SOM}$ & Soil organic matter \\
\hline WHC & Water holding capacity \\
\hline $\mathrm{y}^{-1} / \mathrm{yr}^{-1}$ & Per year \\
\hline$\rho$ & Density \\
\hline
\end{tabular}




\section{Summary}

Cropland soils may be sources or sinks for atmospheric $\mathrm{CO}_{2}$. In general, it is assumed that $\mathrm{C}$ input into the soil and soil organic matter (SOM) levels are linearly related. This gives rise to environmental concerns regarding the removal of crop residue. In recent years, it has been shown that residue incorporation increases SOM levels to only a small extent, and high C input is not directly beneficial for SOM stabilization. Similar observations have been reported from a well-documented long-term field experiment at Puch, Germany, which contradicted the predicted (linear) relationship between $\mathrm{C}$ inputs (1-5 $\left.\mathrm{Mg} \mathrm{Cha}^{-1} \mathrm{y}^{-1}\right)$ and SOM changes. Several factors have been suggested to explain the relationship between high $\mathrm{C}$ inputs and small observed increases of SOM: (i) alteration of soil physical properties, affecting residue mineralization and protection; (ii) differences in residue input quality, recalcitrant belowground versus labile aboveground inputs; (iii) decomposition of native SOM through priming effects of incorporated residues; (iv) partitioning of residue $\mathrm{C}$ between protected and less protected SOM fraction; and (v) translocation of part of the unprotected $\mathrm{C}$ to the subsoil. The aim of this thesis was to ascertain whether these factors can really explain the limited increases of SOM often observed in the context of increasing crop residue inputs.

In order to quantify the effect of crop residue quality and quantity on soil physical structure and SOM stabilization, ${ }^{13} \mathrm{C}$-labeled wheat residues with variable quality (leaves, stems, roots) and quantity were added to the soil and incubated for 2 months. Soil aggregation generally increased with higher residue additions, but the proportion of residue $\mathrm{C}$ protected within aggregates decreased. The protection of aboveground biomass residues (leaves and stems) was more reduced than belowground (root) residues at high additions. However, regardless of residue type, SOM decomposition increased with higher crop residue addition. The decrease of residue protection within aggregates and the increase of SOM mineralization led to a decrease in the rate of $\mathrm{C}$ stabilization within SOM by higher residue additions.

To explore the mechanisms how crop residue quality (leaves, stems, roots) and quantity effect residue and SOM mineralization, with a special focus on the priming effect, an incubation study was conducted over a period of 4 months. The added $\mathrm{C}$ was traced in $\mathrm{CO}_{2}$ and in microbial biomass, and enzyme activities were measured. Roots were least decomposed and the mineralization of aboveground biomass residue disproportionally increased with higher residue additions. However, roots caused much higher SOM priming than leaves and stems. The C 
source partitioning and enzyme activities revealed that SOM priming was mainly controlled by residue-feeding microorganisms. To quantify the relationship between residue decomposition (i.e. quality effect), input levels, and priming, a new unifying model (logistic \& power functions) was proposed. The model enabled the estimation of threshold values for mineralization of low and high residue additions above which incremental priming was maximal: i.e. ca. $20 \%$ for roots, $29-44 \%$ for stems and $39-51 \%$ for leaves. SOM priming depended on residue quality and decreased with increasing $\mathrm{C}$ additions. Nonetheless, priming was a power function of residue mineralization, whereby the threshold for strong increases in priming was lower for root decomposition than for aboveground residues.

In order to determine the effect of long-term $\mathrm{C}$ inputs (straw- or root-dominated) on changes in SOM contents and partitioning of added C between SOM fractions, the soil was sampled (topand subsoil) from a field experiment started in 1983. Where, five organic amendments (either with straw or root dominated $\mathrm{C}$ inputs) were combined with different $\mathrm{N}$ fertilization rates. $\mathrm{C}$ input driven by straw incorporation was highest and increased with $\mathrm{N}$ fertilization. The density fractionation approach was used to separate topsoil SOM fractions. Total SOM content showed an increase with $\mathrm{C}$ inputs, which was mainly explained by the free light fraction of SOM. Despite high inputs, straw contributed little to the free light fraction, but prevented $\mathrm{C}$ losses from the mineral-associated SOM fraction $\left(\rho>1.6 \mathrm{~g} \mathrm{~cm}^{-3}\right)$, which were observed in the absence of straw addition. In contrast to topsoil, subsoil SOM contents decreased with $\mathrm{N}$ fertilization, thus also with $\mathrm{C}$ input. Above- (straw) and belowground (root) residues showed opposite effects on SOM fractions. Root $\mathrm{C}$ remained longer in the light fractions and was responsible for topsoil SOM increase with $\mathrm{N}$ fertilization. Straw decomposed rapidly (from light fractions), and sustained the most stable mineral-associated SOM fraction.

Overall, results from incubation studies and the field experiment reveal that increasing amounts of aboveground residue addition improve soil aggregation. However, low physical protection and disproportionally increased residue mineralization decreases residue stabilization in SOM. Roots are recalcitrant to decomposition, but cause stronger and higher priming effects than aboveground residues. Nevertheless, high aboveground residue mineralization protects $C$ in the most stable mineral-associated SOM fraction. Low root mineralization indicates that root litter can mainly stay in the unprotected free light SOM fraction, but roots can increase SOM losses through priming effects. The often described minor increase of SOM after organic matter input reflects the opposing behaviors of root and aboveground residues in SOM stabilization. 


\section{General introduction}

\subsection{Global carbon cycle}

In the last few decades, the soil has been intensively cultivated to meet the global demands of the growing population for food, fodder, fibers and biofuel (Garnett et al. 2013; Keating et al. 2014). Simultaneously, it is important that any change in land management must maintain soil quality and while not increasing its negative impacts on the environment, such as greenhouse gas emissions. Compared to soil carbon (C), the global distribution of phytomass $\mathrm{C}$ and its relation to the environment is relatively well researched (Harris et al. 2012). The soil C exceeds the amounts which is stored in both plants and atmosphere (Scharlemann et al. 2014). Despite a great deal of research, estimates of global soil C sources and resources are still uncertain, and $\mathrm{C}$ emissions due to land use changes remain the least-understood component of the $\mathrm{C}$ cycle (Scharlemann et al. 2014).

Globally, approximately 1500 Petagrams of C is stored in the soil (Pg C, Scharlemann et al. 2014; Schlesinger 1984). To understand the background of increasing atmospheric $\mathrm{CO}_{2}$ levels, there is a much interest in knowing whether the soil acts as a net source or sink for C (IPCC 2007; Krull et al. 2003). Since 1850, after the industrial revolution, it is estimated that ca. 108 to $188 \mathrm{Pg} \mathrm{C}$ has been lost from the terrestrial ecosystem due to the rapid increase in population and associated land use changes (Houghton 2012). Although there are considerable disagreements between estimates of global C pool sizes, however, it is accepted that approximately 68-100 gigatons $\mathrm{C}$ per year is released to the atmosphere from various ecosystems.

Within this $\mathrm{C}$ loss pool, the contribution of $\mathrm{C}$ evolved from agriculture (i.e. due to land use changes) ranged from approximately 25-50\% (Houghton 2012). These losses due to land use changes represents the second largest anthropogenic $\mathrm{C}$ source released into the atmosphere, after fossil fuel combustion (Lal 2004; Post and Kwon 2000). Perhaps as late as the 1950s, land use changes accounted for higher levels of anthropogenic $\mathrm{CO}_{2}$ emissions than fossil fuel combustion (Lal et al. 2012).

Soil C losses can theoretically be mitigated by adopting recommended management practices (Lal et al. 2012; Sauerbeck 2001). Smith et al. (2013) estimated that, until 2050, agriculture holds the potential to mitigate the release of up to 4.3 gigatons $\mathrm{yr}^{-1} \mathrm{of} \mathrm{CO}_{2}$ to the atmosphere by adopting proper mitigation options. However, some mitigation options are in direct competition 
with each other, e.g., use of crop residue for bioenergy versus crop residue incorporation into the soil for increasing and maintaining SOM levels.

In cropland soils, the main source of biomass is crop residues (Lal 2012). Crop residue is mainly incorporated into the soil with the aim of improving SOM and soil quality. A fraction of added crop residues can be stabilized as SOM by various mechanisms, while the other fraction will be lost to the environment via microbial decomposition. The effectiveness of SOM stabilization depends on the quality and quantity of biomass returned to the soil. Therefore, it is important to investigate the effect of crop residue management on SOM stabilization and the potential losses of soil $\mathrm{C}\left(\right.$ as $\left.\mathrm{CO}_{2}\right)$ following residue addition for sustaining both soil and environmental quality.

\subsection{Soil organic matter stabilization}

SOM has beneficial effects on soil physical, chemical and biological properties, which in turn influence the productive capacity of soils. SOM is also a major contributor of $\mathrm{N}, \mathrm{P}$ and other nutrients to plants. Soil microbial communities are dependent on SOM as a C source for their metabolic activities, which in turn affects soil structure and nutrient fluxes. A majority of models used to predict SOM dynamics assume that the increase of SOM is linearly proportional to the amount of $\mathrm{C}$ input (Six et al. 2002). Thus, SOM levels can theoretically increase without limits, given that $\mathrm{C}$ inputs correspondingly increase without limit. Such predictions of SOM content dynamics are acceptable for soils possessing low to moderate $\mathrm{C}$ contents. However, changes in SOM content resulting from, $\mathrm{C}$ inputs usually depends on the amount and nature of inputs ( $\mathrm{C}$ availability), soil physicochemical properties, management practices and native SOM conditions (e.g. Powlson and Glendining 2011; Heitkamp et al. 2012). Native SOM contents reflect the balance of $\mathrm{C}$ inputs and its losses under specific conditions that do not necessarily represent the maximum ability of a soil to stabilize SOM. The relationship between soil structure and its ability to stabilize $\mathrm{C}$ is a key element for understanding SOM protection (Six et al. 2002). There is a distinction between SOM which is protected against decomposition by various mechanisms from that which is not protected from decomposition.

The protected SOM pools mainly represent the contents of SOM (affected by long-term inputs) and are often characterized by three main protection mechanisms: (i) physical protection, (ii) chemical stabilization, and (iii) biochemical stabilization (Christensen 1996; Six et al. 2002; Six and Paustian 2014). Physical protection by soil aggregates (especially microaggregates) is indicated by the positive influence of aggregation on SOM accumulation (Elliott 1986; Tisdall 
and Oades 1982; Six et al. 2002). Aggregates protect SOM by forming physical barriers between microbes, enzymes and their substrate's diffusion, as well as by controlling food web interactions and consequently SOM decomposition (Six et al. 2000). Chemical stabilization of SOM is known to be the result of the chemical or physicochemical binding of SOM with soil mineral surfaces (i.e. clay and silt particles). The relationship of organic $\mathrm{C}$ stabilization with soils mineral surfaces is often defined as mineral-associated SOM, which has long mean residence times and comprises a large proportion of SOM in cropland soils (Hassink 1997). Biochemical stabilization is understood as the stabilization of SOM due to its own chemical composition (e.g. recalcitrant compounds such as polyphenols and lignin) and through chemical association processes (e.g. condensation reactions) in soil. This mechanism is mostly referred to as biochemical stabilization of SOM through selective protection of recalcitrant SOM compounds. However, all of these mechanisms can only stabilize SOM up to a certain limit. Thereafter, increasing $\mathrm{C}$ inputs may lead to high losses of added organic compounds through mineralization processes. Nevertheless, environmental conditions, management practices and soil physicochemical characteristics may have a strong impact on SOM stabilization by affecting those mechanisms which can limit $\mathrm{C}$ sequestration under high $\mathrm{C}$ inputs.

\subsection{Impact of long-term C inputs on SOM}

Under long-term field conditions, in contrary to general assumptions, SOM does not increase linearly with increasing C inputs (primarily crop residues) (Heitkamp et al. 2012; Stewart et al. 2007) (e.g. Fig. 1-1). This means that, while SOM may continue to increase with increasing C input, the efficiency of the $\mathrm{C}$ input to SOM conversion decreases (i.e. increase in SOM is smaller per unit of $\mathrm{C}$ input). According to specific conditions, there are several factors which can affect SOM stabilization that need to be addressed. For example, Freibauer et al. (2004) reported that, for the EU-15 countries, the addition of 1 to $3.7 \mathrm{Mg} \mathrm{C}^{-1} \mathrm{yr}^{-1}$ (by farmyard manure and straw inputs) resulted in increases in SOM stocks of 0.4 and $0.7 \mathrm{Mg} \mathrm{C}^{-1} \mathrm{yr}^{-1}$ relative to non-amended cropland soils. However, Powlson and Glendining (2011) reported that in most of their 23 long-term experiments, straw incorporation (as compared to removal) had minor effects on SOM storage. Likewise, Stewart et al. (2007) tested C predictions models and found that an asymptotic relationship can best predict the change in SOM against $\mathrm{C}$ inputs within their dataset of 14 experimental sites located in Canada and the US (duration: 12-50 years). More recently, Steinmann et al. (2016) found a loss of SOM ca. $0.6 \mathrm{t} \mathrm{C} \mathrm{ha}^{-1} \mathrm{yr}^{-1}$ (at 60 $\mathrm{cm}$ depth) even under balanced $\mathrm{C}$ input (from 20 to $133 \mathrm{~kg} \mathrm{C} \mathrm{ha}^{-1} \mathrm{yr}^{-1}$ ) across 268 sites in 8 
years. In general, these findings primarily indicate that increasing the amount of $\mathrm{C}$ input does not result in proportional increases in SOM content, as predicted in several studies (Fig. 1-1).

Similarly, Heitkamp et al. (2012) also observed a quadratic relationship between the change in SOM stocks and C-input in a long-term cereal-based crop rotation experiment in Puch, Germany. The organic additions ranged from 1-5 $\mathrm{Mg} \mathrm{C}^{-1} \mathrm{yr}^{-1}$, where $\mathrm{C}$ inputs driven by animal manure were fixed, while those by straw incorporation were increased with $\mathrm{N}$ fertilization levels. Their findings were in agreement with previous works (Paustian et al. 2000; Lorenz and Lal 2012), demonstrating a serious decline in SOM increase when annual C input exceeded 2.4 $\mathrm{Mg} \mathrm{C} \mathrm{ha}^{-1}$.

Overall, the authors could only speculate about the rational of this relationship (see below), but it was clear that increasing amounts of $\mathrm{C}$ input (e.g. from straw) were not efficient in increasing SOM levels (Fig. 1-1). This could give rise to the idea that, e.g., energetic use of crop residue would be a more efficient option in mitigating greenhouse gas $\left(\mathrm{CO}_{2}\right)$ emissions (because of less $\mathrm{C}$ stabilization and high mineralization) compared to residue incorporation in soil.

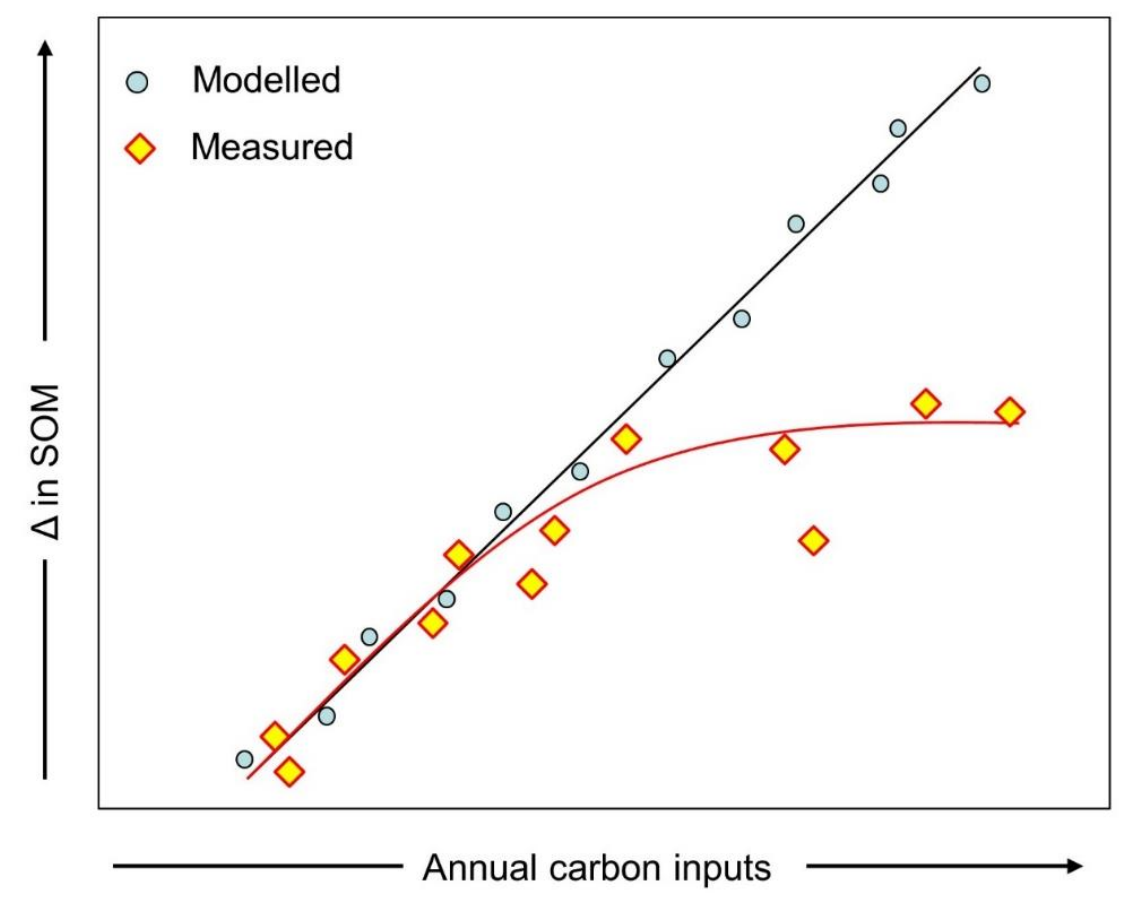

Figure 1-1: Hypothetical relationship between annual carbon inputs and measured (diamond symbols) or modelled (round symbols) long-term changes in soil organic matter (SOM) contents as proposed by Heitkamp et al. (2012a), Powlson et al. (2011) and Stewart et al. (2007). 
Although it is agreed that increasing $\mathrm{C}$ inputs (mainly through straw) is not automatically beneficial for SOM (Fig. 1-1), the reasons for these findings are not completely understood. Potential reasons for these findings could be: (i) alteration of soil physical properties, resulting in conditions favoring high decomposition and less accumulation of SOM in aggregates; (ii) a shift from recalcitrant belowground to labile aboveground residue inputs, (due to high above ground biomass production under high $\mathrm{N}$ fertilization) which may result in higher decomposition and less $\mathrm{C}$ stabilization from crop residue (iii) acceleration of native SOM mineralization through priming effect of incorporated residues (iv) lower partitioning of added $\mathrm{C}$ in stable SOM fractions (i.e. mineral-associated) due to their limited capacity to stabilize SOM, and (v) translocation of a portion of unprotected SOM to the subsoil.

\subsubsection{Alteration of soil physical properties}

The soil structure refers to the arrangement of soil particles into units called aggregates. Wellstabilized and aggregated soil is an important indicator of soil quality and workability. In general, most soil physical properties are related to SOM contents within a given texture (Haynes und Naidu 1998; Bronick und Lal 2005). Soil aggregates vary in size (e.g. macro- and microaggregates) and are strongly influenced by the quality and quantity of added organics, as they influence soil processes involved in aggregation (Abiven et al. 2009; Majumder and Kuzyakov 2010). The addition of readily-decomposable substrates improves aggregation process more so than recalcitrant substrates. During substrate decomposition, microorganisms excrete substances which act as cementing agents (e.g. glomalin, polysaccharides) that bind soil particles together. In addition, fungi hyphae and roots can also act as binding agents. In the presence of organics, binding of soil particles results in microaggregate $(<250 \mu \mathrm{m})$ formation and, thereafter, microaggragates bind with SOM and silt clay particles to form macroaggreagtes (> $250 \mu \mathrm{m}$ ) (Tisdall and Oades 1982). However, microaggregates may form inside macroaggregates and can release during macroaggregates turnover (Six et al. 2000).

Aggregates physically protect SOM from microbial decomposition through spatial inaccessibility of degrading microorganisms and their enzymes (Angers et al. 1997; KögelKnabner et al. 2008). However, aggregates have limited capacity to stabilize SOM. After reaching a threshold level, most of the added organics remain unprotected (Andruschkewitsch et al. 2014; Shahbaz et al. 2016; Stewart et al. 2008). The physically unprotected fraction can serve as a favorable substrate for microorganisms due to its high accessibility, typically resulting in rapid decomposition. An increase in the proportion of macroaggregates is an 
indicator of high soil physical quality (e.g. aeration, water movements, nutrients exchange), as such conditions offer favorable conditions for microbial growth and activities (Schjønning et al. 1999; Jäger et al. 2011). Under such situations (low physical protection and high microbial activity), increased mineralization of unprotected residues may lead to a high residue $\mathrm{C}$ loss to stabilization ratio. This would explain the shape of observed (measured) relationships (Fig. 11) between $C$ input and SOM change under increasing $C$ additions. Nevertheless, residue quality can have a stronger effect on aggregation because it directly affects microbial functioning.

\subsubsection{Changes in crop residue quality}

Crop residue quality is an essential factor controlling SOM formation, stabilization and dynamics. Crop residues vary in their structural and chemical composition (Adair et al. 2008). Residues are often classified on the basis of $\mathrm{C} / \mathrm{N}$ ratio and the contents of a recalcitrant substance such as phenols, tannins, or lignin (Stewart et al. 2015; Wang et al. 2015a). Residue decomposition rates are generally negatively related to the amount of recalcitrant compounds present in their biomass (Bertrand et al. 2006; Castellano et al. 2015). Aboveground residues (e.g. leaves and stems) are considered high quality because they contain less recalcitrant compounds and lower $\mathrm{C} / \mathrm{N}$ ratios than belowground residues (e.g. roots) (Bertrand et al. 2006; Lian et. 2016; Rasse et al. 2005). The application of $\mathrm{N}$ fertilization generally improves crop residue quality by increasing nutrient contents and lowering $\mathrm{C} / \mathrm{N}$ ratio (Schmidt et al. 2015; Silveira et al. 2013).

The role of residue quality in SOM formation is currently under debate. The common view on recalcitrant root residues, which are decomposed slowly and therefore contribute significantly to SOM content (Berg and McClaugherty 2014; Johnson et al. 2014; Rasse et al. 2005), contradicts the view of the large contribution of high quality (easily decomposable) residues to stable SOM formation (Castellano et al. 2015; Cotrufo et al. 2013; Lehmann and Kleber 2015). The latter concept is mainly associated with microbial by-products, which are released and stabilized in the mineral-associated SOM fraction during microbially-mediated plant residue decomposition (Cotrufo et al. 2013; Lehmann and Kleber 2015). Therefore, compared to recalcitrant residues, easily-decomposable residues can greatly contribute to the stable SOM fraction. However, the fast mineralization of easily-decomposable residues (disproportionally increase with addition level) may increase $\mathrm{C}$ losses more than stabilization within SOM fractions (Xiao et al. 2015). 


\subsubsection{Residue partitioning within SOM fractions}

SOM is usually classified into its three main fractions on the basis of density. On the basis of residue decomposability, added crop residues partition into various SOM fractions. The fraction which is least decomposed (fresh input) and remains unprotected by physical mechanisms is referred as the free light fraction of SOM. The SOM fraction that partially decomposes and is protected by physical mechanisms, e.g., inside aggregates, reflects the occluded light fraction of SOM. The third SOM fraction is the heavy fraction, which is highly decomposed and considered stable for decades because of its strong association with mineral particles. The heavy fraction of SOM generally depends on microbial by-products, which are released during crop residue decomposition (Cotrufo et al. 2013; Schrumpf et al. 2013) or microbial turnover (Miltner et al. 2012). On the basis of its formation mechanism, the heavy SOM fraction is highly affected by long-term management practices.

A non-linear increase of SOM levels (as shown in Fig 1-1) under increasing C inputs is primarily linked to the saturation (or less increase per unit of C input) of SOM fractions (Hassink and Whitmore 1997; Six et al. 2002). This means that, besides the unprotected fraction, SOM fractions have only a limited capacity to stabilize SOM. Within SOM fractions, the saturation of mineral-associated fractions is more important, as it represents the major pool (up to 80\%) of SOM in cropland soils (Stewart et al. 2007). It has been observed that the unprotected light fraction of SOM increases proportionally to the $\mathrm{C}$ input, however, mineralassociated or aggregate protected fractions can stabilize SOM only up to a certain limit (Gulde et al. 2008; Stewart et al. 2008). This may explain why Gong et al. (2009) found increases in heavy fraction $\mathrm{C}$ (and also total SOM) with increasing $\mathrm{C}$ input in a soil depleted in SOM, while Heitkamp et al. (2011) did not report any effect in a sandy soil (due to a lower proportion of the heavy SOM fraction). When the heavy or occluded fraction reaches its effective capacity, a higher portion of $\mathrm{C}$ input will be partitioned to a less-protected labile fraction (e.g., light fraction). The light fraction can rapidly mineralize, resulting in greater losses (as $\left.\mathrm{CO}_{2}\right)$ or leaching of unprotected SOM into the subsoil (Stewart et al. 2008).

\subsubsection{Stabilization in subsoil}

The importance of management effects on SOM is mostly considered for topsoil (Ap horizon, plough layer), while information for subsoil is scarce (Gregory et al. 2014; Ogle et al. 2005). Subsoil SOM stabilization mostly occurs through dissolved organic C (leaching from topsoil), bioturbation and root growth (Rumpel and Kögel-Knabner 2011). The subsoil SOM 
stabilization is linked with the soil texture and topsoil management practices (Hobley and Wilson 2016; Hobley et al. 2016). Apparent differences in SOM stocks between land-uses or management practices turned out to be primarily due to redistribution of SOM into deeper soil layers (Don et al. 2009). If translocation of SOM happens only at high rates of C inputs, the relationship observed between input and SOM changes in the topsoil can be similar to that in Fig. 1-1 (nonlinear measured relation). SOM stabilization in subsoil is considered more effective because it generally contains higher clay contents (e.g. Luvisols), which are mostly C-deficient and is less exposed to these changes (Hobley and Wilson 2016; Kögel-Knabner et al. 2008). However, in contrast to the general assumption that subsoil is less affected by management, Khan et al. (2007) showed more serious losses of SOM below the plough layer in a silty-loam soil. A possible explanation of subsoil $\mathrm{C}$ loss can be due to priming, which normally occurs after an input of "fresh C" to the soil (Fontaine et al. 2007).

\subsubsection{Soil priming effect}

Soil priming effect (PE) is the short-term change in native SOM mineralization caused by substrate addition (Fig. 1-2, Kuzyakov et al. 2000). The PE is a natural process that is induced by pulses or continuous inputs of fresh organics (Kuzyakov et al. 2000). Soil microorganisms are frequently $\mathrm{C}$ limited, thus, the input of $\mathrm{C}$-rich crop residues stimulates microbial decomposition of SOM, resulting in PE (Blagodatskaya et al. 2011). The size of PE increases with the amount of substrate addition. Following substrate addition SOM mineralization typically increases, which is defined as a positive PE. However, if SOM decomposition slows following substrate additions then it reflects a negative PE (Fig. 1-2). For instance, if the added substrate is labile, then microorganisms would mainly rely on the added substrate and may decrease their dependence on recalcitrant SOM (Fontaine et al. 2003). This ultimately may result in a negative PE due to high substrate availability (Blagodatskaya and Kuzyakov 2008). On the other hand, if the added substrate stimulates the inactive or dormant soil microflora by providing energy, this would accelerate SOM mineralization (in parallel to substrate decomposition), thus resulting in a positive PE. The quality and amount of substrate is the most important factor that can affect soil PE.

The increase in the number of studies on PE during the last decade reflects the interest in biotic mechanisms of carbon turnover in soil, which is still poorly understood (Blagodatskaya and Kuzyakov 2008; Chen et al. 2014; Fontaine et al. 2003; Wang et al. 2015b; Xiao et al. 2015). Most of the investigations on PE are performed with glucose additions as substrate, because 
most plant polymers are rapidly decomposed to monosaccharides (Gunina and Kuzyakov 2015). The few available studies which have determined the impact of plant residue additions on SOM dynamics primarily found a positive PE following application (Guenet et al. 2010; Moreno-Cornejo et al. 2015; Xiao et al. 2015). There may be several mechanisms explaining the variations in PE under contrasting substrate quality, as substrate quality directly affects microbial activity (Blagodatskaya et al. 2014; Fontaine et al. 2003; Kuzyakov et al. 2000). However, regardless of the specific mechanisms, any positive increase in SOM decomposition following substrate (residue) addition may lead to severe $\mathrm{C}$ losses, which would decrease the overall rate of SOM stabilization under high $\mathrm{C}$ inputs.

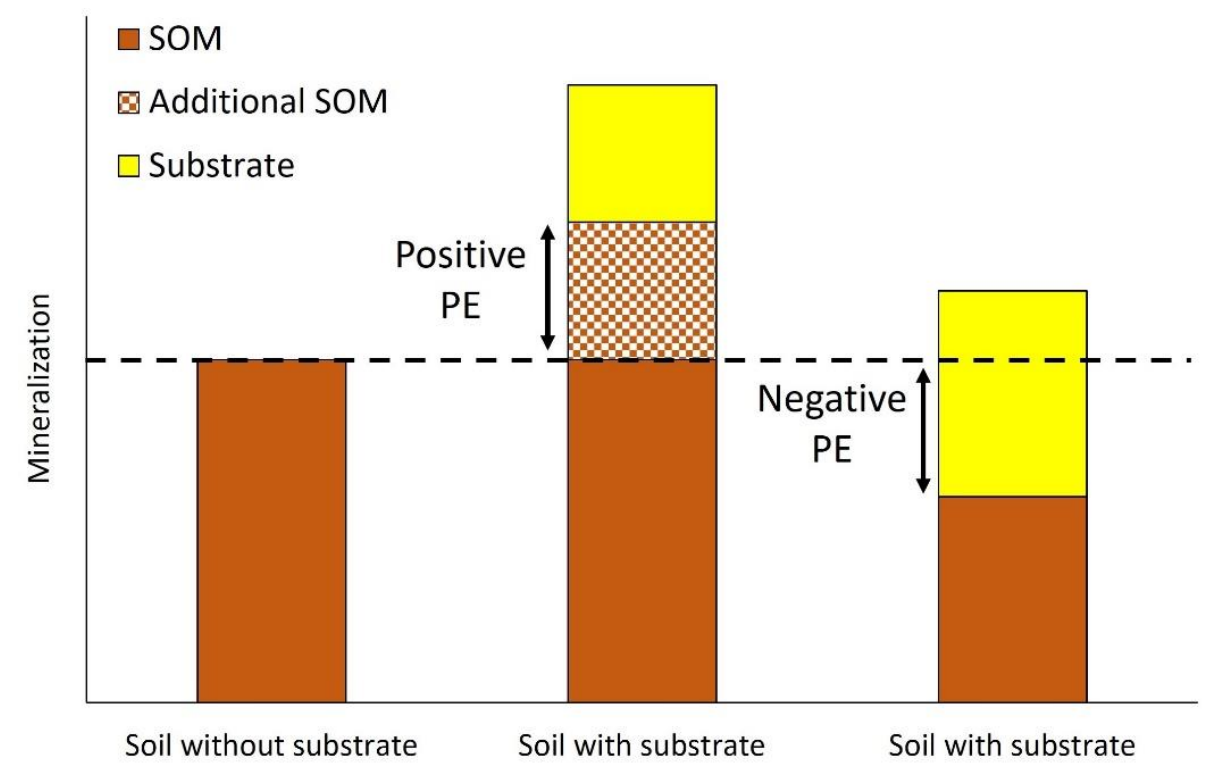

Figure 1-2: Schematic diagram of the influence of organic substrate addition on soil organic matter (SOM) mineralization, i.e. priming effect (PE). The increase of SOM mineralization represents positive $\mathrm{PE}$, while decrease of $\mathrm{SOM}$ mineralization reflects negative PE (modified after Kuzyakov et al. 2000). 


\section{Objectives and Methods}

\subsection{Objectives}

To contribute to knowledge needed, the thesis aim is to explain an unexplained observations from long-term experiment Puch (near to Munich) Germany: where increasing amounts of Cinput with straw did not increase SOM stocks efficiently (Fig.1-1, Heitkamp et al. 2012a). The idea was to test whether soil structure, crop residue quality or quantity, $\mathrm{C}$ partitioning between SOM fraction, C-translocation and SOM priming would explain the pattern of SOM stabilization, which was observed under long-term experiment started in 1983.

The specific study objectives were as following:

(1) To determine the effect of crop residue quality and quantity on soil aggregates formation and SOM physical protection (Chapter 3.1) by hypothesizing that;

(i) regardless of addition level, belowground residues will be mineralized slower than aboveground crop residues;

(ii) the aggregate formation will increase with the residue addition level;

(iii) the percentage of residue derived $\mathrm{C}$ stabilized within aggregates will decrease with the addition level.

(2) To investigate the mechanisms and thresholds levels of wheat residue quality and quantity $\left({ }^{13} \mathrm{C}\right.$-labeled) inducing SOM priming (Chapter 3.2) by hypothesizing that;

(i) the intensity of SOM decomposition will be affected by the residue mineralization rates, i.e. SOM decomposition will be dependent on residue type;

(ii) regardless of residue type, the intensity of $\mathrm{PE}$ will decrease with increasing $\mathrm{C}$ addition;

(iii) we assumed that microorganisms decomposing added residues will represent the most active fraction of soil microflora. Therefore, we further hypothesized that the PE will be the main function of the microbial fraction feeding on residues and of its enzymes activities.

(3) To explain and compare the integrated effect of long-term $\mathrm{C}$ inputs (along $\mathrm{N}$ fertilization rates), either straw or root dominated, on topsoil SOM contents, partitioning 
of $\mathrm{C}$ within topsoil SOM fractions and accumulation of SOM in the subsoil (Chapter 3.3). In particular, the specific goals of this study are;

(i) to estimate and compare the changes in topsoil SOM levels due to C inputs (variable organics) and $\mathrm{N}$ fertilization over the study period, i.e. 32 years;

(ii) to analyze the effects of topsoil managements on SOM accumulation in the subsoil;

(iii) to quantify and compare the effects of $\mathrm{C}$ inputs and $\mathrm{N}$ fertilization on the partitioning of $\mathrm{C}$ among topsoil SOM fractions (f-LF, o-LF and HF), and the overall impact of these fractions on SOM formation.

\subsection{Methods}

The findings from controlled but short-term laboratory experiments and outcomes from the long-term field experiment will be correlated to test and quantify the relevance of SOM stabilization factors (discussed above). The long-term field experiment at Puch is well documented and designed, represents a common soil type (silt loam texture) in central Europe (Luvisol derived from loess) and covers a wide range of management options in a widespread cereal-based crop rotation.

Knowing the reasons for the observed SOM changes versus C inputs is very important: if, e.g., soil limited physical capacity or increasing soil respiration (including priming) would explain low efficiency of SOM stabilization under high $\mathrm{C}$ inputs, then the alternative use of straw can be justified. This can suggest that energetic use of residues would be more efficient e.g. regarding mitigation of greenhouse gas emissions. However, soil physical properties cannot be disregarded in this respect, because it is important for the sustainable use of croplands and soil quality.

\subsubsection{Study site and layout}

The site is located in Puch, Germany close to the Munich $\left(48^{\circ} 11^{\prime} \mathrm{N}, 11^{\circ} 12^{\prime} \mathrm{E}\right)$. The mean annual temperature and precipitation from 1984 to 2009 was $8.4{ }^{\circ} \mathrm{C}$ and $868 \mathrm{~mm} \mathrm{yr}-1$, respectively. The soil is classified as Luvisol (IUSS-WRB 2015) derived from loess sediments (clay: 18\%, silt: $73 \%$, sand: $9 \%$ ) overlying glacial moraine deposits. The $\mathrm{pH}$ value declined from 6.5 to 6.1 during the study period. Before the initiation of the experiment the site was used as cropland probably for decades or centuries. 
The crop rotation is silage maize (Zea mays $\mathrm{L})$ - winter wheat (Triticum aestivum $\mathrm{L}$ ) - winter barley (Hordeum vulgare L). In 1983 the experiment was laid out as a full-factorial strip-design with two factors $(n=3)$. Factor one is organic additions and the second $\mathrm{N}$-fertilization rates (Table 2-1). Application of $\mathrm{P}$ and $\mathrm{K}$ was equal in all treatments but varied between years according to plant needs (Hege and Offenberger, 2006). Five levels of organic amendments are considered here: (i) - Control: no amendment, straw (wheat and barley) removed; (ii) - Slurry: slurry application, straw removed; (iii) - Manure: application of farmyard manure every third year, straw removed; (iv) - Straw: straw incorporated; and (v) - Straw with slurry: slurry application, straw incorporated.
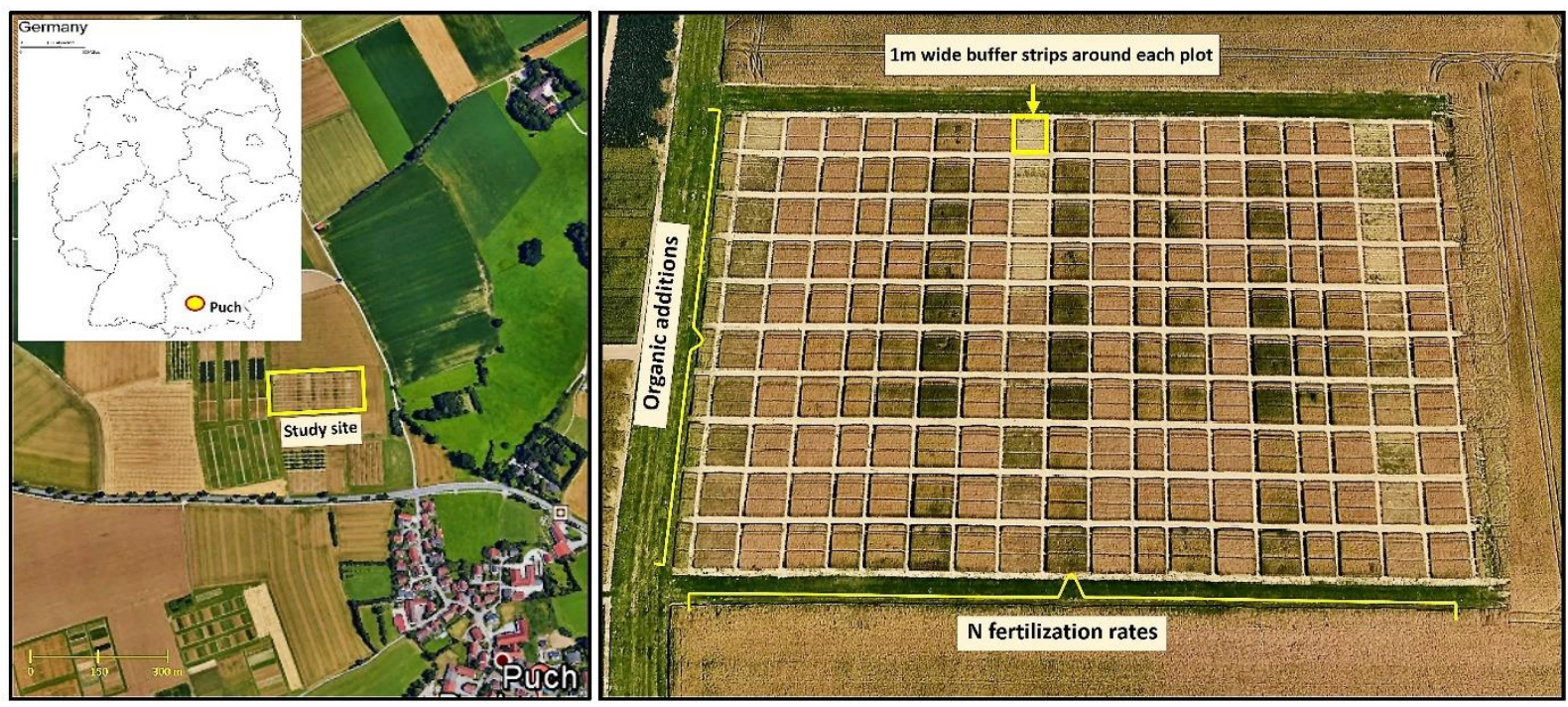

Figure 2-3 An aerial view of the study site located at Puch, close to Munich

$\mathrm{C}$ input by farmyard manure, slurry and straw addition was fixed and measured before the addition. While inputs by crop residues (stubbles and roots) were estimated and were increased with $\mathrm{N}$ fertilization (Heitkamp et al. 2012a). Since already measured C-inputs showed a large gradient of C-input especially with straw and straw plus slurry additions, which make the experiment well suited for the proposed study. Rates of N-fertilizer (three levels, N0, N2 and N4) varied between crops and since 1999 the amounts and frequency of $\mathrm{N}$ fertilization given to winter wheat and winter barley was changed (Table 2-1). 
Table 2-1: Rates of $\mathrm{N}$-fertilizer application and annual $\mathrm{C}$ additions.

\begin{tabular}{llll}
\hline N-addition $\left(\mathrm{kg} \mathrm{ha}^{-1} \mathrm{yr}^{-1}\right)$ & $\mathrm{N} 0$ & $\mathrm{~N} 2$ & $\mathrm{~N} 4$ \\
\hline 1983-1998 & 0 & 60 & $80 / 40$ \\
barley & 0 & $50 / 30^{*}$ & $70 / 50 / 40$ \\
wheat & 0 & 100 & $120 / 80$ \\
maize & & & \\
Since 1999 & 0 & $50 / 30$ & $80 / 40 / 40$ \\
barley & 0 & $50 / 20 / 30$ & $80 / 60 / 60$ \\
wheat & 0 & 100 & $120 / 80$ \\
maize & & & \\
\hline C-addition $\left(\mathrm{Mg} \mathrm{ha}^{-1} \mathrm{yr}^{-1}\right)$ & 1.17 & 1.45 & 1.58 \\
\hline Control & 2.09 & 2.34 & 2.44 \\
Slurry & 2.23 & 2.49 & 2.64 \\
Manure & 1.83 & 2.87 & 3.73 \\
Straw & 3.16 & 4.27 & 4.86 \\
Straw+Slurry & & & \\
\hline
\end{tabular}

${ }^{*} \mathrm{~N}$ amounts divided by slash indicate split applications

\subsubsection{Soil sampling}

To estimate the effects of crop residue quality and quantity inputs on SOM stabilization under controlled conditions the soil (Luvisol) was sampled from the Ap horizon $(0-25 \mathrm{~cm})$ of an experimental-field located in the North West of Göttingen, Germany $\left(51^{\circ} 33^{\prime} 36.8^{\prime \prime} \mathrm{N}\right.$, $9^{\circ} 53^{\prime} 46.9^{\prime \prime}$ E). The sampled soil characteristics were similar to the long-term field experiment located at Puch. The soil had silt-loam texture with following chemical characteristics: the organic $\mathrm{C}$ (with standard error) content of $12.6(0.4) \mathrm{g} \mathrm{kg}^{-1}$, a $\mathrm{C} / \mathrm{N}$ ratio of 9.7 and $\mathrm{pH}\left(\mathrm{CaCl}_{2}\right)$ of 6.0 .

To estimate the long-term management effects on SOM stabilization and to correlate them with the findings of incubation studies, the soil samples were taken from a depth of 0-25 cm (topsoil) and $25-50 \mathrm{~cm}$ (subsoil) from the Puch field site. The sampled topsoil depth $(0-25 \mathrm{~cm})$ represents the plough layer which is annually mixed by tillage. While the purpose of subsoil $(25-50 \mathrm{~cm})$ sampling was to investigate the impact of long-term $\mathrm{C}$ inputs on subsoil SOM accumulation. For each organic additions, the soil was sampled in three field replicates within each selected $\mathrm{N}$ fertilization rate. Three levels of $\mathrm{N}$ fertilization were selected i.e. no- (N0); medium- (N2) and high-fertilization (N4) (Table 2-1). 


\subsection{Summary of experiment and main results}

Table 2-2: Summary of the experiments: objectives, methods and main results.

\begin{tabular}{|c|c|c|}
\hline Objectives/Aims & Methods & Main results \\
\hline $\begin{array}{l}\text { 1. To determine the } \\
\text { effect of crop } \\
\text { residue quality and } \\
\text { quantity on soil } \\
\text { aggregates } \\
\text { formation and SOM } \\
\text { protection }\end{array}$ & $\begin{array}{l}{ }^{13} \mathrm{C} \text {-labeled wheat residue } \\
\text { varying in quality (leaf, stem, } \\
\text { root) and quantity were used to } \\
\text { trace plant residue } \mathrm{C} \text { in various } \\
\text { pools. } \\
\text { Aggregates size fractionations } \\
\text { (macro-, microaggregates and } \\
\text { silt plus clay) was done by wet } \\
\text { sieving method. } \\
\mathrm{C} \text { sources were partitioned in } \\
\mathrm{CO}_{2} \text { efflux, microbial biomass } \\
\text { and aggregates. }\end{array}$ & $\begin{array}{l}\text { Aggregate formation increased } \\
\text { generally with addition level. } \\
\text { Decrease of residue occlusion with } \\
\text { increasing inputs } \\
\text { Aboveground C retention in } \\
\text { aggregates decreased at a high level } \\
\text { of addition. } \\
\text { Soil priming mainly depended on } \\
\text { the level of addition. } \\
\text { Increased mineralization and less } \\
\text { residue physical protection } \\
\text { decreased SOM stabilization. }\end{array}$ \\
\hline $\begin{array}{l}\text { 2. To investigate the } \\
\text { mechanisms and } \\
\text { thresholds levels of } \\
\text { wheat residue } \\
\text { quality and quantity } \\
\left({ }^{13} \text { C-labeled) }\right. \\
\text { inducing SOM } \\
\text { priming }\end{array}$ & $\begin{array}{l}\text { Partitioning of } \mathrm{C} \text { sources in } \\
\mathrm{CO}_{2} \text { and in microbial biomass } \\
\text { at different sampling periods } \\
\text { over a } 120 \text { days incubation } \\
\text { period. } \\
\text { Measurements of enzyme } \\
\text { activities involved in } \mathrm{C}, \mathrm{N} \text { and } \\
\mathrm{P} \text { cycles at different sampling } \\
\text { periods. } \\
\text { Estimation of threshold values } \\
\text { of residue quality for SOM } \\
\text { priming by developing a new } \\
\text { unifying logistic model. }\end{array}$ & $\begin{array}{l}\text { Root residue induced stronger and } \\
\text { higher SOM priming effect than } \\
\text { aboveground crop residues. } \\
\text { Microbial-residues served as SOM } \\
\text { primer. } \\
\text { Priming effect was a power function } \\
\text { of crop residue mineralization rate. } \\
\text { The microbial fraction (and their } \\
\text { enzyme activities) feeding on crop } \\
\text { residues served as an active players } \\
\text { of SOM priming. } \\
\text { Aboveground residues } \\
\text { decomposition disproportionally } \\
\text { increased with the addition level. }\end{array}$ \\
\hline $\begin{array}{l}\text { 3. To determine the } \\
\text { impact of long-term } \\
\mathrm{C} \text { inputs (along } \mathrm{N} \\
\text { fertilization rates), } \\
\text { either root or straw } \\
\text { dominated, on SOM } \\
\text { stabilization and C }\end{array}$ & $\begin{array}{l}\text { Estimation of topsoil }(0-25 \mathrm{~cm}) \\
\text { SOM changes occurred since } \\
\text { the initiation of the experiment } \\
\text { ( } 32 \text { years). } \\
\text { Separation of SOM pools into } \\
\text { free light fraction, occluded } \\
\text { light fraction and mineral- }\end{array}$ & $\begin{array}{l}\text { Topsoil SOM contents increased } \\
\text { with input (also by } \mathrm{N} \text { fertilization), } \\
\text { mainly because of the } \mathrm{C} \text { in the free } \\
\text { light fraction. } \\
\text { The topsoil SOM lost up to } 15 \% \\
\text { under no organic additions during } \\
32 \text { years. }\end{array}$ \\
\hline
\end{tabular}




\begin{tabular}{|c|c|c|}
\hline $\begin{array}{l}\text { partitioning within } \\
\text { topsoil SOM } \\
\text { fractions, and to } \\
\text { estimate the subsoil } \\
\text { SOM contents }\end{array}$ & $\begin{array}{l}\text { associated SOM fraction by } \\
\text { density fractionation using } \\
\text { sodium polytungstate }(p<1.6 \mathrm{~g} \\
\left.\mathrm{cm}^{-3}\right) \text {. } \\
\text { Estimation of subsoil }(25-60 \\
\mathrm{cm}) \text { SOM contents. }\end{array}$ & $\begin{array}{l}\text { Straw contributed little to the f-LF } \\
\text { but prevented C losses from the } \\
\text { mineral-associated SOM fraction, } \\
\text { which observed without straw } \\
\text { additions. } \\
\text { Root } \mathrm{C} \text { retained longer in the light- } \\
\text { fractions and were responsible for } \\
\text { SOM increase with } \mathrm{N} \text { fertilization. }\end{array}$ \\
\hline $\begin{array}{l}4 . \\
\text { studies: } \\
\text { To explore the } \\
\text { responses of SOM } \\
\text { versus residue } \\
\text { mineralization in } \\
\text { response to glucose } \\
\text { addition over an } \\
\text { incubation period of } \\
3 \text { months in a soil } \\
\text { having one month } \\
\text { partially } \\
\text { decomposed wheat } \\
\text { residues (leaves, } \\
\text { root) }\end{array}$ & $\begin{array}{l}\text { A three-source partitioning } \\
\text { approach was applied using } \\
\text { dual isotopic labels }\left({ }^{13} \mathrm{C} /{ }^{14} \mathrm{C}\right) \text { to } \\
\text { partition the decomposition of } \\
\text { glucose, residue and SOM. } \\
\text { Residues were preincubated in } \\
\text { soil (for } 30 \text { days) to obtain } \\
\text { partially decomposed wheat } \\
\text { residues and there after glucose } \\
\text { was added. } \\
\text { Glucose priming effect both on } \\
\text { SOM and residues was } \\
\text { distinguished. } \\
\text { Source partitioning was done } \\
\text { for } \mathrm{CO}_{2} \text { and microbial biomass. }\end{array}$ & $\begin{array}{l}\text { Glucose addition caused negative } \\
\text { priming effect on residues } \\
\text { (predominantly leaves) and strong } \\
\text { positive priming effect on SOM. } \\
\text { Increased SOM derived C } \\
\text { (compared to residue derived) in } \\
\text { microbial biomass suggested that } \\
\text { glucose caused preferential } \\
\text { microbial utilization of SOM over } \\
\text { plant residue. } \\
\text { Priming induced by glucose was } \\
\text { mainly due to SOM decomposing } \\
\text { microorganisms. } \\
\text { The priming effects of residue on } \\
\text { SOM changed by the presence of } \\
\text { glucose. }\end{array}$ \\
\hline
\end{tabular}




\section{Publications and Manuscripts}

\subsection{Study 1}

Decrease of soil organic matter stabilization with increasing inputs: mechanisms and controls

Muhammad Shahbaz $^{1,3, *}$, Yakov Kuzyakov ${ }^{2,3}$, Felix Heitkamp $^{1}$

${ }^{1}$ Section of Physical Geography, Faculty of Geoscience and Geography, Georg August

University Göttingen, Goldschmidtstr 5, 37077 Göttingen, Germany

${ }^{2}$ Department of Soil Science of Temperate Ecosystems, Georg August University Göttingen, Büsgenweg 2, 37077 Göttingen, Germany

${ }^{3}$ Department of Agricultural Soil Sciences, Georg August University Göttingen, Büsgenweg 2, 37077 Göttingen, Germany

Status: Published in Geoderma (2016): http://dx.doi.org/10.1016/j.geoderma.2016.05.019

*Corresponding author:

Department of Agricultural Soil Sciences, Georg August University Göttingen,

Büsgenweg 2, 37077 Göttingen, Germany

Tel: + 4955139 20502; Fax + 49551393310

Email: shahbazmu@yahoo.com 


\section{Highlights}

- Aggregate formation increased generally with addition level.

- Decrease of residue occlusion with increasing inputs

- Aboveground $\mathrm{C}$ retention in aggregates decreased at a high level of addition.

- Soil priming mainly depended on the level of addition.

- Increased mineralization and less residue physical protection decreased SOM stabilization.

\section{Graphical abstract}

Effects of residue addition levels on SOM stabilization

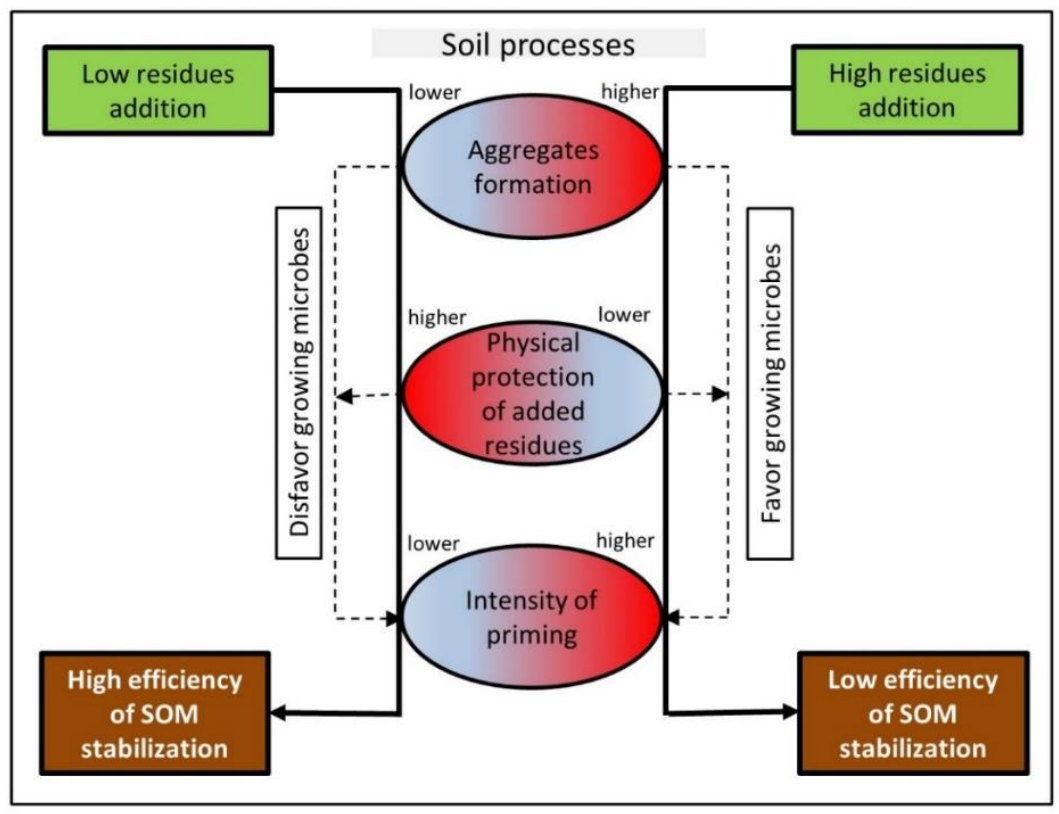

Conceptual diagram of the effects of levels of residue addition on the efficiency of soil organic matter stabilization (SOM) by three processes: Aggregate formation, Physical protection of added residues, and Priming intensity. The red color represents increasing process intensity. The dashed lines indicate the conditions affecting growing fraction of microbial biomass (important for priming) as influenced by the three soil processes. 


\subsubsection{Abstract}

Crop residue addition is a way to increase soil organic matter (SOM) level in croplands. However, organic matter input and SOM stocks are not linearly related. Consequently, adding high amounts of residues, such as straw, may increase SOM to only a small extent, and an alternative use of the residues may be justified. The objective of this study was to test how the level and type (above- or belowground) of residue addition affect SOM stabilization. We hypothesize that (1) root residues will be mineralized slower than leaf and stalk residues, (2) soil aggregate formation will increase with high additions, and (3) wheat residue addition will induce positive priming, with the magnitude depending on the residue level and type. Homogeneously ${ }^{13} \mathrm{C}$-labeled wheat residues (leaves, stalks, roots) were added to a silt-loam soil at levels of 1.40 and $5.04 \mathrm{~g} \mathrm{DM} \mathrm{kg}^{-1}$ and $\mathrm{CO}_{2}$ release and $\delta^{13} \mathrm{C}$ signature were measured over 64 days at $20^{\circ} \mathrm{C}$. Water-stable macroaggregates $(>250 \mu \mathrm{m})$, microaggregates $(53-250 \mu \mathrm{m})$ and silt plus clay size fractions $(<53 \mu \mathrm{m})$ were separated and ${ }^{13} \mathrm{C}$ incorporation from residue was quantified in each fraction after 64 days. Aggregate formation generally increased with added residue amount, but the proportion of residues occluded within aggregates decreased with increasing addition level. The occlusion of residues from aboveground biomass was more reduced with addition level than that of roots. Residue mineralization increased with the addition level, but this increase was less for roots compared to stalks and leaves. Priming effects were similar between residue types and mainly depended on the added amount: SOM mineralization increased by $50 \%$ and $90 \%$ at low and high addition levels, respectively. We conclude that the proportion of residues physically protected within aggregates decreases and priming effects increase with increasing $\mathrm{C}$ input leading to decreasing rate of long-term $\mathrm{C}$ stabilization within SOM by increasing residue addition.

Keywords: root mineralization, straw residue, soil organic matter, carbon sequestration, priming effect, water stable aggregates 


\subsubsection{Introduction}

Globally, anthropogenic loss of carbon (C) from terrestrial ecosystems is estimated from 48 to $114 \mathrm{Pg}$ before the industrial revolution (Houghton, 2012). Since 1850, another 108 to $188 \mathrm{Pg} \mathrm{C}$ has been lost, which mostly stems from biomass but about $25 \%$ of this loss is contributed by soil organic matter (SOM) mineralization (Houghton, 2012; Lal, 2004). The soil C losses can be mitigated by recarbonization using recommended management practices thereby increasing food security (Lorenz and Lal, 2012; Sauerbeck, 2001). However, some mitigation options in agriculture are in direct competition with each other, e.g., use of crop residue for $2^{\text {nd }}$ generation bioenergy crops versus residue incorporation into the soil for maintenance or build-up of SOM.

The incorporation of crop residues, such as cereal straw, is an important measure to maintain or increase SOM levels under cropland (Lugato et al., 2014). Recent studies on long-term field experiments, however, show that incorporation of cereal straw is often not very effective in terms of SOM increases (Heitkamp et al., 2012b; Poeplau et al., 2015; Powlson et al., 2011). Resultantly, the efficiency (i.e. the increase of SOM per unit of input) of residue incorporation decreases with the amount added, as shown in a long-term experiment on a silt-loam Luvisol (Heitkamp et al., 2012b). Reasons for this may be (1) a lower proportion of belowground plant biomass, which is supposed to be more recalcitrant and have longer mean residence time in soil (Rasse et al., 2005), (2) a finite capacity of aggregates, which provide physical protection of SOM against mineralisation, and (3) priming of SOM by incorporation of plant residues.

The biochemical composition and physical structure of crop residue affect mineralization (Prescott, 2010). Plant parts differ in chemical composition and physical structure, especially roots are more recalcitrant and so, have a longer mean residence time in soil (Heitkamp et al., 2012a; Rasse et al., 2005). For instance, a meta-analysis showed that roots of herbaceous species decompose 1.8 times slower than leaves (Freschet et al., 2013). Therefore, increasing aboveground input by crop residue shifts the input away from below-ground sources and can decrease the average litter mean residence time in soil. Occlusion within aggregates is another important mechanism to protect litter from mineralization (Six et al., 2004; von Lützow et al., 2008).

Aggregates, which protect SOM by physical occlusion, are formed by biological and physicochemical processes (Six et al., 2004). Aggregates are often classified according to stability (e.g. resistance against slaking) and size. The addition of residue forms hotspots of 
microbial activity triggering the formation of aggregates. The amount and type of organic matter input having differential decomposition rates can affect aggregate dynamics (Gunina et al., 2015). However, due to the limited capacity of storage, some studies showed that residue addition levels had little effect on aggregate $C$ contents (Andruschkewitsch et al., 2014; Stewart et al., 2008). In consequence, a higher proportion of crop residue would remain physically unprotected when incorporation of residues is increased. In contrast Poirier et al. (2014) observed macroaggregates formation was leveled off at increasing residue input, however, residue kept accumulating in aggregates due to occlusion and adsorption mechanisms.

In the soil, labile substances can cause positive priming, i.e. additional (compared to without substrate addition soil) $\mathrm{CO}_{2}$ release by accelerated $\mathrm{SOM}$ mineralization. Many experiments on priming were performed with glucose because the most plant polymers will be decomposed to monosaccharides rapidly (Gunina and Kuzyakov, 2015). Only a few studies investigated priming effects of crop residue on SOM (Guenet et al., 2010; Moreno-Cornejo et al., 2015). These studies show contrasting results: whereas Guenet et al. (2010) reported that priming of SOM by wheat residues is a non-linear function which saturates with the addition of $2.2 \mathrm{~g}$ straw $\mathrm{kg}^{-1}$ soil, Poirier et al. (2013) showed an almost linear increase up to $40 \mathrm{~g}$ maize residue $\mathrm{C} \mathrm{kg}^{-1}$ soil. Xiao et al. (2015) suggested that priming increases linearly with litter addition upon the response of enhanced microbial biomass and activity. Residues with lower $\mathrm{C} / \mathrm{N}$ ratio or mineral $\mathrm{N}$ addition decreased the priming effect slightly (Guenet et al., 2010; Moreno-Cornejo et al., 2015; Wang et al., 2015).

Summarizing, with increasing levels of residue incorporation the increase of SOM per unit of input may decrease 1) due to a shift from recalcitrant below to labile aboveground input, 2) by a lower proportion of fresh residues protected within aggregates or 3) by inducing positive priming of SOM. In a controlled experiment, we tested these three possibilities by incorporation of ${ }^{13} \mathrm{C}$ labeled wheat plant parts (leaves, stalks and roots) at two levels into a silt-loam soil during 64 days of incubation. We hypothesise that (1) regardless of addition level, root residue will be mineralised slower than leaves and stalk residue, (2) aggregate formation will increase with addition level, but the proportion of residue $\mathrm{C}$ stabilized within aggregates will decrease, and (3) wheat residue addition will induce positive priming, with its magnitude depending on the level of addition and the type of residue. 


\subsubsection{Materials and methods}

\subsubsection{Soil and wheat residue}

The soil (Haplic Luvisol) samples were taken from the Ap horizon $(0-25 \mathrm{~cm})$ of an experimental field, located on a terrace plain of the river Leine in the North West of Goettingen, Germany $\left(51^{\circ} 33^{\prime} 36.8^{\prime \prime} \mathrm{N}, 9^{\circ} 53^{\prime} 46.9^{\prime \prime} \mathrm{E}\right)$. The soil had silt-loam texture (clay: $7.0 \%$, silt: $87.2 \%$, sand: $5.8 \%$ ) and was carbonate-free with a mean organic $\mathrm{C}$ (with standard error) content of $12.6(0.4)$ $\mathrm{g} \mathrm{kg}^{-1}$, a $\mathrm{C} / \mathrm{N}$ ratio of 9.7 and $\mathrm{pH}\left(\mathrm{CaCl}_{2}\right)$ of 6.0 . Since more than 25 years the field has been cultivated with annual C3 crops (predominantly wheat; Kramer et al., 2012). The soil was air dried after sampling. Larger clods were crushed with mortar and pestle, sieved $(<2 \mathrm{~mm})$ and fine roots and other visible plant debris were carefully removed.

The wheat (Triticum aestivum L.) plants were labeled with ${ }^{13} \mathrm{C}$ every week after emergence for at least 8 hours in a growth chamber. Seeds were planted into pots filled with quartz sand, were watered regularly and once a week Hoagland's nutrient solution (N: 210, K 235, Ca 200, P 31, S64, Mg: 48 ppm plus micronutrients) was added. Labeled (99 Atom\%) $\mathrm{NaH}^{13} \mathrm{CO}_{3}$ was injected into $\mathrm{H}_{2} \mathrm{SO}_{4}$ positioned in the chamber. In the night (dark period) the chamber was left closed and was opened in the morning after respired $\mathrm{CO}_{2}$ was taken up again. Further details are presented by Bromand et al. (2001). Plants were harvested after senescence, where roots were washed free from the sand with tap water. Wheat biomass was carefully separated into leaves, stalks and roots. Each part was chopped and sieved $(<2 \mathrm{~mm})$ to achieve more homogeneous mixing with soil for incubation. The content of $\mathrm{C}, \mathrm{N}$ and ${ }^{13} \mathrm{C}$ Atom \% (At\%) was measured with an isotope ratio spectrometer coupled to an elemental analyzer (Delta plus, EA-IRMS, see detail section 3.1.3.5). The mean $\mathrm{C}$ concentrations of leaves, stalk and roots were in the order: 391.9 $\pm 6.1(\mathrm{C} / \mathrm{N}: 17.2 \pm 0.3), 409.6 \pm 8.7(\mathrm{C} / \mathrm{N}: 21.5 \pm 1.17)$ and $278.3 \pm 5.9(\mathrm{C} / \mathrm{N}: 15.5 \pm 0.5) \mathrm{g} \mathrm{kg}^{-1}$, respectively. The $\mathrm{At} \%{ }^{13} \mathrm{C}$ values for the residue types were $1.55 \pm 0.00$ (leaves), $1.34 \pm 0.01$ (stalks) and $1.51 \pm 0.03$ (roots).

\subsubsection{Incubation and sampling}

Maximum water holding capacity (WHC) of the soil was determined by soaking for 24 hours, subsequent free drain for 1 hour and weighing in the wet and dry state. A hundred grams of sieved and dried soil was weighed into 750-ml incubation jars. The soil was then preincubated at $50 \%$ of its WHC for seven days, because rewetting and sieving affect the availability of SOM for microorganisms and may cause a respiration flush (Blagodatskaya and Anderson, 1999). 
The pre-incubated soil was amended with labeled wheat leaves, stalks or roots with low or high amounts and one control were left without residue addition $(n=4)$. The added residues were thoroughly mixed with incubated soil. Water contents were then adjusted to $70 \%$ of WHC before starting the incubation for 64 days. Residues were added at rates of 1.4 and $5.04 \mathrm{~g} \mathrm{DM}$ $\mathrm{kg}^{-1}$ as low and high addition level, respectively. These amounts correspond to 5 and $18 \mathrm{Mg} \mathrm{ha}^{-}$ ${ }^{1}$ of residues under field conditions assuming $25 \mathrm{~cm}$ depth and a bulk density of $1.5 \mathrm{~g} \mathrm{~cm}^{-3}$. We added residues on a dry matter base, however, $\mathrm{C}$ input by roots with lower $\mathrm{C}$-contents corresponds to ca. $70 \%$ of the $\mathrm{C}$ amount added with leaves or stalks.

\subsubsection{2 $\mathrm{CO}_{2}$ efflux}

Released $\mathrm{CO}_{2}$ was trapped in small bottles with $10 \mathrm{~mL}$ of $1 \mathrm{M} \mathrm{NaOH}$ placed in the incubation jars (including 4 controls without soil) which were closed air-tight. The $\mathrm{NaOH}$ traps were replaced after 2, 6, 11, 17, 27, 51 and 64 days. Therefore, jars were not closed longer than 14 days and the capacity of $\mathrm{NaOH}$ was never used up to more than $60 \%$. To quantify respired $\mathrm{CO}_{2}$, $\mathrm{NaOH}$ was titrated with $0.1 \mathrm{M} \mathrm{HCl}$ until $\mathrm{pH} 8.2$ using phenolphthalein as indicator. Excess 0.5 $\mathrm{M} \mathrm{BaCl}_{2}$ was added to precipitate $\mathrm{CO}_{3}{ }^{2-}$ before titration. Another Aliquot of $\mathrm{NaOH}$ was mixed with $1 \mathrm{M} \mathrm{SrCl}_{2}$ in a $15 \mathrm{ml}$ centrifugation tube and centrifuged for $5 \mathrm{~min}$ at $2000 \mathrm{rpm}$ (Blagodatskaya et al., 2011). The centrifugation process was repeated until the $\mathrm{pH}$ level of the aliquot reached 7. The $\mathrm{SrCO}_{3}$ pellets were dried at $60{ }^{\circ} \mathrm{C}$ and stored for $\delta^{13} \mathrm{C}$ analysis.

\subsubsection{Fractionation of soil aggregates}

Water stable aggregates were separated at the end of incubation. The soil was oven-dried at $40^{\circ} \mathrm{C}$ for $24 \mathrm{~h}$. Then, $70 \mathrm{~g}$ of dry soil was placed on a $250 \mu \mathrm{m}$ sieve and submerged in ca. $1.5 \mathrm{~L}$ distilled water for 5 min to allow slaking (Six et al., 1998). Thereafter, the sieve was moved up and down into the water with 50 repetitions in $2 \mathrm{~min}$. Water-stable aggregates remaining on the mesh (macroaggregates $>250 \mu \mathrm{m}$ ) were collected in pre-weighed aluminum foil then dried and weighed. Aggregates which passed the $250 \mu \mathrm{m}$-sieve were poured onto the next smaller mesh size (microaggregates: $53-250 \mu \mathrm{m}$ ) and the fractionation-procedure was continued as described above. Finally, the silt and clay size fraction together with the finest microaggregates $<53 \mu \mathrm{m}$ was collected in a pre-weighed container, dried and weighed.

\subsubsection{Microbial biomass}

The fumigation extraction method was used to measure microbial biomass $\mathrm{C}$, as described by Vance et al. (1987). Briefly, $10 \mathrm{~g}$ of moist soil was divided and one subsample was fumigated 
for $24 \mathrm{~h}$ at $25{ }^{\circ} \mathrm{C}$ with ethanol-free $\mathrm{CHCl}_{3}$. Both subsamples were shaken for $1 \mathrm{~h}$ at $175 \mathrm{rev}$. $\mathrm{min}^{-1}$ with $20 \mathrm{~mL}$ of $0.05 \mathrm{M} \mathrm{K}_{2} \mathrm{SO}_{4}$. The obtained extracts were kept cold $\left(<4{ }^{\circ} \mathrm{C}\right)$ and analyzed the next day for total C concentration (Multi N/C 2100, Analytik Jena, Germany). Microbial biomass $\mathrm{C}$ was calculated as $\mathrm{EC} / \mathrm{K}_{\mathrm{EC}}$, where $\mathrm{EC}=$ (organic $\mathrm{C}$ from fumigated soils $)-($ organic $\mathrm{C}$ from non-fumigated soils) and $\mathrm{K}_{\mathrm{EC}}=0.45$ (Wu et al., 1990).

\subsubsection{Isotopic analysis and calculations}

At the end of incubation period, soil aggregates size classes were ground to a fine powder using a ball mill for 3 minutes and then analyzed for carbon concentration as well as ${ }^{13} \mathrm{C} /{ }^{12} \mathrm{C}$ ratios. The analyses were performed at the Centre for Stable Isotope Research and Analysis (KOSI) University of Goettingen, Germany, using an isotope ratio mass spectrometer (Delta plus, IRMS; Thermo Fisher Scientific, Bremen, Germany), coupled to an elemental analyzer (NC 2500; CE Instruments, Milano, Itlay). The values were calibrated with reference to the international VPDB (Vienna Peedee Belemnite) standard. For ${ }^{13} \mathrm{C} /{ }^{12} \mathrm{C}$ ratio measurements in microbial biomass, the extracts from fumigated and nonfumigated samples were freeze-dried and weighed in capsules. As incorporated wheat residues were highly enriched, residue derived $\mathrm{C}$ in all pools was calculated by using $\mathrm{At} \%{ }^{13} \mathrm{C}$ values. $\mathrm{At} \%{ }^{13} \mathrm{C}$ values originated from the incubated soil were calculated according to the following Eq. (1):

At $\%{ }^{13} C=\left[\right.$ number of ${ }^{13} \mathrm{C}$ atoms $/\left(\right.$ numberof $\left({ }^{12} C+{ }^{13} C\right)$ atoms $] * 100$

In the various pools, the fraction of total $\mathrm{C}(f \mathrm{C})$ derived from residues was calculated using Eq. (2):

$f C=\left[\left(A t_{t r}-A t_{c}\right) /\left(A t_{r}-A t_{c}\right)\right]$

Where $\mathrm{At}_{\text {tr }}$ represents $\mathrm{At} \%{ }^{13} \mathrm{C}$ values of, aggregate size fractions, $\mathrm{CO}_{2}-\mathrm{C}$ trapped in $\mathrm{NaOH}$, extracted $\mathrm{C}$, derived from the residues amended soil. While $\mathrm{At}_{\mathrm{r}}$ represents $\mathrm{At}^{13}{ }^{13} \mathrm{C}$ values of initially incorporated wheat residues (leaves, stalk or roots), $\mathrm{At}_{\mathrm{c}}$ represents $\mathrm{At} \%{ }^{13} \mathrm{C}$ values of each corresponding pool coming from the unamended sample. Thus, the amount of residue derived $\mathrm{C}\left(\mathrm{C}_{\text {res-derived }}\right)$ in various pools, was computed using Eq. (3) (Poirier et al., 2013).

$C_{\text {res-derived }}=f C *[A]$

Where $[A]$ represent either total organic $\mathrm{C}$ in aggregates size classes $\left(\mathrm{g} \mathrm{kg}^{-1}\right.$ soil) measured by a dry combustion method, total respired $\mathrm{CO}_{2}\left(\mathrm{mg} \mathrm{C} \mathrm{kg}^{-1}\right)$ measured by titration method, $\mathrm{C}$ contents of fumigated or non-fumigated $\mathrm{K}_{2} \mathrm{SO}_{4}$ extract $\left(\mathrm{mg} \mathrm{kg}^{-1}\right)$. 
Similarly, the amount of SOM derived C ( $\left.\mathrm{C}_{\text {SOM-derived }}\right)$ was calculated by subtracting $\mathrm{C}_{\text {res-derived }}$ from total $\mathrm{C}$ of the corresponding pool. The amount of priming effect (PE, $\mathrm{mg} \mathrm{C} \mathrm{kg}^{-1}$ ) was calculated according to the following Eq. (Blagodatskaya et al., 2011).

$P E=\left(\mathrm{CO}_{2 \text { total }}-\mathrm{CO}_{2 \text { res-derived }}\right)-\mathrm{CO}_{2 \text { control }}$

For the estimation of total residues derived $\mathrm{C}$ incorporation in microbial biomass, firstly residues derived $\mathrm{C}$ was calculated separately from fumigated and non-fumigated samples by using Eq. 3, thereafter values of the non-fumigated sample were subtracted from fumigated.

\subsubsection{Statistical analysis}

The experiment was laid out as a full-factorial, fully randomized design. The factor "type" had three levels (leaves, stalks, roots) and the factor "level" had three (no addition, 1.4. and $5.04 \mathrm{~g}$ $\mathrm{kg}^{-1}$ ) or two levels. Two levels were used when comparing residue-derived $\mathrm{C}$ in fractions, where inclusion of "no addition" was not suitable. Statistical analyses were performed with SPSS 11 using a two-way ANOVA with "level" and "type" as fixed effects. When significant $(\mathrm{p} \leq 0.05)$ effects were found, post hoc comparisons of means were performed using Fisher's Least Significant Difference (Webster, 2007). A students t-test was used to test whether the increase in mineralization was different from the increase in addition within the different residue types. Assumptions of a normal distribution were tested by the Kolmogorov-Smirnov test while homoscedasticity was checked using Levene's test. When assumptions were not met, a logarithmic transformation was used. The results are presented as means of 4 replicates for nonisotopic, and 3 replicates for isotopic measurements.

\subsubsection{Results}

\subsubsection{Effect of residue addition on aggregates and C distribution}

The distribution of the water-stable macroaggregates $(>250 \mu \mathrm{m})$ was strongly affected by both residue level $(\mathrm{p} \leq 0.001)$ and type $(\mathrm{p} \leq 0.001)$. The interaction of level and type showed a strong tendency $(\mathrm{p}=0.068)$ to affect macroaggregate distribution, meaning that the effect of residue type tended to be more pronounced at high level (Fig. S1-1). At high addition level, the proportion of macroaggregates decreased with residue type in the order: leaves $(45 \pm 2.9 \%)$, stalk $(37.3 \pm 3.8 \%)$ and roots $(28.2 \pm 2.4 \%)$. Correspondingly, the proportion of microaggregates increased in the same sequence (Fig. S1-1). The proportion of macroaggregates (17-23\%) at 
low addition level did not differ from unamended soil. Proportions of microaggregates were inversely related to macroaggregates.

The formation of aggregates was accompanied by incorporation of wheat residues. Up to 58\% of the residue $\mathrm{C}$ was incorporated in all aggregate fractions and about $37 \%$ was protected in macroaggregates (Table S1-1, Fig. S1-2). A much lower portion of residue derived C was observed in the microaggregates (7-15\%) and in the silt plus clay fraction (1.5-2.7\%, Fig. S12). Absolute amounts of residue $\mathrm{C}$ were higher at high level throughout all size classes. However the portion of residue derived C (\% of initial input) incorporated into aggregates was smaller at high addition level in macro- and microaggregates (Fig. S1-2). Moreover, the portion of root-derived $\mathrm{C}$ in microaggregates was significantly higher compared to stalk and leaves (Fig. S1-2).

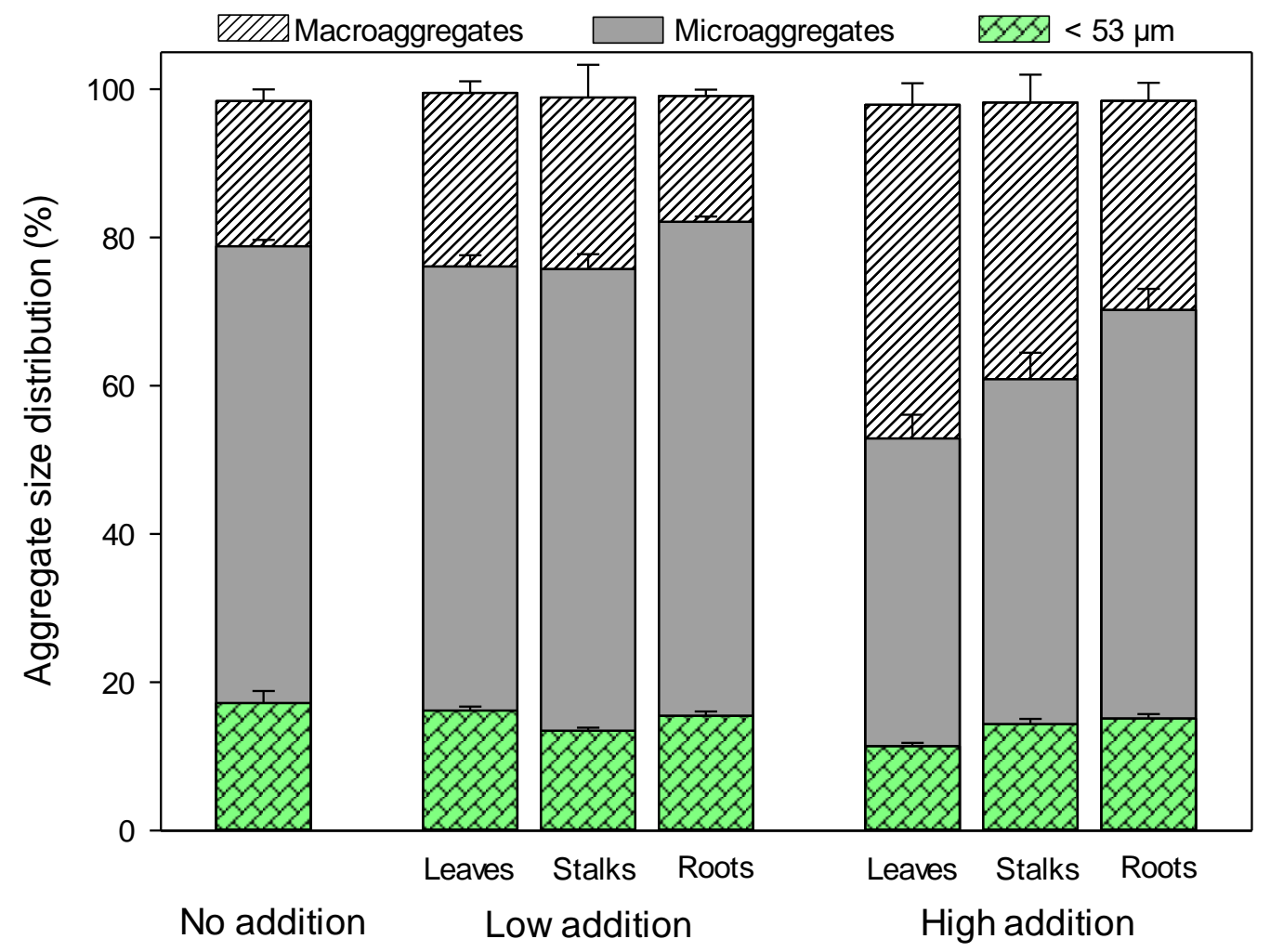

Figure S1-1 The relative distribution of aggregate size classes (Macro $>250 \mu \mathrm{m}$, Micro 53 $250 \mu \mathrm{m}$ and silt plus clay $<53 \mu \mathrm{m}$ ) after 64 days of incubation depending on type and level of crop residue additions. Means and standard errors $(n=4)$. The probability levels of the ANOVA for accepting the null hypothesis that the factors have no effect are as follows: macroaggregates (type $<0.001$; level $<0.001$; type $\times$ level $=0.068$ ), microaggregates (type $<0.001 ;$ level $=0.001 ;$ type $\times$ level $=0.349),<53 \mathrm{~mm}($ type $=0.034 ;$ level $=0.116 ;$ type $\times$ level $=0.003$ ). 
Table S1-1. The contribution of residue-C (as \% of initial input) protected in different soil aggregate fractions (macroaggregates $>250 \mu \mathrm{m}$, microaggregates $53-250 \mu \mathrm{m}$ and silt plus clay $<53 \mu \mathrm{m}$ ), and mineralized as $\mathrm{CO}_{2}$, in total recovery of added residue after 64 days of incubation, depending on the level and type of addition. Unrecovered plant residues were not incorporated into aggregates and removed from samples. Numbers in the brackets represent SE $(n=3)$.

\begin{tabular}{|c|c|c|c|}
\hline \multirow[t]{2}{*}{ Treatment } & \multicolumn{2}{|c|}{ Residue C (\% of initial input) } & \multirow[t]{2}{*}{ Total recovery $(\%)$} \\
\hline & Aggregate classes & $\mathrm{CO}_{2}$ & \\
\hline \multicolumn{4}{|c|}{ Low addition level } \\
\hline Leaf & $47.3(3.9)$ & $42.6(0.8)$ & $89.9(4.7)$ \\
\hline Stalk & $55.2(1.5)$ & $34.7(2.2)$ & $89.8(3.5)$ \\
\hline Root & $58.6(0.9)$ & $37.1(1.4)$ & $95.7(2.3)$ \\
\hline \multicolumn{4}{|c|}{ High addition level } \\
\hline Leaf & $34.0(0.3)$ & $40.2(0.9)$ & $74.2(0.9)$ \\
\hline Stalk & $38.2(0.7)$ & $39.0(1.6)$ & $77.2(2.2)$ \\
\hline Root & $47.62(5.2)$ & $25.6(1.4)$ & $73.2(4.3)$ \\
\hline \multicolumn{4}{|c|}{ ANOVA results $(p$ values $)$} \\
\hline Type & 0.003 & $<0.001$ & 0.758 \\
\hline Level & $<0.001$ & 0.018 & $<0.001$ \\
\hline Level x Type & 0.567 & 0.001 & 0.332 \\
\hline
\end{tabular}

\subsubsection{Microbial biomass}

Residue-derived C in microbial biomass was affected both by type $(\mathrm{p}=0.001)$ and level $(\mathrm{p}<$ 0.001) of addition. More $\mathrm{C}$ was incorporated at high level of all residue types (2-3 times), and incorporation was highest from leaves followed by stalks and roots (Fig. S1-3).

Microbial biomass C derived from SOM was affected by the interaction of residue type and level ( $\mathrm{p}=0.001$, Fig. S1-3). Addition with leaves and stalks decreased C contents of microbial biomass by 24 and $45 \mathrm{mg} \mathrm{kg}^{-1}$ at high compared to low addition level, respectively.

\subsubsection{Mineralisation}

Residue mineralization (Fig. S1-4) after 64 days depended on the type and level of the addition (for both $\mathrm{p}<0.001$ ). For instance, residue mineralization at high addition level was 3.4 times higher for leaves (230 and $790 \mathrm{mg} \mathrm{CO}_{2}-\mathrm{C} \mathrm{kg}^{-1}$, low and high level, respectively) and 4.1 times higher for stalks (200 and $820 \mathrm{mg} \mathrm{CO}_{2}-\mathrm{C} \mathrm{kg}^{-1}$, low and high level, respectively) than at low level. Therefore, the increase in mineralisation was in the same magnitude as to the increase in addition level, which was 3.6 times higher (t-values 1.4 and 2.1 for leaves and stalks, respectively, critical t-value: 4.3). $\mathrm{CO}_{2}$ efflux derived from roots was lower (150 and $370 \mathrm{mg}$ $\mathrm{kg}^{-1}$, low and high level, respectively; $\mathrm{p}<0.001$ ) as compared to leaves or stalks (Fig. S1-4). 
$\mathrm{CO}_{2}$ evolution at low addition level was 65 to $75 \%$ compared to leaves and stalks and is fully explained by the lower $\mathrm{C}$ content of roots. At high level, however, mineralization of roots is less than $50 \%$ of leave and stalks. The increase of mineralization from low to high level was only 2.4 times (significantly different from 3.6, t-value: 7.0). Therefore, the type of residues was more important at high input level (type $\times$ level $\mathrm{p}<0.001)$.

Mineralisation of SOM (Fig. S1-4) increased ( $<$ < 0.001) with the level of residue addition. Consequently, SOM mineralisation was 50 to $90 \%$ increased due to the addition of fieldequivalent amounts of 5 and $18 \mathrm{Mg} \mathrm{ha}^{-1}$ crop residue (Fig. S1-4).

\subsubsection{Discussion}

Overall, results confirmed, at least in parts, all of our hypotheses. Our first hypothesis assumed that root residue mineralisation will be lower than of stalk and leaf. This was confirmed at least at high addition level (Table S1-1, Fig. S1-4) and is corroborated by previous work (Bertrand et al., 2006; Freschet et al., 2013; Rasse et al., 2005). The lower root mineralisation is generally explained by biochemical composition (more lignin, suberin, and less $\mathrm{N}$ ) of roots being more recalcitrant (Bertrand et al., 2006; Rasse et al., 2005). It is, however, noteworthy that residuederived $\mathrm{CO}_{2}-\mathrm{C}$ efflux increased less with addition level for roots as compared to stalks and leaves (Fig. S1-4). Whereas residue input increased 3.6 fold, mineralisation of leaves increased 3.4 fold, of stalks 4.1 fold and of roots only 2.4 fold. The mechanisms explaining the microbial activity with root input at high level cannot be elucidated unequivocally from our experiment. On the one hand, some compounds in roots may directly affect microbial activity negatively (e.g. phenolic compounds, Bertrand et al., 2006). On the other hand, interactions with the mineral soil matrix, such as aggregation, could protect residues from mineralisation. For instance, the proportion of root-derived $\mathrm{C}$ in microaggregates and the fraction $<53 \mu \mathrm{m}$ is significantly higher for roots than for stalks and leaves (Fig. S1-2).

The second hypothesis assumed that formation of aggregates will increase with the residue input level, but the proportion of residue-C incorporated within aggregates will decrease. The increase in macroaggregate formation was strikingly demonstrated (Fig. S1-1), as reported before in other studies using various organic additions (Abiven et al., 2009; Andruschkewitsch et al., 2014; Helfrich et al., 2008; Six et al., 2004). Correlation of microbial respiration with macroaggregate portion (Andruschkewitsch et al., 2014) confirms the contribution of active 

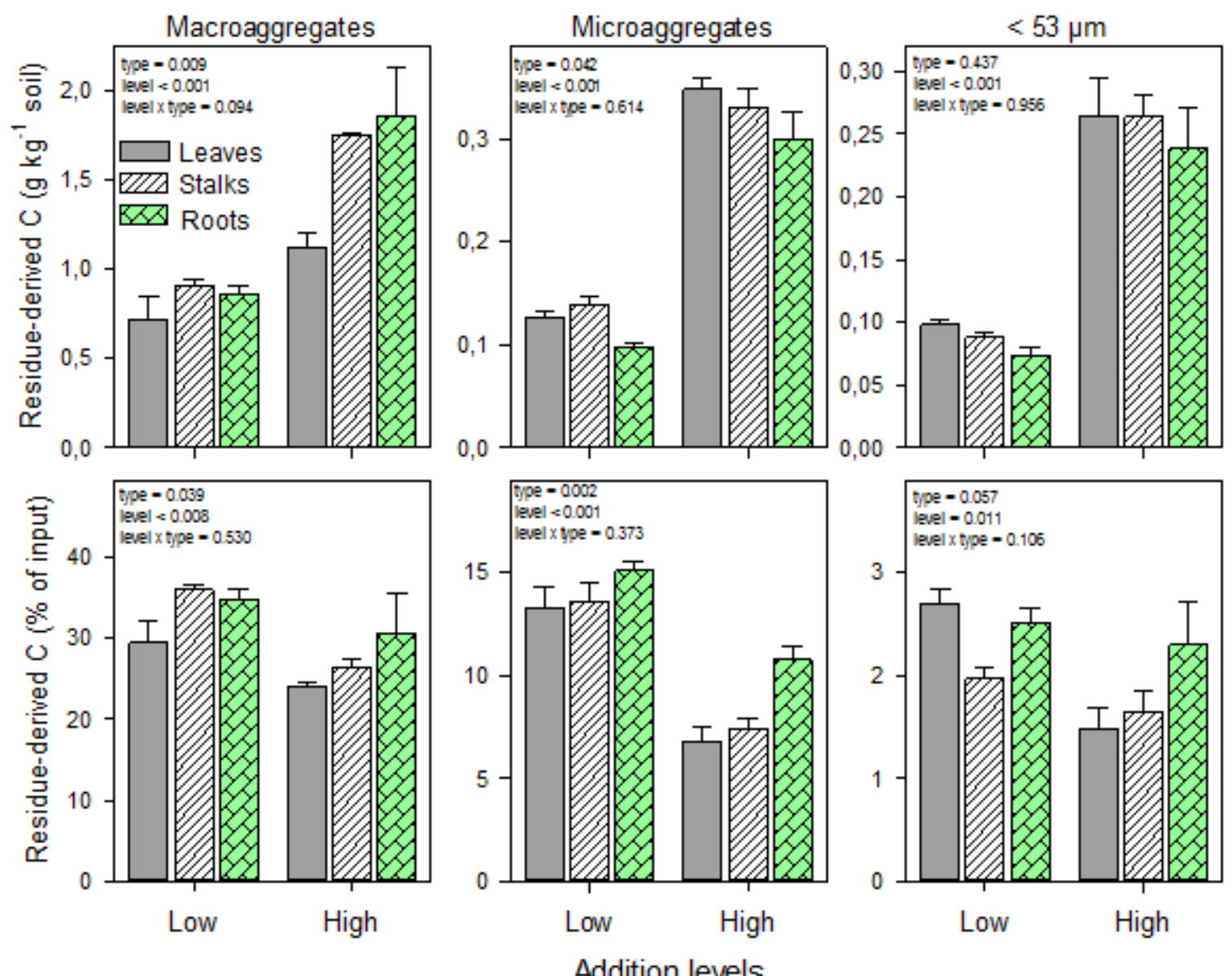

Addition levels

Figure S1-2 Residue-derived $C$ in the soil aggregate size classes (Macro $>250 \mu \mathrm{m}$, Micro 53-250 $\mu \mathrm{m}$ and silt plus clay $<53 \mu \mathrm{m})$. Upper subfigures present total aggregate protected $\mathrm{C}$ in soil and lower subfigures show protected $\mathrm{C}$ portion of initially added residueC. Means and standard errors $(n=3)$. The p-values calculated by an ANOVA show probability levels for accepting the null hypothesis that the factors have no effect.

microorganisms to aggregate formation. The correlation of the mass of macroaggregates with the $\mathrm{CO}_{2}$ release was better with residue-derived $\mathrm{CO}_{2}(\mathrm{r}=0.8)$ than with $\mathrm{SOM}$-derived $\mathrm{CO}_{2}(\mathrm{r}=$ 0.5). The proportion of protected residue-derived $\mathrm{C}$ was smaller at high addition level for all types of residue (Table S1-1, Fig. S1-2). Thus, increasing addition level promotes macroaggregate formation. However, the low proportion of physically protected residues at high addition levels leads a decreasing C-stabilization rate within SOM. Only in case of high addition with roots, however, we found a potentially protecting effect of occlusion within aggregates. For instance, if occlusion within aggregates protects residues from mineralisation (Six et al., 2002) then residue mineralization (as a proportion of total input) should be lower when aggregate occlusion is higher. Table S1-1 clearly shows that this was only the case when 
roots were added at high level, whereas there was no significant difference for any other treatment in the proportion of mineralised residue. Therefore, physical protection did not play a marked role in $\mathrm{C}$ stabilization of aboveground residues. Although there are widespread assumptions that aggregates protect organic matter from mineralisation, this may not necessarily apply to freshly incorporated aboveground residues within macroaggregates (Andruschkewitsch et al., 2014). Microaggregates may be more effective in stabilising C (von Lützow et al., 2008) because sorption instead of physical occlusion may be the prevailing process (Lehmann et al., 2007). At high addition level of roots, we found not only a lower proportion of mineralisation (Table S1-1) but also a higher association of root $\mathrm{C}$ with microaggregates and the $<53 \mu \mathrm{m}$ fraction (Fig. S1-2). Overall there was no evidence for physical short-term stabilisation of aboveground plant parts and higher association of large amounts of roots may indicate preferential long-term stabilisation under field conditions (Baldock and Skjemstad, 2000; Six et al., 2002; von Lützow et al., 2008).
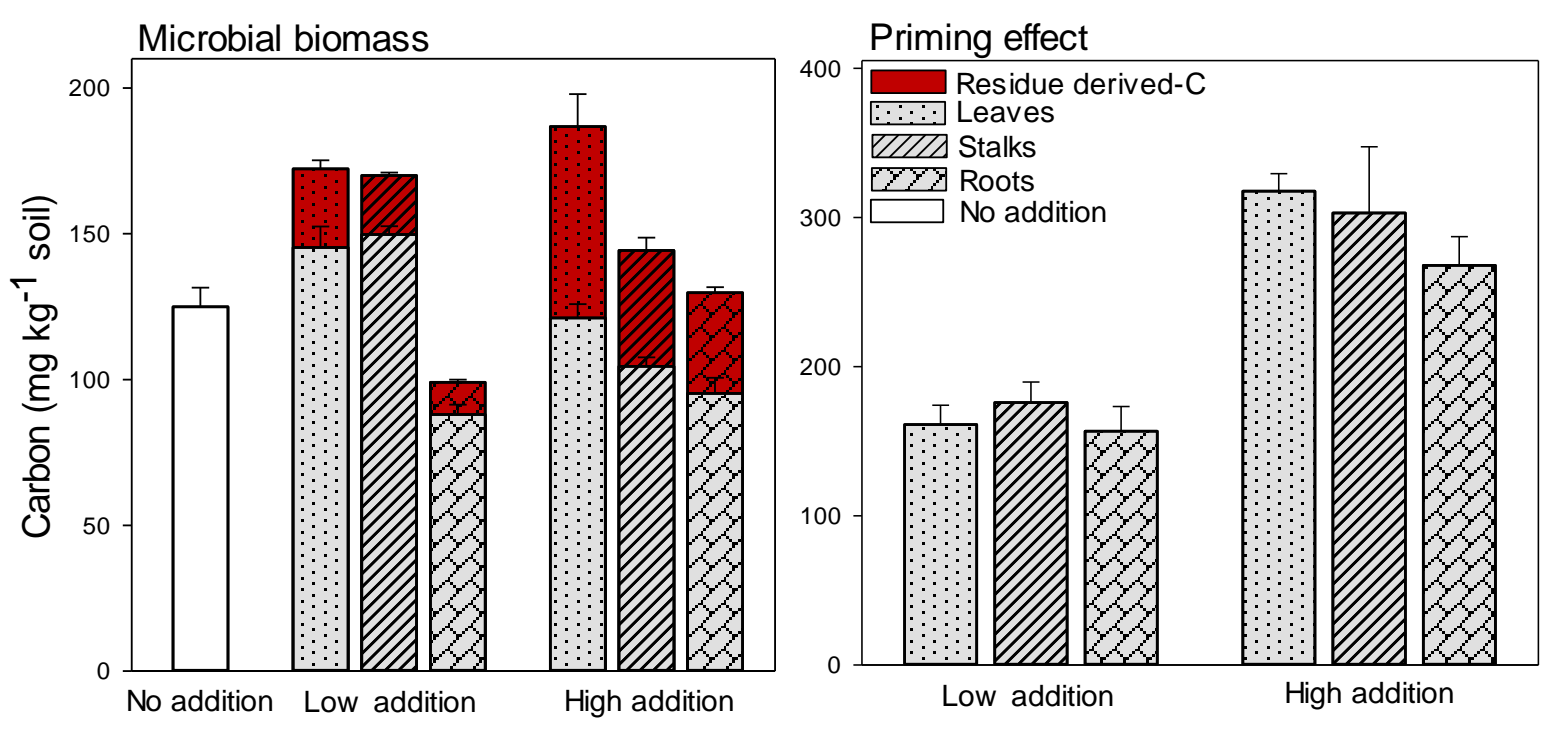

Figure S1-3 The contribution of residue derived and soil organic matter (SOM) derived C to microbial biomass (left) and the amount of primed $\mathrm{C}$ due to low and high level of crop residue addition (right). Means with standard errors $(n=3)$. The probability levels of the ANOVA for accepting the null hypothesis that the factors have no effect are as follows: SOM derived C (type $<0.001$; level $=0.001$; level $\times$ type $=0.001$ ), residue derived $\mathrm{C}$ (type $=0.001$; level $<0.001$; level $\times$ type $=0.118)$, primed $\mathrm{C}($ type $=0.413$; level $<0.001$; level $\times$ type $=0.613$ ). 


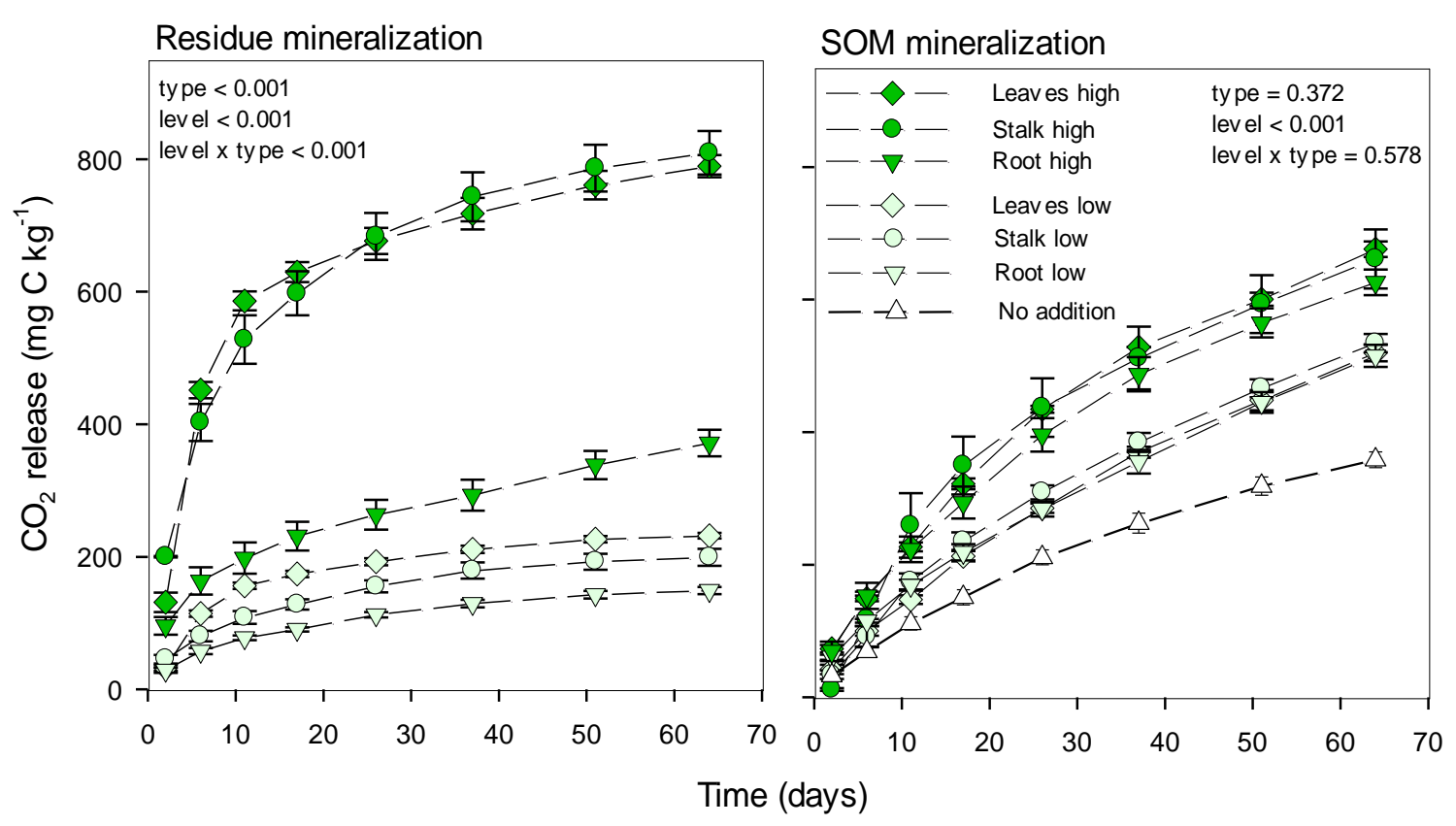

Figure S1-4 Cumulative CO2-C release during 64 days of incubation depending on type and level of crop residue additions. Left: release from crop residues; right: release from soil organic matter $(\mathrm{SOM})$. Mean values with standard errors $(n=3)$. The $p$-values calculated by an ANOVA show probability levels for accepting the null hypothesis that the factors have no effect.

Our third hypothesis assumed that the incorporation of wheat residue will induce positive priming of SOM, with its magnitude depending on the level of addition and the type of residue. The priming of added residues was evident from increased mineralization of SOM which mainly depended upon the amount of addition. (Fig. S1-4) Regardless of residue type, mineralization of SOM increased up to from 50 to $90 \%$ due to addition of low and high levels, respectively, whereas residue addition was increased 3.6 times. Therefore, the amount of primed $\mathrm{CO}_{2}$ decreased per unit of applied residue. This was also reported by Guenet et al. (2010) and Xiao et al. (2015). Generally, the addition of substrates activates microbial biomass, whose enhanced production of extra-cellular enzymes causes priming (Kuzyakov et al. 2009; Loeppmann et al. 2016; Wu et al. 1993). This is shown in our study by a growing fraction of microbial biomass which preferentially used residue C instead of SOM (Fig. S1-3; Xiao et al. 2015). Indeed, primed $C$ is related to residue-derived microbial $C\left(R^{2}=0.47\right)$ and also to residue-derived $C$ in microaggregates $\left(R^{2}=0.80\right)$. We conclude that the intimate contact of residue and soil in microaggregates promotes diffusion of enzymes between the substrates 
(SOM and residues). Due to the smaller proportion of residues in aggregates with high addition level (Fig. S1-2, Table S1-1), the priming effect on a per-input-base levels off. This may also explain the lack of an effect of residue type on priming. We expected that the different mineralization of residue types would be reflected in the intensity of priming. Roots at high level showed least mineralization, but similar priming. Both findings can be linked to the higher incorporation of root residues into aggregates.

\subsubsection{Conclusions}

Our initial hypotheses were not all fully confirmed. Firstly, we hypothesised that mineralization of root residues will be lower regardless of addition level. Root residues at the low addition level were mineralised to a similar extent as leaves and stalks, and root mineralisation was lower only at high addition levels. Secondly, the portion of residue-C as percent of initial input incorporated into macro- and microaggregates was decreased with increasing input level, as we hypothesised. Roots at the high addition level, however, were incorporated into aggregates more effectively than leaves and stalks. Our third hypothesis assumed that priming would depend on the type and addition level of residues. Mineralisation of SOM was accelerated by 50 to $90 \%$ and increased with residue addition levels. Contrary to our hypothesis, the type of residue showed no effect on priming. Overall, SOM stabilization decreased with increase in addition level. However, at the high addition level a higher portion of roots, compared to stalk and leaves, was incorporated into aggregates, which was accompanied by decreased mineralisation. Priming induced by freshly incorporated residues should be further investigated in aggregates with a special focus on dynamics and enzyme activities. Feedbacks between incorporation of fresh residues into aggregates and priming may be important under field conditions. We conclude that the proportion of residues physically protected within aggregates decreases and priming effects increase with increasing $\mathrm{C}$ input leading to decreasing rate of long-term $\mathrm{C}$ stabilization within SOM by increasing residue addition.

In order to sustain sufficient SOM levels in arable soils, an efficient crop residue management under specific field conditions is rquired. Our findings highlight the necessity to connect the quantity and quality of crop residues for better predicting mineralization and stabilization of SOM. Specifically, this may also help to resolve the global implications to characterize and identify key soil and residue parameters for modeling of greenhouse gas emissions from soil. 


\subsubsection{Acknowledgements}

We acknowledge the support provided by German Academic Exchange Service (DAAD) to MS and the help of Klaus Schützenmeister for labeling of the plant material and Ms. Karin Schmidt for measuring microbial C. We also highly appreciate the comments and suggestions of anonymous reviewers. The isotopic analysis was performed by the Kompetenzzentrum Stabile Isotope (KOSI). This study was funded by the Deutsche Forschungsgemeinschaft (DFG, projects HE 6726/6 and KU 1184/29).

\subsubsection{References}

Abiven, S., Menasseri, S., Chenu, C., 2009. The effects of organic inputs over time on soil aggregate stability - A literature analysis. Soil Biol. Biochem. 41, 1-12.

Andruschkewitsch, R., Geisseler, D., Dultz, S., Joergensen, R.G., Ludwig, B., 2014. Rate of soil-aggregate formation under different organic matter amendments-a short-term incubation experiment. J. Plant Nutr. Soil Sci. 177, 297-306.

Baldock, J.A., Skjemstad, J.O., 2000. Role of the soil matrix and minerals in protecting natural organic materials against biological attack. Org. Geochem. 31, 697-710.

Bertrand, I., Chabbert, B., Kurek, B., Recous, S., 2006. Can the biochemical features and histology of wheat residues explain their decomposition in soil? Plant Soil 281, 291307.

Blagodatskaya, E., Anderson, T.H., 1999. Adaptive Responses of Soil Microbial Communities under Experimental Acid Stress in Controlled Laboratory Studies. Appl. Soil Ecol. 11, 207-216

Blagodatskaya, E., Yuyukina, T., Blagodatsky, S., Kuzyakov, Y., 2011. Threesourcepartitioning of microbial biomass and of $\mathrm{CO}_{2}$ efflux from soil to evaluate mechanisms of priming effects. Soil Biol. Biochem. 43, 778-786.

Bromand, B., Whalen, J.K., Janzen, H.H., Schjoerring, J.K., Ellert, B.H., 2001. A pulselabelling method to generate ${ }^{13} \mathrm{C}$-enriched plant materials. Plant Soil 235, 253-257.

Freschet, G.T., Cornwell, W.K., Wardle, D.A., Elumeeva, T.G., Liu, W., Jackson, B.G., Onipchenko, V.G., Soudzilovskaia, N.A., Tao, J., Cornelissen, J.H.C., 2013. Linking 
litter decomposition of above- and below-ground organs to plant-soil feedbacks worldwide. J. Ecol. 101, 943-952.

Guenet, B., Neill, C., Bardoux, G., Abbadie, L., 2010. Is there a linear relationship between priming effect intensity and the amount of organic matter input? Appl. Soil Ecol. 46, 436-442.

Gunina, A., Kuzyakov, Y., 2015. Sugars in soil and sweets for microorganisms: Review of origin, content, composition and fate. Soil Biol. Biochem. 90, 87-100.

Gunina, A., Ryzhova, I., Dorodnikov, M., Kuzyakov, Y., 2015. Effect of plant communities on aggregate composition and organic matter stabilisation in young soils. Plant Soil 387, 265-275.

Heitkamp, F., Jacobs, A., Jungkunst, H.F., Heinze, S., Wendland, M., Kuzyakov, Y., 2012a. Processes of soil carbon dynamics and ecosystem carbon cycling in a changing world. In: R. Lal, K. Lorenz, R.F. Hüttl, B.U. Schneider, J. von Braun (Eds.), Recarbonization of the Biosphere. Springer, Dordrecht, pp. 395-428.

Heitkamp, F., Wendland, M., Offenberger, K., Gerold, G., 2012b. Implications of input estimation, residue quality and carbon saturation on the predictive power of the Rothamsted Carbon Model. Geoderma 170, 168-175.

Helfrich, M., Ludwig, B., Potthoff, M., Flessa, H., 2008. Effect of litter quality and soil fungi on macroaggregate dynamics and associated partitioning of litter carbon and nitrogen. Soil Biol. Biochem. 40, 1823-1835.

Houghton, R., 2012. Historic changes in terrestial carbon storage. In: Lal R, Lorenz K, Hüttl R F, Schneid er B U, von Braun J (Ed) Recarbonization of the biosphere. Springer, S. 5982.

Kramer, S., Marhana, S., Ruess, L., Armbruster, W., Butenschoend, O., Haslwimmer, H., Kuzyakov, Y., Pauschf, J., Scheunemannd, N., Schoene, J., Schmalwasser, A., Totsche, K.U., Walker, F., Stefan, S., Kandeler, E., 2012. Carbon flow into microbial and fungal biomass as a basis for the belowground food web of agroecosystems. Pedobiologia 55, 111-119.

Kuzyakov, Y., Blagodatskaya, E., Blagodatsky, S., 2009. The Biology of the Regulatory Gate: Comments on the paper by Kemmitt et al. (2008) 'Mineralization of native soil organic 
matter is not regulated by the size, activity or composition of the soil microbial biomass - a new perspective' [Soil Biol Biochem 40, 61-73]. Soil Biol. Biochem. 41, 435-439.

Lal, R., 2004. Soil carbon sequestration impacts on global climate change and food security. Sci. 304, 1623-1627.

Lehmann, J., Kinyangi, J., Solomon, D., 2007. Organic matter stabilization in soil microaggregates: implications from spatial heterogeneity of organic carbon contents and carbon forms. Biogeochemistry 85, 45-57.

Loeppmann, S., Blagodatskaya, E., Pausch, J., Kuzyakov, Y., 2016. Substrate quality affects kinetics and catalytic efficiency of exo-enzymes in rhizosphere and detritusphere. Soil Biol. Biochem. 92, 111-118.

Lorenz, K., Lal, R., 2012. Cropland soil carbon dynamics. In: Lal, R., Lorenz, K., Hüttl, R.F., Schneider, B.U., von Braun, J., (Ed) Recarbonization of the biosphere. Springer, S. 303346.

Lugato, E., Bampa, F., Panagos, P., Montanarella, L., Jones, A., 2014. Potential carbon sequestration of European arable soils estimated by modelling a comprehensive set of management practices. Glob. Chang. Biol. 20, 3557-3567.

Moreno-Cornejo, J., Zornoza, R., Doane, T., Faz, Á., Horwath, W., 2015. Influence of cropping system management and crop residue addition on soil carbon turnover through the microbial biomass. Biol. Fertil. Soils 51, 839-845.

Oades, J.M., 1993. The role of biology in the formation, stabilization and degradation of soil structure. Geoderma 56, 377-400.

Poeplau, C., Kätterer, T., Bolinder, M.A., Börjesson, G., Berti, A., Lugato, E., 2015. Low stabilization of aboveground crop residue carbon in sandy soils of Swedish long-term experiments. Geoderma 237-238, 246-255.

Poirier, V., Angers, D.A., Rochette, P., Whalen, J.K, 2013. Initial soil organic carbon concentration influences the short-term retention of crop-residue carbon in the fine fraction of a heavy clay soil. Biol. Fertil. Soils 49, 527-535.

Poirier, V., Angersa, D.A., Whalen, J.K., 2014. Formation of millimetric-scale aggregates and associated retention of ${ }^{13} \mathrm{C}-{ }^{15} \mathrm{~N}$-labelled residues are greater in subsoil than topsoil. Soil Biol. Biochem. 75, 45-53. 
Powlson, D.S., Glendining, M.J., Coleman, K., Whitmore, A.P., 2011. Implications for soil properties of removing cereal straw: Results from long-term studies. Agron. J. 103, 279287.

Prescott, C.E., 2010. Litter decomposition: what controls it and how can we alter it to sequester more carbon in forest soils? Biogeochemistry 101, 133-149.

Rasse, D.P., Rumpel, C., Dignac, M.F., 2005. Is soil carbon mostly root carbon? Mechanisms for a specific stabilisation. Plant Soil 269, 341-356.

Sauerbeck, D.R., 2001. $\mathrm{CO}_{2}$ emissions and $\mathrm{C}$ sequestration by agriculture - perspectives and limitations. Nutr. Cycl. Agroecosys. 60, 253-266.

Six, J., Bossuyt, H., Degryze, S., Denef, K., 2004. A history of research on the link between (micro)aggregates, soil biota, and soil organic matter dynamics. Soil Till. Res. 79, 7-31.

Six, J., Conant, R.T., Paul, E.A., Paustian, K., 2002. Stabilization mechanisms of soil organic matter: Implications for C-saturation of soils. Plant Soil 241, 155-176.

Six, J., Elliott, E.T., Paustian, K., Doran, J.W., 1998. Aggregation and soil organic matter accumulation in cultivated and native grassland soils. Soil Sci. Soc. Am. J. 62, 13671377 .

Stewart, C.E., Plante, A.F., Paustian, K., Conant, R.T., Six, J., 2008. Soil carbon saturation: Linking concept and measurable carbon pools. Soil Sci. Soc. Am. J. 72, 379-392.

Vance, E., Brookes, P., Jenkinson, D., 1987. An extraction method for measuring soil microbial biomass C. Soil Biol. Biochem. 19, 703-707.

von Lützow, M., Kögel-Knabner, I., Ludwig, B., Matzner, E., Flessa, H., Ekschmitt, K., Guggenberger, G., Marschner, B., Kalbitz, K., 2008. Stabilization mechanisms of organic matter in four temperate soils: Development and application of a conceptual model. J. Plant Nutr. Soil Sci. 171, 111-124.

Wang, H., Boutton, T.W., Xu, W., Hu, G., Jiang, P., Bai, E., 2015. Quality of fresh organic matter affects priming of soil organic matter and substrate utilization patterns of microbes. Sci. Rep. 5, 10102.

Webster, R., 2007. Analysis of variance, inference, multiple comparisons and sampling effects in soil research. Eur. J. Soil Sci. 58, 74-82. 
Wu, J., Joergensen, R.G., Pommerening, B., Chaussod, R., Brookes, P.C., 1990. Measurement of soil microbial biomass, by fumigation-extraction - an automated procedure. Soil Biol. Biochem. 20, 1167-1169.

Wu, J., Brookes, P.C., Jenkinson, D.S., 1993. Formation and destruction of microbial biomass during the decomposition of glucose and ryegrass in soil. Soil Biol. Biochem. 25, 14351441.

Xiao, C., Guenet, B., Zhou, Y., Su, J., Janssens, I.A., 2015. Priming of soil organic matter decomposition scales linearly with microbial biomass response to litter input in steppe vegetation. Oikos 124, 649-657. 


\subsection{Study 2}

\section{Microbial decomposition of soil organic matter is mediated by quality and quantity of} crop residues: mechanisms and thresholds

Muhammad Shahbaz ${ }^{1,2, *}$, Yakov Kuzyakov ${ }^{1,4}$, Muhammad Sanaullah ${ }^{3}$, Felix Heitkamp ${ }^{2}$, Vladimir Zelenev ${ }^{5}$, Amit Kumar ${ }^{1}$, Evgenia Blagodatskaya ${ }^{1,4,6}$

${ }^{1}$ Department of Agricultural Soil Sciences, Georg August University Göttingen, Büsgenweg 2, 37077 Göttingen, Germany

${ }^{2}$ Section of Physical Geography, Faculty of Geoscience and Geography, Georg August University Göttingen, Goldschmidtstr 5, 37077 Göttingen, Germany

${ }^{3}$ Institute of Soil and Environmental Sciences, University of Agriculture, Faisalabad, Pakistan

${ }^{4}$ Department of Soil Science of Temperate Ecosystems, Georg August University Göttingen, Büsgenweg 2, 37077 Göttingen, Germany

${ }^{5}$ Department of Microbiology, Biological Faculty, Moscow State University, Vorob'evy Gory, 119899 Moscow, Russia

${ }^{6}$ Institute of Physicochemical and Biological Problems in Soil Science, Russian Academy of Sciences, Institutskaya, 26 Pushchino, 142290, Moscow Region, Russia

Status: Published in Biology and Fertility of Soils (2017): doi: 10.1007/s00374-016-1174-9

*Corresponding author:

Department of Agricultural Soil Sciences, Georg August University Göttingen,

Büsgenweg 2, 37077 Göttingen, Germany

Tel.: +49-(0)551-3920502; Fax: +49 -(0)551-3933310

Email: shahbazmu@yahoo.com 


\subsubsection{Abstract}

Crop residue quality and quantity have contrasting effects on soil organic matter (SOM) decomposition, but the mechanisms explaining such priming effect (PE) are still elusive. To reveal the role of residue quality and quantity in SOM priming, we applied two rates (5.4-10.8 $\mathrm{g} \mathrm{kg}^{-1}$ ) of ${ }^{13} \mathrm{C}$-labeled wheat residues (separately: leaves, stems, roots) to soil and incubated for 120 days. To distinguish PE mechanisms, labeled $\mathrm{C}$ was traced in $\mathrm{CO}_{2}$ efflux and in microbial biomass and enzyme activities (involved in $\mathrm{C}, \mathrm{N}$ and $\mathrm{P}$ cycles) were measured during the incubation period. Regardless of residue type, PE intensity declined with increasing C additions. Roots were least mineralized but caused up to $60 \%$ higher PE compared to leaves or stems. During intensive residue mineralization (first 2-3 weeks), the low or negative PE resulted from pool-substitution. Thereafter (15-60 days), a large decline in microbial biomass along with increased enzyme activity suggested that microbial-necromass served as SOM primer. Finally, incorporation of SOM-derived C into remaining microbial biomass corresponded to increased enzyme activity, which is indicative of SOM co-metabolism. Both PE and enzyme activities were primarily correlated with residue-metabolizing soil microorganisms. A unifying model demonstrated that PE was a function of residue mineralization, with thresholds for strong PE increase of up to $20 \%$ root, $44 \%$ stem and $51 \%$ leaf mineralization. Thus, root mineralization has the lowest threshold for a strong PE increase. Our study emphasizes the role of residuefeeding microorganisms as active players in the PE, which are mediated by quality and quantity of crop residue additions.

Keywords: ${ }^{13} \mathrm{C}$-labeled crop residues, Enzyme activities, Litter quality, Microbial necromass, Priming effect, Soil organic matter 


\subsubsection{Introduction}

Soil organic matter (SOM) is primarily formed through the partial degradation and transformation of crop residues by microorganisms (Castellano et al. 2015). The quality and quantity of crop residues influence the microbial decomposition processes, which may affect residue and SOM mineralization rates, leading to a priming effect (PE). The PE represents the changes of native SOM decomposition as a result of exogenous substrate inputs such as crop residues (Jenkinson et al. 1985; Kuzyakov 2010). As soil microorganisms are mostly C-limited, input and/or high availability of substrates may alter their activities, resulting in a PE (Blagodatskaya and Kuzyakov 2008). While increasing amounts of substrate addition can decrease PE, the effect, however, depends on the substrate quality (Guenet et al. 2010). If substrate composition and availability are heterogeneous (e.g. crop residues), then a cascade of apparent (due to microbial turnover) and real (due to SOM decomposition) PE can be induced over time at various stages of substrate decomposition (Kuzyakov 2010; Xu et al. 2011).

Crop residues vary in their structural and chemical composition (Adair et al. 2008; Aber and Melillo 1982). Residue decomposition rates are generally negatively related to the amount of recalcitrant compounds present in their biomass, such as lignin, phenols, tannins etc. (Bertrand et al. 2006; Castellano et al. 2015; Aber and Melillo 1982). Aboveground crop residues (e.g. leaves and stems) are considered high quality compared with belowground residues, which are relatively recalcitrant to decomposition e.g. roots (Bertrand et al. 2006; Rasse et al. 2005). The role of residue quality in SOM formation is currently under debate. The common view on recalcitrant root residues, which are decomposed slowly and therefore contribute largely to SOM (Berg and McClaugherty 2014; Johnson et al. 2014; Rasse et al. 2005), contradicts the view of the great contribution of easily decomposable residues in SOM formation (Cotrufo et al. 2013; Lehmann and Kleber 2015). The latter concept is mainly associated with the microbial by-products, which are released and stabilized in the soil mineral fraction during crop residue decomposition (Cotrufo et al. 2013; Ladd et al. 1996; Shahbaz et al. 2016b) and microbialturnover (Ladd et al. 1996; Miltner et al. 2012).

The soil microbial turnover depends on substrate quality and availability (Leifeld and von Lützow 2014; Nguyen and Marschner 2016). If substrate availability or input is interrupted, microorganisms may respond by a switch to dormancy or their biomass decreases after microbial cell death. Such a relatively fast decrease of substrate dependent microbial biomass (MB) was already detected in several laboratory incubation experiments (e.g. Blagodatskaya et 
al. 2011a; Jiang-shan et al. 2005; Tian et al. 2015; Wang et al. 2016). The decrease in MB results in accumulation of microbial-necromass (after their cell death), which is already considered as an important source for stable SOM (Miltner et al. 2009, 2012; Wagner 1968). Due to its heterogeneous nature, microbial-necromass may serve as labile substrates for living microorganisms and its re-utilization can represent SOM priming.

The PE has often been explained by the microbial activation hypothesis (Chen et al. 2014). Instead of total microorganisms, the active microbial fraction is considered to be more important (Blagodatskaya and Kuzyakov 2013). The active fraction mostly consists of the growing portion of microorganisms, which respond rapidly to substrate addition, e.g. by producing enzymes (Blagodatskaya and Kuzyakov 2013; Fontaine et al. 2007). Depending on substrate quality (i.e. labile substance or $\mathrm{C} / \mathrm{N}$ ratio), the active microbial fraction produces enzymes either to degrade added organics or to decompose SOM to meet their nutritional demands (Schnecker et al. 2014; Wang et al. 2015). This, again, may result in variable successions of PE over time. The changes in microbial activity due to substrate decomposition (rapidly or slowly) can therefore be recognized, for example by the changes in enzyme activities (Burns et al. 2013; Nannipieri et al. 2002, 2012; Schnecker et al. 2014).

Most of the studies investigating PE used labeled low molecular weight substances such as glucose and amino acids (e.g. Blagodatskaya et al. 2011a; Hoyle et al. 2008; Tian et al. 2015). Only a few studies have distinguished PE using labeled crop residues, mostly with contrasting results depending on the residue type. PE proves to be a linear function of MB but is also a saturation function of the substrate's C amount (Guenet et al. 2010; Xiao et al. 2015). Although the effect of residue quality on PE is not obvious, the role of residue-decomposing microbial fractions in PE is highlighted based on the contrasting quality of substrate additions (Wang et al. 2015). We lack information explaining the mechanisms of PE under contrasting quality and quantity of crop residue $\mathrm{C}$ based on the active residue-feeding microbial fraction.

The present study is designed to explain the mechanisms of PE induced by crop residues varying in their amount and quality. Here, we used homogeneously ${ }^{13} \mathrm{C}$-labeled wheat (Triticum aestivum L.) biomass to partition residue- and SOM-derived $\mathrm{C}$ within total $\mathrm{CO}_{2}$ and $\mathrm{MB}$. We added contrasting quality wheat residues from both aboveground (leaves, stems) and belowground (roots) parts to soil at two levels. We hypothesized that: i) the intensity of SOM decomposition will be affected by the residue mineralization rates, i.e. SOM decomposition will be dependent on residue type; ii) regardless of residue type, the intensity of PE will decrease 
with increasing $\mathrm{C}$ addition. We assumed that microorganisms decomposing added residues will represent the most active fraction of soil microflora. Therefore, we further hypothesized that; (iii) the PE will be the main function of the soil microorganisms feeding on residues and of its enzymes activities

\subsubsection{Materials and methods}

\subsubsection{Study area and soil}

The soil used for the incubation was sampled from the Ap horizon $(0-25 \mathrm{~cm})$ of an experimental field located on a terrace plain of the Leine River north-west of Goettingen, Germany $\left(51^{\circ} 33^{\prime} 36.8^{\prime \prime} \mathrm{N}, 9^{\circ} 53^{\prime} 46.9^{\prime \prime} \mathrm{E}\right)$. Since more than 25 years the field has been cultivated with annual C3 crops, predominantly wheat (Kramer et al. 2012). The soil was classified as Luvisol and had a silt-loam texture (6\% sand, $87 \%$ silt, $7 \%$ clay). The $\mathrm{pH}$ and a test with $10 \%$ hydrochloric acid indicated the absence of carbonates. The carbonate-free soil had the following characteristics: MB $0.40 \pm 0.0 \mathrm{~g} \mathrm{C} \mathrm{kg}^{-1}$ soil, organic C $12.8 \pm 0.4 \mathrm{~g} \mathrm{~kg}^{-1}$; total N $1.3 \pm 0.0 \mathrm{~g} \mathrm{~kg}^{-1}$, $\mathrm{pH}\left(\mathrm{CaCl}_{2}\right) 6.0 ; \delta^{13} \mathrm{C}-26.8 \%$. After sampling, the soil was air dried, sieved $(<2 \mathrm{~mm})$ and fine roots and other visible crop debris and small stones were carefully removed.

\subsubsection{Production of ${ }^{13}$ C-labeled crop residues}

Wheat plants were grown to produce ${ }^{13} \mathrm{C}$-labeled residues as described in detail by Bromand et al. (2001). Briefly, wheat (Triticum aestivum L.) seeds were grown in pots filled with quartz sand and were watered regularly once a week with Hoagland nutrient solution (N: 210, K: 235, Ca: 200, P: 31, S: 64, Mg: $48 \mathrm{mg} \mathrm{L}^{-1}$ plus micronutrients). Following seedling emergence (11 days after seeding $)$, plants were placed inside a transparent closed chamber $(120 \mathrm{~cm}$ wide $\times 104$ $\mathrm{cm}$ high $\times 60$-cm deep) enclosed within a climate-controlled growth cabinet with the following conditions: $16 / 8 \mathrm{~h}$ photoperiod, light intensity at approximately $600 \mu \mathrm{mol} \mathrm{m} \mathrm{m}^{-2} \mathrm{~s}^{-1}$, mid day and night temperatures of $25^{\circ} \mathrm{C}$ and $15^{\circ} \mathrm{C}$, respectively. The plants were labeled (for at least $8 \mathrm{~h}$ ) continuously with ${ }^{13} \mathrm{C}$ every week until harvesting. The intended enrichment of $\mathrm{CO}_{2}$ in the chamber was $\sim 99$ atom $\%{ }^{13} \mathrm{C}$. To accomplish this, the $\mathrm{CO}_{2}$ concentration was first allowed to fall to 327 ppmv in the chamber. Thereafter, ${ }^{13} \mathrm{C}$-labeled $\mathrm{CO}_{2}$ was generated by injecting $\mathrm{NaH}^{13} \mathrm{CO}_{3}$ (as $\sim 99$ atom\% ${ }^{13} \mathrm{CO}_{2}$ source) solution through a septum into a generation flask containing $1 \mathrm{M} \mathrm{H}_{2} \mathrm{SO}_{4}$. The evolved $\mathrm{CO}_{2}$ was swept into the sealed chamber with a small pump through a closed loop of tubing, and a fan circulated the $\mathrm{CO}_{2}$ inside the chamber. Wheat plants 
continued to grow in the chamber until maturity (120 days of growth). Thereafter, the plants were harvested and roots were gently washed to remove the sand particles.

To avoid any preferred decomposition of above- and belowground parts of the wheat biomass, plant residues were carefully separated into leaves, stems and roots. For homogeneous mixing of residues within the soil, each part of the residues was chopped and sieved ( $2 \mathrm{~mm})$. Carbon and $\mathrm{N}$ contents of applied residues varied between residue types, whereby leaves, stems and roots had $\mathrm{C}$ contents of $391.9 \pm 6.1(\mathrm{C} / \mathrm{N}: 17.2 \pm 0.3), 409.6 \pm 8.7(\mathrm{C} / \mathrm{N}: 21.5 \pm 1.17)$ and 298.3 $\pm 5.9(\mathrm{C} / \mathrm{N}: 15.5 \pm 0.5) \mathrm{g} \mathrm{kg}^{-1}$, respectively. The atom $\%{ }^{13} \mathrm{C}$ values were measured with an isotope ratio spectrometer coupled to an elemental analyzer (Delta plus, EA-IRMS, see detail section 3.2.3.7) (Table S2-1).

\subsubsection{Incubation and sampling}

For incubation, $50 \mathrm{~g}$ soil (dry weight basis) was weighed into $250-\mathrm{ml}$ incubation bottles. The soil was then pre-incubated (at $22{ }^{\circ} \mathrm{C}$ ) at $50 \%$ water holding capacity (WHC) for one week. Thereafter, the 120-day full-factorial incubation experiment with two factors - wheat residue type and residue addition level - was designed. Accordingly, eight treatments were included: three ${ }^{13} \mathrm{C}$-labeled wheat residue types (leaves, stem, roots), two addition levels (low and high, respectively 5.4 and $10.8 \mathrm{~g}$ dry mass $\mathrm{kg}^{-1}$ soil) and one control without residue addition. A reference treatment with the decomposition of crop residues in autoclaved sand was also conducted to consider isotopic fractionation during incubation. All treatments were set with three replicates. The added residues were thoroughly mixed in the soil, and the water contents were then adjusted to $70 \%$ WHC. Note, the control soils (without residue addition) also treated in the same way as those with residue addition. The residues were added on a dry matter basis. Accordingly, the $\mathrm{C}$ input by roots (with lower $\mathrm{C}$ content) corresponds to ca. $70 \%$ of the $\mathrm{C}$ amount added with leaves or stems.

To estimate MB and enzyme activities, samples were destructively harvested at day 15, 30, 60 and 120 of incubation.

To prove that crop residue were homogeneously labeled, we sampled the partially decomposed residues during the incubation period (destructive sampling). A portion of the incubated soil (ca. $20 \mathrm{~g}$, having residues) was submerged into distilled water; thereafter, the floating material was collected, dried $\left(60^{\circ} \mathrm{C}\right)$ and analyzed for ${ }^{13} \mathrm{C}$ values at IRMS (section 3.2.3.7). The isotopic signature of partially decomposed residues revealed that after 2-weeks (intensive residue 
mineralization), the differences in ${ }^{13} \mathrm{C}$ values for the rest of incubation period did not exceed 0.03 atom $\%$ in all treatments (Table 1). This indicated that possible error due to the inhomogeneous (non-uniform) labeling of the residues was minimal and that it did not exceed the variation in ${ }^{13} \mathrm{C}$ between the replicates. The isotopic signature was used as the residue reference material for the mass balance equation.

\subsubsection{4 $\mathrm{CO}_{2}$ efflux}

In order to measure soil respiration, $\mathrm{CO}_{2}$ was trapped in $5 \mathrm{~mL} 1 \mathrm{M} \mathrm{NaOH}$ trap solution. The trap solution was replaced with fresh $1 \mathrm{M} \mathrm{NaOH}$ aliquot at day 2, 4, 7, 11, 23, 30, 36, 46, 60, 81, 101 and 120 of incubation. Therefore, incubation bottles were not closed longer than 21 days and the capacity of $\mathrm{NaOH}$ was never used up by more than $60 \%$. An aliquot of sampled $\mathrm{NaOH}$ was immediately used to measure total soil and residue-derived $\mathrm{CO}_{2}$. The total amount of $\mathrm{CO}_{2}$ trapped in the $\mathrm{NaOH}$ solution was determined by titration with $0.05 \mathrm{M} \mathrm{HCl}$ against phenolphthalein, after addition of $0.5 \mathrm{M} \mathrm{BaCl}_{2}$ solution.

\subsubsection{Microbial biomass}

To determine the $\mathrm{C}$ content in $\mathrm{MB}$ at all destructive sampling periods, the chloroform fumigation-extraction method was used as already described by Makarov et al. (2015) and Vance et al. (1987). Briefly, $6 \mathrm{~g}$ (moist) soil were extracted with $24 \mathrm{ml}$ of $0.05 \mathrm{M} \mathrm{K}_{2} \mathrm{SO}_{4}$ for one hour. The other $6 \mathrm{~g}$ soil was firstly fumigated with ethanol-free $\mathrm{CHCl}_{3}$ for $24 \mathrm{~h}$ at $22^{\circ} \mathrm{C}$ and then extracted in the same way. The obtained extract were analyzed for total $\mathrm{C}$ content using a TOC/TIC analyzer (Multi N/C 2100, Analytik Jena, Germany). The MB-C ( $\mathrm{K}_{2} \mathrm{SO}_{4}$ extractable) was calculated as $E_{C} / K_{E C}$, where $E_{C}=$ is the difference between extracted organic $C$ of fumigated and non-fumigated soils and $\mathrm{K}_{\mathrm{EC}}=0.45$ (Wu et al. 1990).

\subsubsection{Enzyme assays}

The enzyme activities at all sampling periods (15, 30, 60 and 120 days) were measured using fluorogenically labeled substrates (Pritsch et al. 2004; Sanaullah et al. 2016). Five fluorogenic enzyme substrates based on 5- methylumbelliferone (MUF) were used: MUF- $\beta$-Dcellobiohydrolase (MUF-C; EC 3.2.1) for cellobiohydrolase, MUF- $\beta$-D-xylopyranoside (MUF-C; EC 3.2.1) for xylanase, MUF-N-acetyl- $\beta$-D-glucosaminide dehydrate (MUF-NAG; EC 3.2.1.14) for chitinase, MUF- $\beta$-D-glucopyranoside (MUF-G; EC 3.2.1.21) for $\beta$ glucosidase and MUF-phosphate monoester (EC 3.1.3.2) for acid phosphomonoesterase (Nannipieri et al. 2011). 1-Leucine-7-amino-4-methylcoumarin (AMC) substrate was used to 
estimate L-leucine aminopeptidase (LAP) activity. All enzyme substrates were purchased from Sigma (Germany).

Briefly, $0.5 \mathrm{~g}$ of soil (dry weight basis) were dispersed in $50 \mathrm{ml}$ of deionized water for $2 \mathrm{~min}$ using low energy sonication $\left(40 \mathrm{~J} \mathrm{~S}^{-1}\right)$. Then, $50 \mu \mathrm{l}$ of the suspension were pipetted into $150 \mu \mathrm{l}$ specific enzyme substrate solution (containing $50 \mu 1$ of MES or Trizma buffer for MUF or AMC substrates, respectively) having a final concentration of $200 \mu \mathrm{mol} \mathrm{g}{ }^{-1}$ soil. Fluorescence was measured by incubations of soil suspension (for $2 \mathrm{~h}$ at $22^{\circ} \mathrm{C}$ ) in 96-well microplates (puregrade, Germany) with fluorogenic substrates at an excitation wavelength of $355 \mathrm{~nm}$ and an emission wavelength of $460 \mathrm{~nm}$, slit width of $25 \mathrm{~nm}$, with a Victor R ${ }^{3} 1420$ Multilabel Counter (Perkin Elmer, Waltham USA).

\subsubsection{Isotopic analysis}

Since we used ${ }^{13} \mathrm{C}$-enriched plant material, the $\mathrm{CO}_{2}$-trapped $\mathrm{NaOH}$ samples were specifically prepared for isotopic analysis. For this, $3 \mathrm{ml}$ of $\mathrm{CO}_{2}$-trapped $\mathrm{NaOH}$ solution was precipitated with an equal volume of $1 \mathrm{M} \mathrm{SrCl}_{2}$ solution. The $\mathrm{NaOH}$ solution containing $\mathrm{SrCO}_{3}$ precipitates was then centrifuged for $5 \mathrm{~min}$ at $2680 \times \mathrm{g}$. The process was repeated with distilled water to remove excess $\mathrm{NaOH}$ and to reduce $\mathrm{pH}$ to 7 . After removing water, $\mathrm{SrCO}_{3}$ pellets were dried at $60^{\circ} \mathrm{C}$ and stored for ${ }^{13} \mathrm{C}$ analysis by an isotope ratio mass spectrometer (Delta plus, IRMS; Thermo Fisher Scientific, Bremen, Germany). The ${ }^{13} \mathrm{C}$ values were expressed as atom $\%$. The estimations were calibrated with reference to the international VPDB (Vienna Peedee Belemnite) standard. For ${ }^{13} \mathrm{C}$ measurement of $\mathrm{MB}$, an aliquot (ca. $10 \mathrm{~mL}$ ) of the $\mathrm{K}_{2} \mathrm{SO}_{4}$ extract was freeze-dried and thereof solid material was analyzed.

\subsubsection{Calculations}

To partition residue- and SOM-derived $\mathrm{C}$ in total $\mathrm{CO}_{2}$ and microbial $\mathrm{C}$, calculations were done step by step as suggested earlier (Blagodatskaya et al. 2011a; Poirier et al. 2013)

Firstly, the ${ }^{13} \mathrm{C}$ values (atom $\%$ ) were calculated according to the following equation.

Atom $\%{ }^{13} \mathrm{C}=\left[\right.$ number of ${ }^{13} \mathrm{C}$ atoms $/$ numberof $\left({ }^{12} \mathrm{C}+{ }^{13} \mathrm{C}\right)$ atoms $] \cdot 100$

Then the fraction of residue-derived $\mathrm{C}\left(f \cdot \mathrm{C}_{\mathrm{res}}\right)$ was calculated according to the mass balance equation (Hayes 2004):

$f \cdot C_{\text {res }}=\left(A t_{\text {mix }}-A t_{\text {con }}\right) /\left(A t_{\text {res }}-A t_{\text {con }}\right)$ 
Where $\mathrm{At}_{\text {mix }}$ represents ${ }^{13} \mathrm{C}$ atom\% values of the residues-amended soil evolved as $\mathrm{CO}_{2}$ (trapped in $\mathrm{NaOH}$ ), or present in fumigated or non-fumigated $\mathrm{K}_{2} \mathrm{SO}_{4}$ extracts. $\mathrm{At}_{\text {res }}$ represents specific ${ }^{13} \mathrm{C}$ atom\% values of the corresponding residue source (i.e. leaves, stems, roots). $\mathrm{At}_{\mathrm{con}}$ shows ${ }^{13} \mathrm{C}$ atom\% values of each corresponding pool of soil without residue addition.

Finally, the amount of residue-derived $\mathrm{C}\left(\mathrm{C}_{\text {res }}, \mathrm{g} \mathrm{kg}^{-1}\right)$ was calculated according to equation (3): $C_{\text {res }}=f \cdot C_{\text {res }} \cdot[T C]$

Where $[T C]$ represents the total $\mathrm{C}$ amount of the corresponding pool (i.e. $\mathrm{CO}_{2}$, fumigated and non-fumigated $\mathrm{K}_{2} \mathrm{SO}_{4}$ extract)

The amount of SOM-derived C $\left(\mathrm{C}_{\mathrm{SOM}}, \mathrm{g} \mathrm{kg}^{-1}\right)$ was simply calculated by subtracting $\mathrm{C}_{\text {res }}$ from the total $\mathrm{C}$ of the corresponding pool.

The amount of primed $\mathrm{C}$ released as total $\mathrm{CO}_{2}$, i.e. $\mathrm{PE}\left(\mathrm{g} \mathrm{C} \mathrm{kg}^{-1}\right)$, was calculated according to the following equation.

$\mathrm{PE}=\mathrm{CO}_{2} \cdot \mathrm{C}_{\text {total }}-\mathrm{CO}_{2} \cdot \mathrm{C}_{\text {res }}-\mathrm{CO}_{2} \cdot C_{\text {control }}$

To estimate the residue-derived C fraction present as $\mathrm{MB}$ (Res_C $\mathrm{C}_{\mathrm{MB}}$ ) in each destructive sampling and at the end of incubation, firstly residue-derived $\mathrm{C}$ was calculated separately for fumigated and non-fumigated samples using equation 3 . Then calculations were done according to following equation.

$R e s_{-} C_{M B}=\left(f \cdot C_{r e s}-n f \cdot C_{r e s}\right) /(f \cdot C-n f \cdot C)$

Where $\mathrm{f} \cdot \mathrm{C}_{\text {res }}$ and $\mathrm{nf} \cdot \mathrm{C}_{\text {res }}$ are the $\mathrm{C}_{\text {res }}$ values of fumigated and non-fumigated samples, respectively, calculated according to Eq. 3. $\mathrm{f} \cdot \mathrm{C}$ and $\mathrm{nf} \cdot \mathrm{C}$ are the amounts of total $\mathrm{C}$ in fumigated and non-fumigated samples, respectively, determined as discussed in section 3.2.3.5.

The relationship of both $\mathrm{CO}_{2}$ efflux and enzyme activities were highly positively correlated with the Res_C $\mathrm{C}_{\mathrm{MB}}$ instead of total MB-C. Therefore, to estimate specific PE and enzyme activities (in relation to Res_ $\mathrm{C}_{\mathrm{MB}}$ ), the absolute amounts of PE (calculated according to Eq. 4) and enzyme activities (as described in section 3.2.3.6) were divided by the total amounts of Res_C $\mathrm{C}_{\mathrm{MB}}$, which was calculated according to Eq. 5.

\subsubsection{Threshold values for PE increase}


The relationship between the fraction of mineralized residue, $\mathrm{x}$ (as $\%$ of initial input) and specific priming effect (PE), was best explained and fitted by a unifying model (combining logistic and power functions):

$P E(x)=a \cdot x^{2}+b /[1+\exp (-c \cdot(x-d))]+e$

where $\mathrm{PE}(\mathrm{x})$ represents the specific $\mathrm{PE}, \mathrm{x}$ the value of mineralized fraction of crop residues, a the residue quality coefficient, $b$ the maximal PE value, $c$ the residue-specific maximal rate of $\mathrm{PE}$ increment, $\mathrm{d}$ the mineralized fraction of residues at maximal rate of PE increment, and e the minimal PE value. Model parameters were optimized for best fitting of the model output to experimental data. All fits were done with Excel Solver facilities. For all the types of crop residues, the model demonstrated an excellent goodness of fit with $r^{2}$ above 0.98 . The model enabled estimation of the threshold value of the mineralized fraction of crop residues when maximal changes in PE increment occur. That corresponds to the point where the second derivative of the function (6) has its maximum.

\subsubsection{Statistical analysis}

The experiment was carried out as a full factorial, completely randomized design. The factor "type" had three levels (leaves, stems, roots) and the factor "addition" had two or three levels (no, low and high addition). Time was considered as a random factor where applicable. Two addition levels were used when comparing residue-derived $\mathrm{C}$ where inclusion of "no addition" was not suitable. Statistical analyses were performed with SPSS 11 using a two-way ANOVA (when the time was not considered) and three-way ANOVA with "addition level", "type" as fixed effects and "time" as a random effect. When significant $(p \leq 0.05)$ effects were found, post hoc comparisons of means were performed using Fisher's Least Significant Difference test (Webster 2007). The error propagation was calculated when the mean values were used for determining PE (Meyer 1975). Correlations (r) between MB (derived from residue and SOM) values and $\mathrm{CO}_{2}$ or potential enzyme activities in soils were analyzed by Pearson's correlation method.

\subsubsection{Results}

\subsubsection{1 ${ }^{13} \mathrm{C}$ in crop residues during incubation}

The ${ }^{13} \mathrm{C}$ values of incorporated residues were specific to residue type i.e. leaves, stem and root had $1.54,1.36$ and $1.51{ }^{13} \mathrm{C}$ atom\%, respectively. During the incubation period, the ${ }^{13} \mathrm{C}$ values 
of partially decomposed residues mainly declined until day 15 , and thereafter remained nearly constant for the rest of incubation period, indicating that residues were homogeneously labeled (Table S2-1). The averaged $( \pm \mathrm{SD}){ }^{13} \mathrm{C}$ (atom\%) values of partially decomposed residues of leaves, stem and roots across all sampling period were $1.41 \pm 0.01,1.32 \pm 0.01,1.44 \pm 0.03$, respectively. Accordingly, a very similar ${ }^{13} \mathrm{C}$ values of the $\mathrm{CO}_{2}$ evolved from reference treatments with sand were detected. The average $( \pm \mathrm{SD})$ values of ${ }^{13} \mathrm{C}$ (atom\%) across sampling periods were $1.41 \pm 0.03,1.30 \pm 0.02$, and $1.42 \pm 0.01$ for leaves, stems and roots, respectively.

Table S2-1: The ${ }^{13} \mathrm{C}$ values (atom\%) of leaves, stems and roots of wheat residues at different decomposition stages over the incubation period at days 0, 15, 30, 60 and 120. Numbers in brackets: \pm SE of mean.

\begin{tabular}{llllll}
\hline Residue type & 0 day & 15 day & 30 day & 60 day & 120 day \\
\hline $\begin{array}{l}\text { Leaves }\left({ }^{13} \mathrm{C}\right. \\
\text { atom\%) }\end{array}$ & $1.54(0.00)$ & $1.41(0.01)$ & $1.43(0.00)$ & $1.40(0.02)$ & $1.41(0.01)$ \\
$\begin{array}{l}\text { Stems }\left({ }^{13} \mathrm{C}\right. \\
\text { atom\%) }\end{array}$ & $1.36(0.00)$ & $1.32(0.00)$ & $1.33(0.00)$ & $1.31(0.00)$ & $1.31(0.01)$ \\
$\begin{array}{l}\text { Roots }\left({ }^{13} \mathrm{C}\right. \\
\text { atom\% })\end{array}$ & $1.51(0.00)$ & $1.46(0.00)$ & $1.47(0.01)$ & $1.40(0.04)$ & $1.45(0.01)$ \\
\end{tabular}

\subsubsection{Residue and soil organic matter mineralization}

Residue addition caused a significant increase in total soil $\mathrm{CO}_{2}$ efflux compared to the control without additions. At low additions, the amount of total $\mathrm{CO}_{2}$ efflux was higher in leaves and stems (for both, up to $1.9 \mathrm{~g} \mathrm{C} \mathrm{kg}^{-1}$ ) than in roots $\left(1.5 \mathrm{~g} \mathrm{C} \mathrm{kg}^{-1}\right.$ ) (Fig. S2-S1 supplementary material). At the high residue addition level, absolute $\mathrm{CO}_{2}$ efflux also increased. Similar to low additions, no differences in total efflux between leaves and stems $\left(3.3 \mathrm{~g} \mathrm{C} \mathrm{kg}^{-1}\right)$ were also found at high additions.

The total amount of SOM-mineralized $\mathrm{C}$ in the control was $0.65 \mathrm{~g} \mathrm{C} \mathrm{kg}^{-1}$ soil over 120 days of incubation. Mineralization of SOM significantly increased with residue addition depending on the type and amount of residue (Fig. S2-1a). At the doubled amount of residue addition, the cumulative SOM mineralization remained similar between low and high addition levels of leaves (up to $\left.0.9 \mathrm{~g} \mathrm{C} \mathrm{kg}^{-1}\right)$ and stems $\left(1.1 \mathrm{~g} \mathrm{C} \mathrm{kg}^{-1}\right)$. In contrast, SOM mineralization under high root addition increased up to $15 \%$ compared with low additions (Fig. S2-1a). 
The residue mineralization rate was significantly affected by both type and level of additions. Total mineralization was highest in leaves, lowest in roots (Fig. S2-1b). Depending on the quality and on the added amount, two distinct residue mineralization phases (intensive and slow) were observed. Remarkably, during the intensive phase, the residue decomposition was proportional to the added amount (for leaves and stems ca. 2-3 weeks) (Fig. S2-1b). During the slow phase (after 2-3 weeks), residue mineralization was disproportionally stronger for high versus the low amount of leaves and stems, but not for roots.

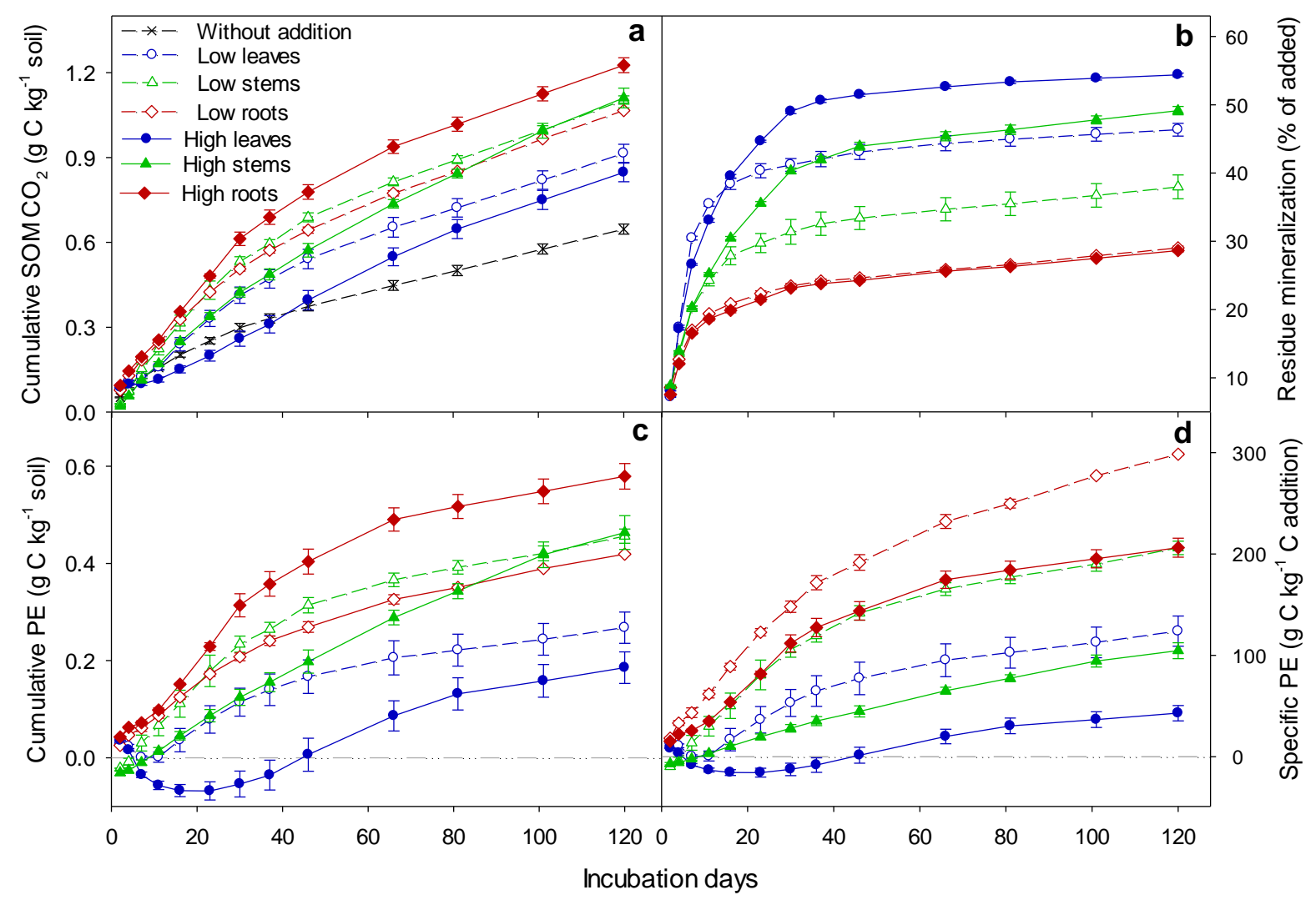

Figure S2-1. Cumulative CO2 release originated from soil organic matter (SOM, a), crop residue decomposition (\% of initial addition, b), total priming effect (PE, c), and specific PE (d) over 120 days of incubation, depending on the residue type and addition level. Mean values with standard errors $(n=3)$. The $p$-values of the ANOVA showing the effect of different factors for all; cumulative $\mathrm{CO} 2$ release originated from SOM (a); residue decomposition (\% of initial addition, b); total PE (c) and; specific PE (d) are as follows: type $<0.001$, level $<0.001$ and their interactions; level $\times$ type $<0.001$.

Therefore, at the end of the experiment, at low addition, the leaf-, stem- and root-derived $\mathrm{CO}_{2}$ reached 1.0, 0.9 and $0.4 \mathrm{~g} \mathrm{C} \mathrm{kg}^{-1}$, corresponding to 46,38 and $29 \%$ of their initial additions, respectively (Fig. S2-1b). Relative root mineralization after intensive phase was similar at high 
and low addition (i.e. $29 \%$ of initial input), whereas the leaf and stem mineralization rate were up to 17 and $30 \%$ faster at high than at low additions, respectively (Fig. S2-1b).

\subsubsection{Priming effect}

A significant increase in the $\mathrm{SOM}$-originated $\mathrm{CO}_{2}$ efflux after residue addition caused a positive $\mathrm{PE}$, but the PE intensity was strongly affected by residue quality and amount (Fig. S2-1c). The maximum PE was recorded for root (increase with the addition level: 0.42 to $0.58 \mathrm{~g} \mathrm{C} \mathrm{kg}^{-1}$ ) and lowest (even negative) for leaf addition ( 0.20 to $\left.0.27 \mathrm{~g} \mathrm{C} \mathrm{kg}^{-1}\right)$. Remarkably, larger PE was observed at low versus the high amount of stems and leaves during the intensive phase of decomposition. Furthermore, the cumulative PE remained negative under high leaf addition during the initial ca. 6 weeks of incubation (Fig. S2-1c).

As the added residues varied in their $\mathrm{C}$ contents (see above), the specific PE was calculated based on $\mathrm{C}$ addition (Fig. 1d). The amount of specific PE (per unit of $\mathrm{C}$ ) in root treatments was significantly higher than that of leaves and stems at both residue addition levels (Fig. S2-1d). The total amounts of specific PE in root treatments were 300 and $200 \mathrm{~g} \mathrm{C} \mathrm{kg}^{-1}$ at low and high root-C addition, respectively.

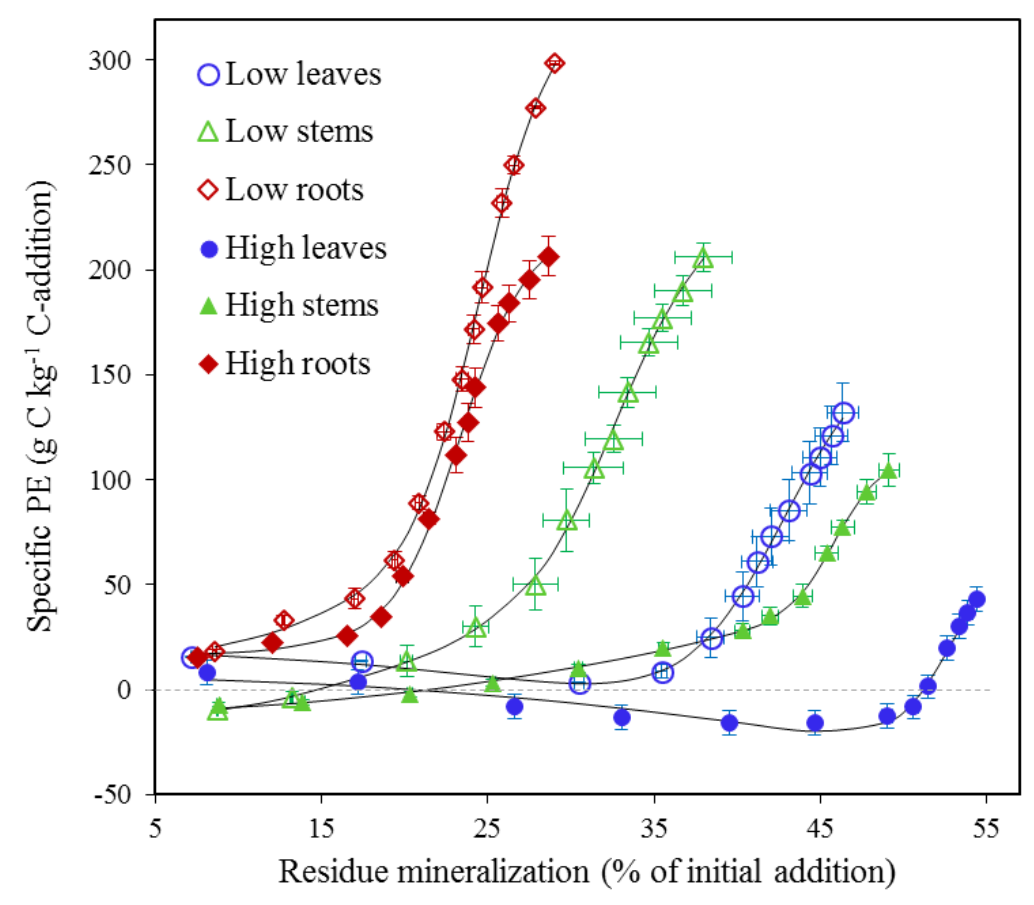

Figure S2-2. The relationship between the fraction of mineralized residue, $x$ (as $\%$ of initial input) and soil specific priming effect (PE), was best explained and fitted by a unifying model (combined with logistic and power functions): $P E(x)=a \cdot x^{2}+b /[1+\exp (-c$. $(x-d))]+e$. Means and standard error $(\mathrm{n}=3)$. 
Regardless of residue type, specific PE decreased at high versus low C addition (Fig. S2-1d), suggesting that the PE depended on the amount of decomposed residues. To clarify this relationship, we plotted the cumulative specific PE against residue-originated $\mathrm{CO}_{2}$ (Fig. S2-2). After a lag-period, the PE increased strongly over the course of residue decomposition. This demonstrates that during the initial intensive phase the decomposition rate of residues exceeded the PE. During the slow phase of residue decomposition, however, the PE increased drastically. A threshold (calculated by the second derivative, see section 3.2.3.9) of the decomposition function indicated that such a drastic increase in PE occurred when ca. 20, 29-44 and 39-51\% of (low and high) roots, stems and leaves were decomposed, respectively (Fig. S2-2).

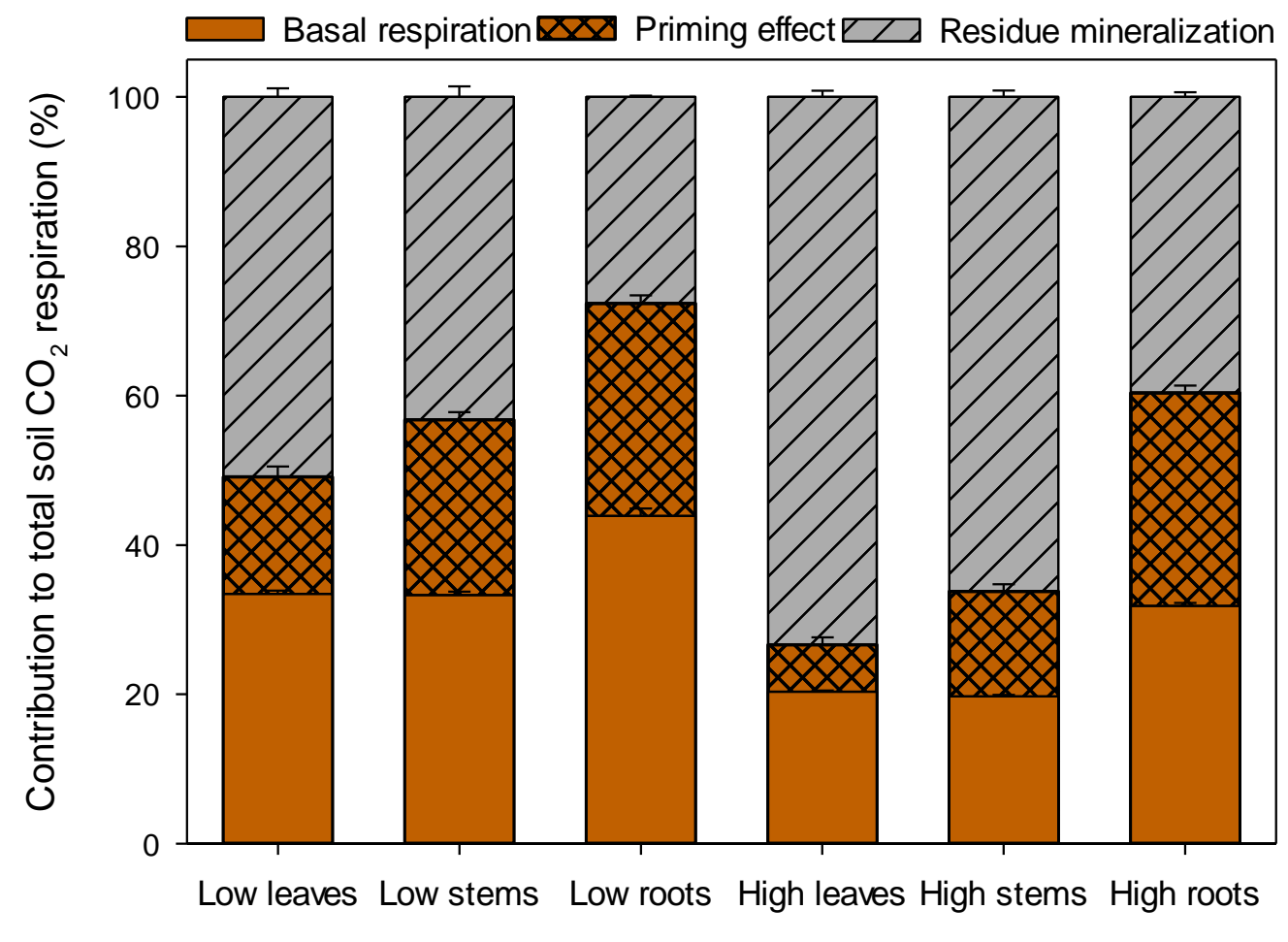

Residue addition

Figure S2-3. The relative contribution (\%) of carbon (C) sources from basal respiration, priming effect and residue mineralization) to their corresponding total soil $\mathrm{CO}_{2}$ efflux after 120 days of incubation, depending on the residue type and addition level. Basal respiration (without addition) was assumed to be constant for all residue treated soils. Means and standard errors $(n=3)$. The $\mathrm{p}$-values from the ANOVA showing the factors effect is as: basal respiration (type $<0.001$; level $<0.001$; and their interactions: type $\times$ level $=0.081$ ), and for both; priming effect and residue mineralization is as (type $<0.001$; level $<0.001$; and their interactions: type $\times$ level $<0.001)$.

To differentiate the contribution of various sources of $\mathrm{CO}_{2}$ efflux from soil (within residue additions), respired from soil over 120 days, total respiration was partitioned (\% contribution) 
into basal respiration, residue originated, and PE (Fig. S2-3). The basal respiration (from the control $0.65 \mathrm{~g} \mathrm{C} \mathrm{kg}^{-1}$ ) was assumed to be constant for all residue additions. At the end of the experiment, $53-73 \%, 43-66 \%$ and $28-40 \%$ of added leaves-, stems- and roots-originated $\mathrm{CO}_{2}$ contributed to their corresponding total $\mathrm{CO}_{2}$ efflux. At high addition, the percentage of primed $\mathrm{C}$ in total $\mathrm{CO}_{2}$ efflux was lower in the leaves and stems versus their low addition level. At high additions, root-induced primed $\mathrm{C}$ percentage of total respiration remained the same as at its low addition levels, but the contribution of basal respiration was reduced, which was substituted by residue-originated C (Fig. S2-3).

\subsubsection{Microbial biomass}

Consistent with the $\mathrm{CO}_{2}$ efflux, adding residues significantly (28-85\%) increased MB-C compared with control. This highlights the microbial demands for $\mathrm{C}$ and nutrients. The MB-C significantly increased (compared to the control) during the intensive decomposition phase of the residues (during the first two weeks), with an average of 42-85, 42-53 and 28-54\% due to leaf, stem and root addition, respectively (Fig. S2-4a). Remarkably, the increase of MB-C was solely (intensive phase) or mainly (slow phase) due to residue-feeding microorganisms, because the differences in SOM-decomposed biomass were insignificant (except at day 120). The amount of residue-derived $\mathrm{C}$ present as MB (Res_ $\left.\mathrm{C}_{\mathrm{MB}}\right)$ was the highest under leaves $(0.07$ to $0.37 \mathrm{~g} \mathrm{C} \mathrm{kg}^{-1}$ soil) and the lowest under root additions (0.02-0.17 $\mathrm{g} \mathrm{C} \mathrm{kg}^{-1}$ soil) across all sampling periods (Fig. S2-4a). Despite a major overall drop (15-60 days) in biomass during the slow decomposition phase, the MB in residue-treated soil still remained higher than in the control (exception: low root treatment at days 30 and 60). This again was mainly due to residuedecomposing microorganisms. Remarkably, the percentage of SOM-derived C in MB in all residue treatments exceeded the control, only at day 120 indicating a relative increase of SOM$\mathrm{C}$ incorporation in MB. A stronger positive correlation between ${ }^{13} \mathrm{C}$ labeled MB (Res_C $\mathrm{C}_{\mathrm{MB}}$ ) than SOM was found with total $\mathrm{CO}_{2}$ and residue-originated $\mathrm{CO}_{2}$ effluxes, at all sampling periods (Table S2-S1, Supplementary Material). Similarly to specific PE, the PE calculated per unit of Res_C $\mathrm{C}_{\mathrm{MB}}$ was greater at low than at high residue addition (Fig. S2-4b). At both addition levels, the PE per unit Res_ $\mathrm{C}_{\mathrm{MB}}$ from roots was significantly higher than that of leaves and stems. 


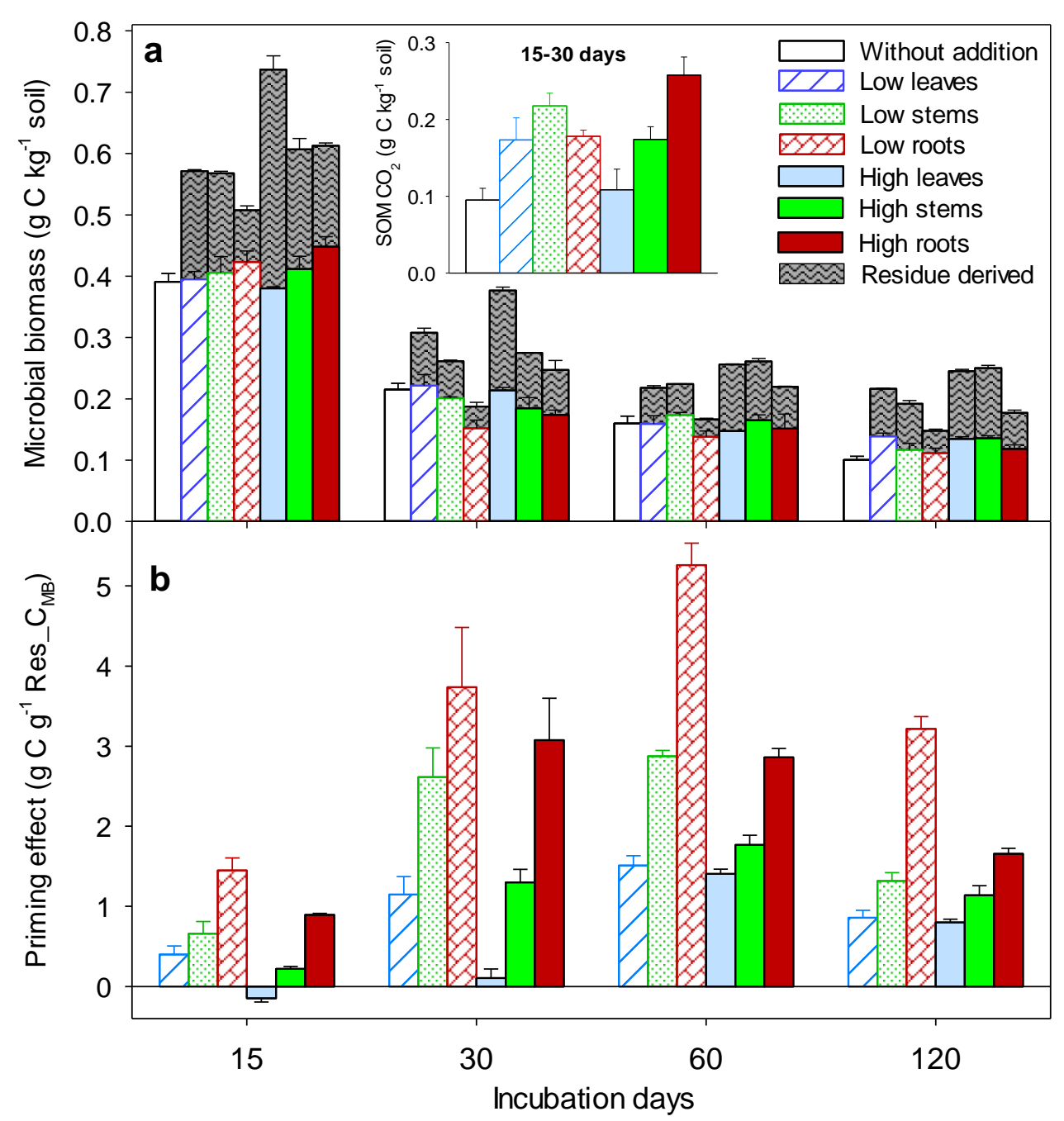

Figure S2-4. The contribution of soil organic matter (SOM) and crop residues originated C (Res_C $\mathrm{C}_{\mathrm{MB}}$ ) to total microbial biomass (a); and the amount of priming effect per unit of Res_C $\mathrm{C}_{\mathrm{MB}},(\mathrm{b})$, depending on the residue type, addition level and time of sampling. The inset (a) shows amount of total SOM derived $\mathrm{CO}_{2}$ during the period of 15-30 days. Means with standard errors $(n=3)$. The $p$-values from the ANOVA showing the factors effect on SOM originated microbial biomass (type $=0.043$, level $=0.174$, time $<0.001$, type $\times$ level $=$ 0.042 , type $\times$ time $<0.001$, level $\times$ time $=0.661$, and level $\times$ type $\times$ time $=0.546$ ); and on Res_ $\mathrm{C}_{\mathrm{MB}}$ (for all factors i.e. type, level, time and their interactions, $\mathrm{p}<0.001$ ). Similarly pvalues for Priming effect per unit Res_ $\mathrm{C}_{\mathrm{MB}}(\mathrm{b})$ are as, for all factors and interactions $\leq 0.001$ (except the interaction of type $\times$ time, $\mathrm{p}=0.307$ ).

\subsubsection{Enzyme activities}

The activities of all tested enzymes increased significantly after residue addition. Enzyme activity highly depended on residue type and the amount of addition (generally increasing with addition level) and sampling time (Fig. S2-S2, Supplementary Material). The correlation between enzyme activity and MB-C was relatively weak, but it was highly strengthened when 
it correlated with ${ }^{13} \mathrm{C}$ MB-C (Res_C $\mathrm{C}_{\mathrm{MB}}$ ) (Table S2-2, Supplementary Material). The correlation between enzyme activity and SOM-derived MB was mainly negative or insignificant.

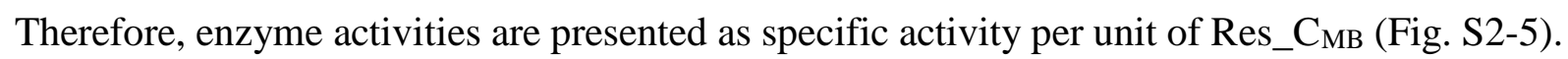

Overall, the specific enzyme activities ( $n m o l \mu \mathrm{g}^{-1} \mathrm{Res}_{-} \mathrm{C}_{M B} \mathrm{~h}^{-1}$ ) were lowest on incubation day 15 (Fig. S2-5). At both addition levels, the activities involved in the C-cycle (ß-glucosidase, Bcellobiohydrolase, chitinase, xylanase) remained stable. The acid phosphomonoesterase and leucine aminopeptidase activity increased until day 60 and then decreased again (Fig. S2-5). Enzyme specific activity was significantly higher under root than under both leaf and stem addition at all sampling periods. With the increase of residue addition level, however, the specific activity significantly decreased compared with low residue addition (Fig. S2-5). No significant differences in enzyme activities between leaf and stem additions were observed at both addition levels. The positive correlation between the specific PE and enzyme activities consistently increased with the increased specific PE and was the strongest for $\beta$-glucosidase, acid phosphomonoesterase and leucine aminopeptidase activity (Table S2-2).

Table S2-2. The Pearson correlations (r) between specific priming effect and values of specific enzyme activities at days 15, 30, 60 and 120 of incubation in soils amended with residues

\begin{tabular}{|c|c|c|c|c|c|c|}
\hline & $\begin{array}{l}\text { ß- } \\
\text { Glucosidase }\end{array}$ & $\begin{array}{l}\text { Acid } \\
\text { Phosphatase }\end{array}$ & Chitinase & Xylanase & Cellubiosidase & LAP* \\
\hline 15 days & 0.74 & 0.61 & -0.19 & 0.43 & 0.27 & 0.71 \\
\hline 30 days & 0.69 & 0.78 & 0.66 & 0.66 & 0.40 & 0.67 \\
\hline 60 days & 0.82 & 0.80 & 0.64 & 0.69 & 0.68 & 0.82 \\
\hline 120 days & 0.90 & 0.82 & 0.77 & 0.72 & 0.74 & 0.81 \\
\hline
\end{tabular}

*leucine aminopeptidase 


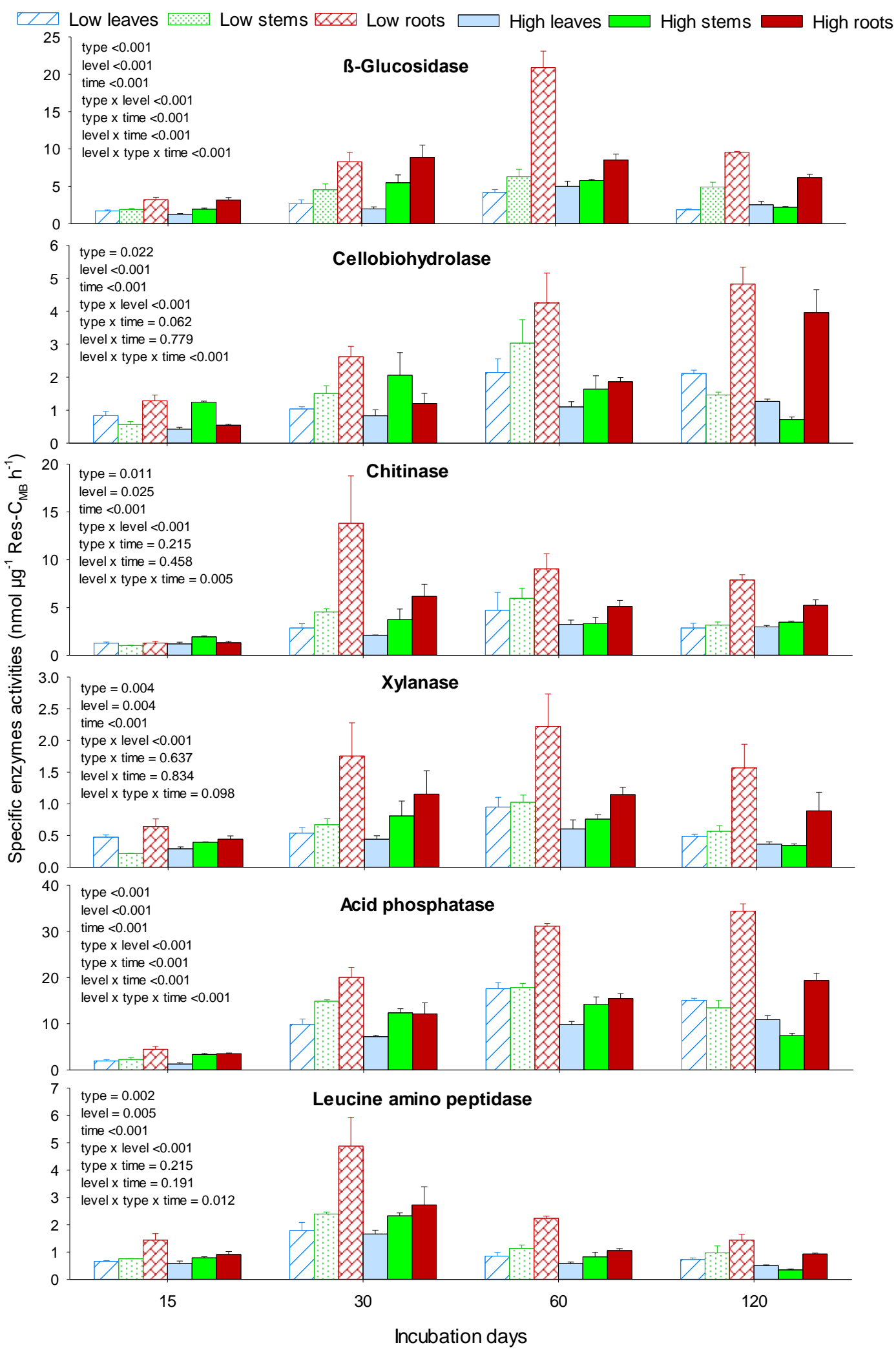

Figure S2-5. Specific enzyme activities (enzyme activities per unit of residue originated microbial biomass (Res_ $\left.\mathrm{C}_{\mathrm{MB}}\right)$ ), depending on the residue type, addition level and time of incubation. Mean values with standard errors $(n=3)$. The presented $p$-values are from the ANOVA of the data (residue type, addition level, time of sampling and their interactions) 


\subsubsection{Discussion}

\subsubsection{Residue and soil organic matter decomposition}

\subsection{Residue quality effects}

Our first hypothesis (i.e. SOM decomposition dependence on residue type) was confirmed by the simultaneous but inverse intensity of $\mathrm{CO}_{2}$ efflux originating from $\mathrm{SOM}$ and from crop residues. SOM decomposition was very low during the intensive phase of residue mineralization (up to 3 weeks) and thereafter increased when residue mineralization rate declined. Roots had a lower and shorter intensive mineralization phase than leaves and stems, but relatively intensive SOM decomposition indicated high SOM vulnerability (Chen et al. 2015; Shahbaz et al. 2016a). Note, however, a 2-fold increase of residue addition triggered an up to 2.3 and 2.6 times higher mineralization of leaves and stems, whereas SOM decomposition remained unaffected. This demonstrated that high rates of residue mineralization reflect great substrate C availability, which did not cause an increase in SOM decomposition. Microorganisms preferably utilize substrates if their availability is high and therefore SOM decomposition is not necessarily to be increased (Nottingham et al. 2009; Wang et al. 2015). In contrast to this, SOM decomposition was substantially increased (up to 15\%) at the doubled amount of root additions. This proved the high susceptibility of SOM to decomposition in the presence of decaying roots (Shahbaz et al. 2016a). Despite roots were characterized by the C/N ratio close to leaves, the roots were least decomposed. This can be attributed to the biochemical composition: root contains relatively less readily decomposable compounds and high amount of recalcitrant substances such as lignin, suberin, phenols and tannin (Aber and Melillo 1982; Bertrand et al. 2006; Lian et al. 2016; Rasse et al. 2005). Soil microorganisms feeding on such slowly decomposable substances produce enzymes able to degrade similar compounds in SOM via co-metabolism (Horvath 1972; Kuzyakov et al. 2000). Here we extend the meaning of cometabolism assuming that microorganisms producing such enzymes can also utilize SOM decomposition products.

\subsection{Priming effect as a function of residue mineralization threshold levels}

The occurrence of PE after residue incorporation suggests that substrate-addition (C availability) changed microbial stoichiometry that accelerated SOM decomposition for balanced microbial growth (Chen et al. 2014). This explains, in accordance with the priming conceptual models, the development of PE due to microbial C limitation (Blagodatskaya and 
Kuzyakov 2008). Here, we further developed a concept on the PE dynamics as depending on the quality and quantity of crop residues.

In accordance with our second hypothesis, specific PE (per unit of residue-C) was lower at high than at low residue additions. Such decrease in PE mostly occurs when the abundant amount of easily decomposable substrate is available (Guenet et al. 2010). This is often explained by the microbial substrate $\mathrm{C}$ saturation and their preferential substrate utilization over SOM (Blagodatskaya and Kuzyakov 2008; Xiao et al. 2015). The decrease of PE at high C additions highlights the relation of PE with residue decomposition (Wang et al. 2015). The PE was lowest during the intensive phase of residue mineralization and thereafter increased strongly. According to a unifying model (logistic and power functions) a threshold of ca. 20, 29-44 and $39-51 \%$ mineralization of roots, stems and leaves, respectively, exhibited the strong increase of $\mathrm{PE}$ at the slow residue decomposition phase (Fig. S2-2). This showed that the onset of strong priming growth was up to 2.5 times faster (earlier) under root additions compared with leaf and stem additions. Accordingly, at high crop residue addition, the start of strong increase of PE was delayed by a factor of up to 1.5 for both leaves and stems (exhibiting quantity effect) versus not for roots. This residue decomposition and PE phenomena (depending on quality and quantity of input) indicated a changing microbial substrate utilization pattern (Nguyen and Marschner 2016; Wang et al. 2015), which may result is a variable amount of apparent and real PE (Garcia-Pausas and Paterson 2011; Blagodatskaya et al. 2014).

\subsubsection{Mechanisms of priming effect}

\subsection{Apparent and real priming effect in relation to residue mineralization}

The mechanisms of PE relate the extra- $\mathrm{CO}_{2}$ emission with the sources of the primed organic matter. During the intensive residue mineralization phase: the low or even negative PE suggested a preferential substrate utilization (or pool substitution) mechanism mainly for leaves (ca. 2-3 weeks) and stems (Blagodatskaya and Kuzyakov 2008; Fontaine et al. 2003). Importantly, this phase lasted much longer for leaf and stem additions than for the roots, showing apparent PE (Figs S2-2 and S2-6) (Paterson and Sim 2013). Afterward (15-60 days), the increase in primed $\mathrm{CO}_{2}$ was accompanied by up to $60 \%$ decrease in $\mathrm{MB}$, and by increased specific enzyme activities (compared with at day 15). Surprisingly, no incorporation of SOMderived $\mathrm{C}$ into $\mathrm{MB}$ was detected during this period. This suggested an occurrence of a new mechanism of real PE primarily from re-utilization of microbial-necromass (produced after a 
strong decrease in MB), indicating that necromass served as SOM primer (Fig. S2-6) (Miltner et al. 2009; 2012). At a later stage, the PE strongly exceeded residue decomposition and it was accompanied by incorporation of SOM-derived C into MB. This indicated an occurrence of real PE, possibly due to microbial shifts i.e. from fast- to slow-growing (e.g. fungi) SOM-feeding populations (Blagodatsky et al. 2010; Nannipieri et al. 1978). This phase of PE was much faster (started earlier) and stronger under root versus leaf and stem addition (Figs S2-2 and S2-6). Therefore, the sequence of PE mechanisms was more complex during decomposition of aboveground crop residues compared with roots.

\subsection{Priming effect mechanisms in relation to microbial biomass and enzyme activities}

The lower amount of root- than leaf- or stem-originated $\mathrm{C}$ in $\mathrm{MB}$ confirms that root-C was relatively less labile and its decomposition was slower (Cotrufo et al. 2013; Stewart et al. 2015). The MB peaked due to residue additions at day 15, without an increase in SOM-originated C compared to the control. The correlation between the PE and enzyme activity was relatively weak in that period. We therefore, interpret the PE occurring during the intensive decomposition phase as apparent, mainly due to the pool substitution (or preferential use) mechanism (Blagodatskaya and Kuzyakov 2008; Garcia-Pausas and Paterson 2011). The fast decline of MB demonstrates the exhaustion of the labile portion of residue and SOM-originated C, which is often observed in other studies (Blagodatskaya et al. 2011b; Wang et al. 2016). The decline of MB during 15-30 days e.g. by ca. $0.2 \mathrm{~g} \mathrm{C} \mathrm{kg}^{-1}$ in the without addition control was confirmed by at least $0.1 \mathrm{~g} \mathrm{C} \mathrm{kg}^{-1}$ of SOM derived $\mathrm{CO}_{2}-\mathrm{C}$ emissions during that period (Fig. $\mathrm{S} 2-4 \mathrm{a})$. Similar pattern observed in the residue treated soils where SOM-derived $\mathrm{CO}_{2}-\mathrm{C}$ emission corresponded well to the decline in SOM-originated microbial C. Such PE can already be considered as real assuming extra $\mathrm{CO}_{2}$ originated from the labile SOM-fraction (i.e. microbial-necromass) and that the PE was accompanied by increased enzyme activity (Blagodatskaya and Kuzyakov 2008; Miltner et al. 2009; Paterson and Sim 2013). The specific $\mathrm{PE}$ and enzyme activities mainly correlated with residue-metabolizing microbial biomass, indicating the link of the residue-feeding microbial fraction to PE. Remarkably, this PE mechanism has never been before experimentally demonstrated. The significant increase of SOM derived $\mathrm{C}$ in $\mathrm{MB}$ after 120 days corresponded to the strong correlation between the PE and enzyme activity (Fig. S2-4a and Table S2-2). This suggests that the possible mechanism of real PE was due to the co-metabolism of recalcitrant SOM during the decomposition of less labile crop residues. 
Residue addition enhanced microbial activity, boosting enzyme production (Fig. S2-S2, Supplementary Material) (Blagodatskaya and Kuzyakov 2013; Fontaine et al. 2003). Due to stronger positive correlations, the residue-originated (Res_ $\mathrm{C}_{\mathrm{MB}}$ ) rather than the SOM-originated soil microflora appeared to be mainly responsible for decompositions and enzyme activities (Table S2-S1, Supplementary Material), further supporting our third hypothesis.

Residue addition stimulated specific activities (per unit of Res_C $\mathrm{C}_{\mathrm{MB}}$ ) of all six tested enzymes (Fig. S2-5). The decrease of specific enzyme activities at high residue additions can be due to the decreasing rate of enzyme production because of lower energy demands (microbial saturation by substrate) (Xiao et al. 2015). The increase of these activities after the intensive phase of residue decomposition confirms that microorganisms were at a nutrient limitation - or starving stage, causing (real) PE (Blagodatskaya et al. 2014). Accordingly, a strong interaction between specific enzyme activities and PE further supported microbial-necromass re-utilization mechanism, i.e. a real PE.

At both addition levels, higher root-induced specific PE and enzyme activities than leaves and stems may be due to the complex root structure (less decomposability) and low C availability. Thus, microorganisms synthesized more enzymes able to hydrolyse root components as well as similar compounds from SOM. This caused real PE based on co-metabolism (Kuzyakov et al. 2000; Paterson and Sim 2013). Although residue-originated C in MB under root additions was lowered compared with leaves and stems, microorganisms involved in root degradation produced enzymes (specific activity): probably this community was more efficient due to substrate quality (Fig. S2-5). Our study emphasizes the role of crop residue-feeding microorganisms as active players explaining the mechanisms and thresholds of PE, which are induced by contrasting crop residue quality and quantity. 


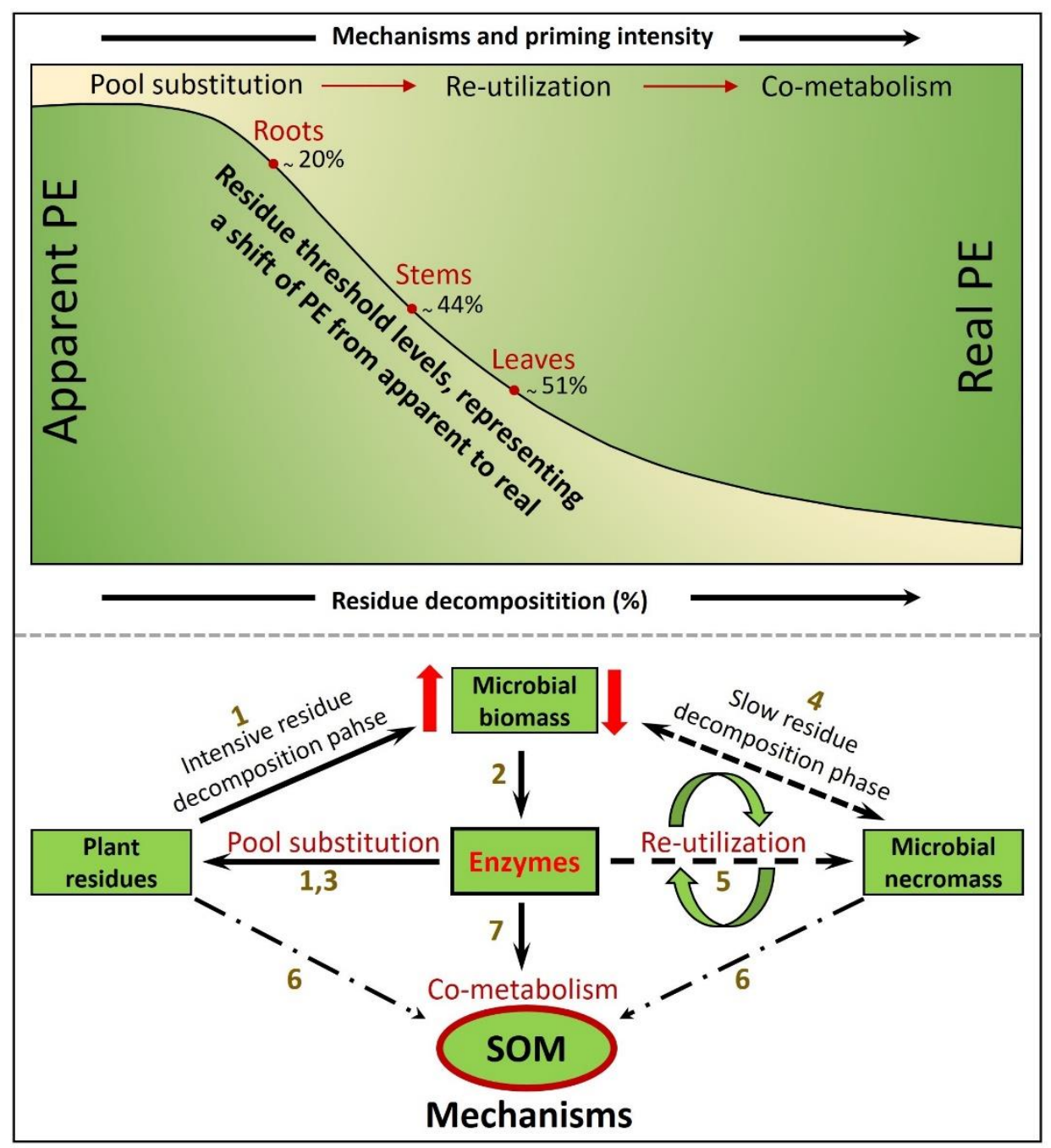

Fig. S2-6. Conceptual scheme of apparent and real priming effect (PE) in soil after residue addition, explained by three main mechanisms: pool substitution, re-utilization and cometabolism. Residue mineralization threshold levels, as estimated by a unifying model (logistic plus power functions), represent the shifts of PE from apparent to real when ca. $20 \%$ (roots), $44 \%$ (stems) and $51 \%$ (leaves) of added residues (i.e. at high additions) were mineralized.

Mechanisms: 1- Microbial uptake of plant residues degraded by existing enzymes lead to initial increase of microbial (active) biomass (MB), which is mainly due to the residuefeeding population; 2- Acceleration in enzyme production after residue-induced increase in MB (depending upon residue type); 3- Preferential substrate utilization (under high substrate $C$ availability) leading to pool substitution mechanism $(1,2,3) ; 4$ - Decrease of MB during slow residue decomposition phase (after exhaustion of labile substrate) which results in the accumulation of microbial-necromass i.e. after microbial starvation and cell death; 5Re-utilization $(2,4,5)$ of microbial-necromass under low substrate availability; 6- Direct contribution of microbial-necromass and plant compounds in soil organic matter (SOM) formation; 7- Increase of enzymatic SOM decomposition by co-metabolism under low availability of labile crop residue compounds (depending on residue quality). 
Overall, we summarize that the partitioning of $\mathrm{C}$ sources (residue and primed) during residue decomposition is combined with residue-originated MB and specific enzyme activity (Figs S24 and S2-5). The results demonstrated that instead of the total MB, the crop residue-feeding microorganisms, served as the main player regulating PE mechanisms, which depended on residue mineralization stage (threshold levels). Residue quality and amount strongly influenced the MB and microbial activity (high MB under leaf, low under root additions) involved in crop residue and SOM decomposition (Fig. S2-6) (Blagodatskaya et al. 2014). The increase in MB after residue addition was mainly due to crop residue feeding microbial fraction. During intensive phase, crop residues preferably decomposed due to accelerated enzyme production (specific), which mainly correlated with the residue-feeding microbial population. This caused apparent PE by a pool substitution (roots and stems) and negative PE by preferential residue decomposition mechanisms (Fig. S2-1d, stages 1, 2 and 3 in Fig. S2-6). Later, a strong decrease in MB (resulted in an increase of microbial-necromass) and a high correlation of enzyme activity with PE occurred. This indicated real PE induced primarily by the re-utilization of microbial-necromass (stage 2, 4 and 5 in Fig S2-6, Miltner et al. 2012). Subsequently, cometabolism of recalcitrant SOM was seen when an increase in SOM-originated C in MB was accompanied by an increase in specific enzyme activities. The specific enzyme activity strongly depends on crop residue $\mathrm{C}$ availability: unless the decomposability or $\mathrm{C}$ availability is high, microorganisms will produce less enzymes capable to co-metabolize SOM and there will be a less need for re-utilization of microbial-necromass (resulting in low or negative PE). Under low residue decomposability, i.e. less $\mathrm{C}$ availability (e.g. roots), microbial dynamics yield only a brief pool substitution stage. Nonetheless, re-utilization and co-metabolism will be the dominating processes, creating real PE (Fig. S2-6).

\subsubsection{Conclusions}

Root residues induce faster and stronger PE than aboveground plant parts. For all residue types, specific PE (per unit of $\mathrm{C}$ addition) decreased with added residue amounts. The slow root decomposition leads to stronger PE. The leaf and stem residues were intensively mineralized and yielded negative or apparent PE for extended periods, due to preferential utilization and pool substitution mechanisms. This resulted in a shorter real PE compared to root addition. During the 15-60 days, the MB declined strongly but specific enzyme activities increased. Remarkably, no incorporation of SOM-derived C into MB was detected during up to 60 days. Therefore, this suggest that the PE was primarily caused by re-utilization of microbial- 
necromass i.e. necromass served as SOM primer. At the end of incubation, the incorporation of SOM-originated $\mathrm{C}$ into microbial biomass and a corresponding increase in enzyme activities indicated the co-metabolism of SOM. The amount of primed SOM correlated with the residuefeeding microorganisms and depended on residue decomposition phases, residue quality and the added amounts. This underlines the role of residue-feeding microbial community as an active player for PE that is responsible for the contrasting PE mechanisms. We recorded threshold levels for the onset of strong PE increase versus the fraction of mineralized residues at ca. 20, 29-44 and 39-51\% mineralization of low and high input of root, stem and leaves, respectively. We conclude that for microbially-mediated SOM decomposition the residue mineralization stage is crucial, which depends not only on the quality but also the quantity of added residues. Further research efforts should focus on evaluating the role of microbialnecromass in stable SOM formation and PE under contrasting substrate quality, and on utilizing enzyme assays (e.g. for oxidative enzymes) to assess the recalcitrance of newly-formed SOM compounds.

\subsubsection{Acknowledgements}

We acknowledge the financial support provided by the German Academic Exchange Service (DAAD) to MS, Alexander von Humboldt foundation (AvH) to MSU. EB's participation was supported by the Russian Science Foundation (project N 14-14-00625). We also acknowledge the technical support of Klaus Schützenmeister in isotope labeling of the plant material. We are thankful to Karin Schmidt and Anita Kriegel for laboratory assistance. The isotopic analyses were performed at the Kompetenzzentrum Stabile Isotope (KOSI), Goettingen. This study was funded by the Deutsche Forschungsgemeinschaft (DFG, projects HE 6726/6 and KU 1184/29).

\subsubsection{References}

Adair EC, Parton WJ, Del Grosso SJ, Silver WL, Harmon ME, Hall SA, Burke IC, Hart SC (2008) Simple three-pool model accurately describes patterns of long-term litter decomposition in diverse climates. Glob Chang Biol 14:2636-2660. doi:10.1111/j.13652486.2008.01674.x

Aber JD, Melillo JM (1982) Nitrogen immobilization in decaying hardwood leaf litter as a function of initial nitrogen and lignin content. Can J Bot 60:2263-2269. doi: $10.1139 / \mathrm{b} 82-277$ 
Berg B, McClaugherty C (2014) Decomposition as a process: some main features. in: (Eds) plant litter. Springer, Berlin Heildelberg, pp. 11-34. doi:10.1007/978-3-642-38821-7_2

Bertrand I, Chabbert B, Kurek B, Recous S (2006) Can the biochemical features and histology of wheat residues explain their decomposition in soil?. Plant Soil 281:291-307. doi:10.1007/s11104-005-4628-7.

Blagodatskaya E, Kuzyakov Y (2008) Mechanisms of real and apparent priming effects and their dependence on soil microbial biomass and community structure: critical review. Biol Fertil Soils 45:115-131. doi:10.1007/s00374-008-0334-y

Blagodatsky S, Blagodatskaya E, Yuyukina T, Kuzyakov Y (2010) Model of apparent and real priming effects: Linking microbial activity with soil organic matter decomposition. Soil Biol Biochem 42:1275-1283. doi:10.1016/j.soilbio.2010.04.005

Blagodatskaya E, Yuyukina T, Blagodatsky S, Kuzyakov Y (2011a) Three-sourcepartitioning of microbial biomass and of $\mathrm{CO}_{2}$ efflux from soil to evaluate mechanisms of priming effects. Soil Biol Biochem 43:778-786. doi:10.1016/j.soilbio.2010.12.011

Blagodatskaya E, Yuyukina T, Blagodatsky S, Kuzyakov Y (2011b) Turnover of soil organic matter and of microbial biomass under $\mathrm{C} 3-\mathrm{C} 4$ vegetation change: Consideration of ${ }^{13} \mathrm{C}$ fractionation and preferential substrate utilization. Soil Biol Biochem 43:159-166. doi:10.1016/j.soilbio.2010.09.028

Blagodatskaya E, Kuzyakov Y (2013) Active microorganisms in soil: Critical review of estimation criteria and approaches. Soil Biol Biochem 67:192-211. doi:10.1016/j.soilbio.2013.08.024

Blagodatskaya E, Khomyakov N, Myachina O, Bogomolova I, Blagodatsky S, Kuzyakov Y (2014) Microbial interactions affect sources of priming induced by cellulose. Soil Biol Biochem 74:39-49. doi:10.1016/j.soilbio.2014.02.017

Bromand S, Whalen J, Janzen H (2001) A pulse-labelling method to generate ${ }^{13} \mathrm{C}$-enriched plant materials. Plant Soil 235:253-257. doi:10.1023/A:1011922103323

Burns RG, DeForest JL, Marxsen J, Sinsabaugh RL, Stromberger ME, Wallenstein MD, Weintraub MN, Zoppini A (2013) Soil enzymes in a changing environment: Current knowledge and future directions. Soil Biol Biochem 58:216-234. doi:10.1016/j.soilbio.2012.11.009 
Castellano, MJ, Mueller KE, Olk, DC, Sawyer JE, Six J (2015) Integrating plant litter quality, soil organic matter stabilization, and the carbon saturation concept. Glob Chang Biol 21, 3200-3209. doi:10.1111/gcb.12982

Chen R, Senbayram M, Blagodatsky S, Myachina O, Dittert K, Lin X, Blagodatskaya E, Kuzyakov Y (2014) Soil C and N availability determine the priming effect: Microbial N mining and stoichiometric decomposition theories. Glob Chang Biol 20:2356-2367. doi:10.1111/gcb.12475

Chen S, Wang Y, Hu Z, Gao H (2015) $\mathrm{CO}_{2}$ emissions from a forest soil as influenced by amendments of different crop straws: Implications for priming effects. Catena 131:5663. doi:10.1016/j.catena.2015.03.016

Cotrufo MF, Wallenstein MD, Boot CM, Denef K, Paul E (2013) The Microbial EfficiencyMatrix Stabilization (MEMS) framework integrates plant litter decomposition with soil organic matter stabilization: Do labile plant inputs form stable soil organic matter? Glob Chang Biol 19:988-995. doi:10.1111/gcb.12113

Cotrufo MF, Soong JL, Horton AJ, Campbell EE, Haddix ML, Wall DH, Parton WJ (2015) Formation of soil organic matter via biochemical and physical pathways of litter mass loss. Nat Geosci 8:776-779. doi:10.1038/ngeo2520

Fontaine S, Mariotti A, Abbadie L (2003) The priming effect of organic matter: a question of microbial competition? Soil Biol Biochem 35:837-848. doi.org/10.1016/S00380717(03)00123-8

Fontaine S, Barot S, Barré P, Bdioui N, Mary B, Rumpel C (2007) Stability of organic carbon in deep soil layers controlled by fresh carbon supply. Nature 450:277-280. doi:10.1038/nature06275

Garcia-Pausas J, Paterson E (2011) Microbial community abundance and structure are determinants of soil organic matter mineralisation in the presence of labile carbon. Soil Biol Biochem 43:1705-1713. doi:10.1016/j.soilbio.2011.04.016

Guenet B, Neill C, Bardoux G, Abbadie L (2010) Is there a linear relationship between priming effect intensity and the amount of organic matter input? Appl Soil Ecol 46:436442. doi.org/10.1016/j.apsoil.2010.09.006

Hayes JM (2004) An introduction to isotopic calculations. Woods Hole, MA 02543, USA: 
http://www.whoi.edu/cms/files/jhayes/2005/9/IsoCalcs30Sept04_5183.pdf.

Horvath RS (1972) Microbial co-metabolism and the degradation of organic compounds in nature. Bacteriol Rev 36:146-155.

Hoyle FC, Murphy DV, Brookes PC (2008) Microbial response to the addition of glucose in low-fertility soils. Biol Fertil Soils 44:571-579. doi:10.1007/s00374-007-0237-3

Jenkinson DS, Fox RH, Rayner JH (1985) Interactions between fertilizer nitrogen and soil nitrogen — the so-called 'priming'effect. J Soil Sci 36:425-44. doi: 10.1111/j.13652389.1985.tb00348.x

Jiang-shan Z, Jian-fen G, Guang-shui C, Wei Q (2005) Soil microbial biomass and its controls. J Forest Res 16:327-330. doi:10.1007/BF02858201

Johnson JMF, Novak JM, Varvel GE, Stott DE, Osborne SL, Karlen DL, Lamb JA, Baker J, Adler PR (2014) Crop residue mass needed to maintain soil organic carbon levels: can it be determined? BioEnergy Res 7:481-490. doi:10.1007/s12155-013-9402-8

Kramer S, Marhan S, Ruess L, Armbruster W, Butenschoen O, Haslwimmer H, Kuzyakov Y, Pausch J, Scheunemann N, Schoene J, Schmalwasser A (2012) Carbon flow into microbial and fungal biomass as a basis for the belowground food web of agroecosystems. Pedobiologia 55:111-119. doi:http://dx.doi.org/10.1016/j.pedobi.2011.12.001

Kuzyakov Y, Friedel JK, Stahr K (2000) Review of mechanisms and quantification of priming effects. Soil Biol Biochem 32:1485-98. http://dx.doi.org/10.1016/S00380717(00)00084-5

Kuzyakov Y (2010) Priming effects: Interactions between living and dead organic matter. Soil Biol Biochem 42:1363-1371. doi:10.1016/j.soilbio.2010.04.003

Ladd JN, Foster R, Nannipieri P, Oades JM (1996) Soil structure and biological activity. In Stotzky G and Bollag J-M (Eds). Soil Biochemistry 9. Marcel Dekker, New York, pp 2378

Lehmann J, Kleber M (2015) The contentious nature of soil organic matter. Nature 528:6068. doi:10.1038/nature16069

Leifeld J, von Lützow M (2014) Chemical and microbial activation energies of soil organic matter decomposition. Biol Fertil Soils 50:147-153. doi: 10.1007/s00374-013-0822-6 
Lian T, Wang G, Yu Z, Li Y, Liu X, Jin J (2016) Carbon input from ${ }^{13}$ C-labelled soybean residues in particulate organic carbon fractions in a Mollisol. Biol Fertil Soils 52:331339. doi: 10.1007/s00374-015-1080-6

Makarov MI, Malysheva TI, Menyailo OV, Soudzilovskaia NA, Van Logtestijn RSP, Cornelissen JHC (2015) Effect of $\mathrm{K}_{2} \mathrm{SO}_{4}$ concentration on extractability and isotope signature $\left(\delta^{13} \mathrm{C}\right.$ and $\left.\delta^{15} \mathrm{~N}\right)$ of soil $\mathrm{C}$ and $\mathrm{N}$ fractions. Eur J Soil Sci 66:417-426. doi:10.1111/ejss. 12243

Meyer SL (1975) Data analysis for scientists and engineers. John Wiley and Sons, New York.

Miltner A, Kindler R, Knicker H, Richnow HH Kästner M (2009) Fate of microbial biomassderived amino acids in soil and their contribution to soil organic matter. Org Geochem 40:978-985. doi:10.1016/j.orggeochem.2009.06.008

Miltner A, Bombach P, Schmidt-Brücken B, Kästner M (21012) SOM genesis: microbial biomass as a significant source. Biogeochemistry 111:41-55. doi: 10.1007/s10533-0119658-z

Nannipieri P, Johnson RL, Paul EA (1978) Criteria for measurement of microbial growth and activity in soil. Soil Biol Biochem 10:223-229. doi:10.1016/0038-0717(78)90100-1

Nannipieri P, Kandeler E, Ruggiero P (2002) Enzyme activities and microbiological and biochemical processes in soil. In Burns RG, Dick RP (Eds) Enzymes in the Environment. Activity, ecology and Applications. Marcel Dekker, New York, pp 1-33

Nannipieri P, Giagnoni L, Landi L, Renella G (2011) Role of phosphatase enzymes in soil. In Bunemann EK et al (eds) Phosphorus in Action. Soil Biology 26. Springer Verlag, Berlin Heidelberg, pp 215-241

Nannipieri P, Giagnoni L, Renella G, Puglisi E, Ceccanti B, Masciandaro G, Fornasier F, Moscatelli MC, Marinari S (2012) Soil enzymology: classical and molecular approaches. Biol Fertil Soils 48:743-762. doi:10.1007/s00374-012-0723-0

Nguyen TT, Marschner P (2016) Soil respiration, microbial biomass and nutrient availability in soil after repeated addition of low and high $\mathrm{C} / \mathrm{N}$ plant residues. Biol Fertil Soils 52:165-176. doi: 10.1007/s00374-015-1063-7

Nottingham AT, Griffiths H, Chamberlain PM, Stott AW, Tanner EVJ (2009) Soil priming by sugar and leaf-litter substrates: A link to microbial groups. Appl Soil Ecol 42:183-190. 
doi:10.1016/j.apsoil.2009.03.003

Paterson E, Sim A (2013) Soil-specific response functions of organic matter mineralization to the availability of labile carbon. Glob Chang Biol 19:1562-1571. doi:10.1111/gcb.12140

Poirier V, Angers D, Rochette P, Whalen J (2013) Initial soil organic carbon concentration influences the short-term retention of crop-residue carbon in the fine fraction of a heavy clay soil. Biol Fertil Soils 49:527-535. doi: 10.1007/s00374-013-0794-6

Pritsch K, Raidl S, Marksteiner E, Blaschke H, Agerer R, Schloter M, Hartmann A (2004) A rapid and highly sensitive method for measuring enzyme activities in single mycorrhizal tips using 4-methylumbelliferone-labelled fluorogenic substrates in a microplate system. J Microbioll Meth 58:233-241. doi:10.1016/j.mimet.2004.04.001

Rasse DP, Rumpel C, Dignac MF (2005) Is soil carbon mostly root carbon? Mechanisms for a specific stabilisation. Plant Soil 269:341-356. doi:10.1007/s11104-004-0907-y

Sanaullah M, Razavi BS, Blagodatskaya E, Kuzyakov Y (2016) Spatial distribution and catalytic mechanisms of $\beta$-glucosidase activity at the root-soil interface. Biol Fertil Soils 52:505-514. doi:10.1007/s00374-016-1094-8

Schnecker J, Wild B, Hofhansl F, Alves RJ, Bárta J, Čapek P, Fuchslueger L, Gentsch N, Gittel A, Guggenberger G, Hofer A (2014) Effects of soil organic matter properties and microbial community composition on enzyme activities in cryoturbated arctic soils. PloS one 9:e94076. doi:http://dx.doi.org/10.1371/journal.pone.0094076

Shahbaz M, Kuzyakov Y, Heitkamp F (2016a) Decrease of soil organic matter stabilization with increasing inputs: Mechanisms and controls. Geoderma. doi:10.1016/j.geoderma.2016.05.019

Shahbaz M, Kuzyakov Y, Maqsood S, Wendland M, Heitkamp F (2016b) Decadal nitrogen fertilization decreases mineral-associated and subsoil carbon: a 32 year study. Land Degrad Develop. doi: 10.1002/ldr.2667

Stewart CE, Moturi P, Follett RF, Halvorson AD (2015) Lignin biochemistry and soil N determine crop residue decomposition and soil priming. Biogeochemistry 124:335-351. doi:10.1007/s10533-015-0101-8

Tian J, Pausch J, Yu G, Blagodatskaya E, Gao Y, Kuzyakov Y (2015) Aggregate size and their disruption affect ${ }^{14} \mathrm{C}$-labeled glucose mineralization and priming effect. Appl Soil 
Ecol 90:1-10. doi:10.1016/j.apsoil.2015.01.014

Turmel MS, Speratti A, Baudron F, Verhulst N, Govaerts B (2015) Crop residue management and soil health: A systems analysis. Agr Sys 134:6-16. doi:10.1016/j.agsy.2014.05.009

Vance E, Brookes P, Jenkinson D (1987) An extraction method for measuring soil microbial biomass C. Soil Biol Biochem 19:703-707. doi:10.1016/0038-0717(87)90052-6

Wang H, Boutton T, Xu W, Hu G, Jiang P, Bai E (2015) Quality of fresh organic matter affects priming of soil organic matter and substrate utilization patterns of microbes. Sci Rep 5:10102. doi:10.1038/srep10102

Wang J, Dokohely ME, Xiong Z, Kuzyakov Y (2016) Contrasting effects of aged and fresh biochars on glucose-induced priming and microbial activities in paddy soil. J Soils Sediments 16:191-203. doi:10.1007/s11368-015-1189-0

Wagner GH (1968) Significance of microbial tissue to soil organic matter. In: Isotopes and Radiation in Soil Organic Matter studies. FAO/IAEA, Technical meeting, Vienna, pp 197-205

Webster R (2007) Analysis of variance, inference, multiple comparisons and sampling effects in soil research. Eur J Soil Sci 58:74-82. doi: 10.1111/j.1365-2389.2006.00801.x

Wu J, Joergensen RG, Pommerening B, Chaussod R, Brookes PC (1990) Measurement of soil microbial biomass $\mathrm{C}$ by fumigation-extraction - an automated procedure. Soil Biol Biochem 22:1167-1169. doi:10.1016/0038-0717(90)90046-3

Xiao C, Guenet B, Zhou Y, Su J, Janssens IA (2015) Priming of soil organic matter decomposition scales linearly with microbial biomass response to litter input in steppe vegetation. Oikos 124:649-657. doi:10.1111/oik.01728

Xu X, Ouyang H, Richter A, Wanek W, Cao G, Kuzyakov Y (2011) Spatio-temporal variations determine plant-microbe competition for inorganic nitrogen in an alpine meadow. J Ecol 99:563-571. doi:10.1111/j.1365-2745.2010.01789.x 


\subsection{Study 3}

\section{Decadal nitrogen fertilization decreases mineral-associated and subsoil carbon: a 32 year study}

Muhammad Shahbaz ${ }^{1,2, *}$, Yakov Kuzyakov ${ }^{1,3,5}$, Shafique Maqsood ${ }^{2}$, Matthias Wendland ${ }^{4}$, Felix Heitkamp ${ }^{2}$

${ }^{1}$ Department of Agricultural Soil Sciences, Georg August University Göttingen, Büsgenweg 2, 37077 Göttingen, Germany

${ }^{2}$ Section of Physical Geography, Faculty of Geoscience and Geography, Georg August University Göttingen, Goldschmidtstr 5, 37077 Göttingen, Germany

${ }^{3}$ Department of Soil Science of Temperate Ecosystems, Georg August University Göttingen, Büsgenweg 2, 37077 Göttingen, Germany

${ }^{4}$ Bayrische Landesanstalt für Landwirtschaft, Institut für Agrarökologie, ökologischen Landbau und Bodenschutz, Lange Point 12, 85354 Freising, Germany

${ }^{5}$ Institute of Environmental Sciences, Kazan Federal University, 420049 Kazan, Russia

Status: Published in Land Degradation and Development (2016): doi: 10.1002/ldr.2667

${ }^{*}$ Corresponding author:

Department of Agricultural Soil Sciences, Georg August University Göttingen,

Büsgenweg 2, 37077 Göttingen, Germany

Tel.: +49 -(0)551-3920502; Fax: +49 -551-3933310

Email: shahbazmu@yahoo.com; mshahba@gwdg.de 


\subsubsection{Abstract}

Crop residues and manure are important sources of carbon (C) for soil organic matter (SOM) formation. Crop residue return increases by nitrogen $(\mathrm{N})$ fertilization because of higher plant productivity, but this often results only in minor increases of SOM. In our study, we show how $\mathrm{N}$ fertilization and organic $\mathrm{C}$ additions affected SOM and its fractions within a 32-year long field-experiment at Puch, Germany. Five organic additions: no-addition (control), manure, slurry, straw and straw+slurry, were combined with three mineral $\mathrm{N}$ fertilization rates (no-, medium- and high-fertilization), which resulted in 1.17-4.86 Mg C-input ha ${ }^{-1} \mathrm{yr}^{-1}$. Topsoil (0$25 \mathrm{~cm}) \mathrm{SOM}$ content increased with $\mathrm{N}$ fertilization, mainly due to the $\mathrm{C}$ in free light fraction (f-LF). In contrast, subsoil $(25-60 \mathrm{~cm}) \mathrm{SOM}$ decreased with $\mathrm{N}$ fertilization, probably because of roots' relocation in Ap horizon with $\mathrm{N}$ fertilization at the surface. Despite high inputs, straw contributed little to $\mathrm{f}-\mathrm{LF}$ but prevented $\mathrm{C}$ losses from the mineral-associated SOM fraction $(\rho$ $>1.6 \mathrm{~g} \mathrm{~cm}^{-3}$ ) with $\mathrm{N}$ fertilization, which was observed without straw addition. Above- (straw) and belowground (roots) residues had opposite effects on SOM fractions. Root C retained longer in the light-fractions and was responsible for SOM increase with N fertilization. Straw decomposed rapidly (from f-LF), and fueled the mineral-associated SOM fraction. We conclude that SOM content and composition depended not only on residue quantity, which can be managed by the additions and $\mathrm{N}$ fertilization, but also on the quality of organics. This should be considered for maintaining the SOM level, C sequestration and soil fertility.

Keywords: Soil organic matter; Density fractionation; Nitrogen fertilizer; Manure \& straw slurry; Cropland soil. 


\subsubsection{Introduction}

Improving and maintaining soil organic matter (SOM) levels is necessary for the functioning of physicochemical and biological properties of soils (Keesstra et al., 2016; Laudicina et al., 2015). Poor soil physicochemical functioning can lead to land and nutrients degradations (such as due to erosions) in cropland soils (Auerswald et al., 2009; Novara et al., 2013; Rodrigo Comino et al., 2016a). Crop residue return is important for soil conservation practices because it is a major carbon (C) source for improving SOM levels (Cerdà et al., 2016). The SOM is vital for nutrients conservation and soil structural development, therefore protect the soil against degradation (Brevik et al., 2015; Withers et al., 2007).

The pool size of SOM depends on its formation from plant residues and its mineralization to $\mathrm{CO}_{2}$ (Cotrufo et al., 2015). Generally, it is assumed that increasing amounts of $\mathrm{C}$ inputs to soil, improves SOM levels. Several field studies, however, show that increasing C inputs did not always increase SOM levels (Heitkamp et al., 2012a; Novara et al., 2016; Stewart et al., 2008). Such phenomena of SOM change is often linked with C storage capacity of SOM fractions, which are important for nutrients conservation and soil physicochemical functioning (Prosdocimi et al., 2016; Six et al., 2002).

The SOM fractions are mainly distinguished according to their protection mechanism and decomposition stage (Schrumpf et al., 2013). Mostly, SOM fractions with various protection mechanisms are separated based on density and their association with soil silt and clay particles (Gunina \& Kuzyakov, 2014). The physically unprotected fraction of SOM represented by the free light fraction (f-LF) which is strongly affected by recent $\mathrm{C}$ inputs. Within soil aggregates, SOM is physically protected by spatial separation from decomposing microorganisms (i.e. their extracellular enzymes) and by low oxygen diffusion into aggregates, which slows decomposition (Six et al., 2002). The aggregates associated fraction often termed the occluded light fraction (o-LF). Decomposition of light fractions and also microbial turnover leads to the formation of microbial-residues, which mostly are sorbed to fine mineral-particles and form the heavy fraction (HF) of SOM (Schrumpf et al., 2013). This physicochemical stabilization (after microbial substrate degradation) substantially reduces the turnover of SOM in HF. The SOM increase due to large $\mathrm{C}$ additions (such as crop residue) mostly explained by $\mathrm{C}$ accumulation in HF. However, due to the limited physical or physicochemical protection capacity, large C additions may cause only minor increase of bulk SOM, especially in high-C soils (Six et al., 
2002; Shahbaz et al., 2016). This indicates that C-input driven by e.g. high crop residues return, therefore, would not be directly beneficial for SOM.

Crop residue return frequently increased by nitrogen $(\mathrm{N})$ fertilization, however, the effect of the $\mathrm{N}$-fertilization-triggered increase of $\mathrm{C}$ addition is not always certain (Dou et al., 2016; Zhang et al., 2016). This is because, the stable SOM build-up is not mainly input driven but also depends on residue decomposability and its protection from microbial degradation (Barbera $e t$ al., 2010; García-Orenes et al., 2016). Recent views suggest that stable SOM formation is mainly related to the conversion of residue $\mathrm{C}$ input into microbial-residues that make up most of the C associated with HF (Cotrufo et al., 2013; Gleixner, 2013; Lehmann \& Kleber, 2015). $\mathrm{N}$-fertilization improves aboveground residue quality and decreases $\mathrm{C} / \mathrm{N}$ ratio. Residues with lower $\mathrm{C} / \mathrm{N}$ ratios support high microbial-residues formation compared to low-quality (such as roots; high $\mathrm{C} / \mathrm{N}$ and recalcitrant compounds), which decomposes slowly (Cotrufo et al., 2013). However, in contrast to low quality, accelerated decomposition of high-quality residues (e.g. under high $\mathrm{N}$ availability) can promote $\mathrm{C}$ losses (as $\mathrm{CO}_{2}$ emissions or leaching of dissolved $\mathrm{C}$ ) more than stabilization within SOM (De Almeida et al., 2016; Pabst et al., 2016). The soil $\mathrm{N}$ availability and residue decomposability (with contrasting quality) can, therefore, affect the partitioning of $\mathrm{C}$ within SOM fractions and its distribution along soil depths.

The importance of management effects on SOM levels has mostly been examined for topsoil (0-25 cm, plough layer); information for subsoil is scarce (Gregory et al., 2014; Ogle et al., 2005). Subsoil contains a large fraction of total organic $C$ and is sensitive, for instance, to land use changes (Rumpel and Kogel-Knabner, 2011). The subsoil SOM stabilization is primarily affected by root growth (its exudations) and dissolved C leaching from topsoil (Don et al., 2009; Rumpel \& Kögel-Knabner, 2011). In general, due to relatively less exposure to environmental extreme events and high degree of mineral-associations, subsoil SOM is assumed to be more stable than topsoil (Cerdà et al., 2010; Rumpel \& Kögel-Knabner, 2011). However, subsoil SOM can be destabilized due to priming effects, specifically under high $\mathrm{N}$ fertilization (Kuzyakov et al., 2000; Khan et al., 2007). Subsoil mostly had a mineral-associated C, thus its SOM stabilization can be affected by the factors affecting $\mathrm{C}$ accumulation in topsoil $\mathrm{HF}$ (Stewart et al., 2008; Hobley \& Wilson, 2016). Nonetheless, no clear information is available on the long-term management effects, on total SOM change that can be explained by $\mathrm{C}$ stabilization in its fractions, and we know little about the ultimate effects on subsoil C. 
The present study was therefore designed to explain and compare the integrated long-term impacts of $\mathrm{C}$ inputs (varies in quality and quantity) and $\mathrm{N}$ fertilization rates on topsoil (0-25 $\mathrm{cm}) \mathrm{SOM}$ and its fractions, and to estimate the effects on subsoil $(25-60 \mathrm{~cm}) \mathrm{SOM}$ contents. Density fractionation approach was used to separate C in topsoil SOM fractions. We assumed that $\mathrm{C}$ storage in SOM fractions will reflect the total SOM change, but their response rate can differ. In particular, the specific goals of this study were: i) to estimate and compare the changes in topsoil SOM levels due to $\mathrm{C}$ inputs (variable organics) and $\mathrm{N}$ fertilization over the study period, i.e. 32 years, ii) to analyze the effects of topsoil managements on SOM accumulation in subsoil, iii) to quantify and compare the effects of $\mathrm{C}$ inputs and $\mathrm{N}$ fertilization on partitioning of $\mathrm{C}$ among topsoil SOM fractions (f-LF, o-LF and HF), and overall impact of these fractions on SOM formation.

\subsubsection{Materials and methods}

\subsubsection{Site description}

The long-term (well designed and documented) field experiment (48 $11^{\prime} 37.85^{\prime \prime}$ N, $9^{\circ} 13^{\prime} 04.55^{\prime \prime}$ E) is located at Puch, a village close to Munich, Germany. The study site represents a common soil type in Central Europe and covers a wide range of management options in a widespread, cereal-based crop rotation. The soil was classified as Luvisol (Parabraunerden) (IUSS-WRB, 2015), derived from loess sediments with silt-loam texture (sand: 9\%, silt: 73\%, clay: 18\%) overlying moraine deposits of the Riss glaciation. The mean annual precipitation and temperature since 1983 were $868 \mathrm{~mm} \mathrm{y}^{-1}$ and $8.4^{\circ} \mathrm{C}$, respectively (Heitkamp et al., 2012a). Prior to the experiment, the site was used as cropland for decades or even centuries, and we, therefore, assume no major disequilibrium of $\mathrm{C}$ contents due to land use changes. In the plough layer (0$25 \mathrm{~cm}$, maintained since 1983) the $\mathrm{pH}$ decreased from 6.4 to 6.1 in the studied period (19832015). The $\mathrm{pH}$ and a test with $10 \%$ hydrochloric acid ( $\mathrm{HCl})$ indicated the absence of carbonates. To estimate the changes in SOM contents during the study period, starting conditions of SOM (in 1983) were analyzed using topsoil samples (0-25 cm). Soil samples were taken for plots receiving various organic additions but bulked across replicates and $\mathrm{N}$ fertilization rates (see below, Fig. S3-1). Therefore, in 1983, different amounts of SOM contents ( $\left.\mathrm{g} \mathrm{C} \mathrm{kg}^{-1}\right)$ were calculated for different organic additions that ranged 11.2 (no-addition control); 10.6 (Slurry as well as for Straw) and 10.8 (Manure and Straw+Slurry) (Fig. S3-4a), see further details in Heitkamp et al. (2012a). 


\subsubsection{Experimental design}

The crop rotation is silage maize (Zea mays L.) - winter wheat (Triticum aestivum L.) - winter barley (Hordeum vulgare L.). The experiment was laid out as a full factorial strip design with two factors $(\mathrm{n}=3)$ (Fig. S3-1). Organic additions were considered as the first factor and $\mathrm{N}$ fertilization rate (three levels) as the second factor (Fig. S3-2, Table S3-1). In all organic additions, application of phosphorus $(\mathrm{P})$ and potassium $(\mathrm{K})$ fertilization was equal but varied between years according to crop needs (Hege \& Offenberger, 2006). Five organic addition levels were selected for factor one: i) Control (no addition, straw removed); ii) Manure (straw removed, cattle farmyard manure applied every third year); iii) Slurry (cattle slurry application, straw removed); iv) Straw (alone straw incorporated); v) Straw+Slurry (straw incorporated combined with slurry application).

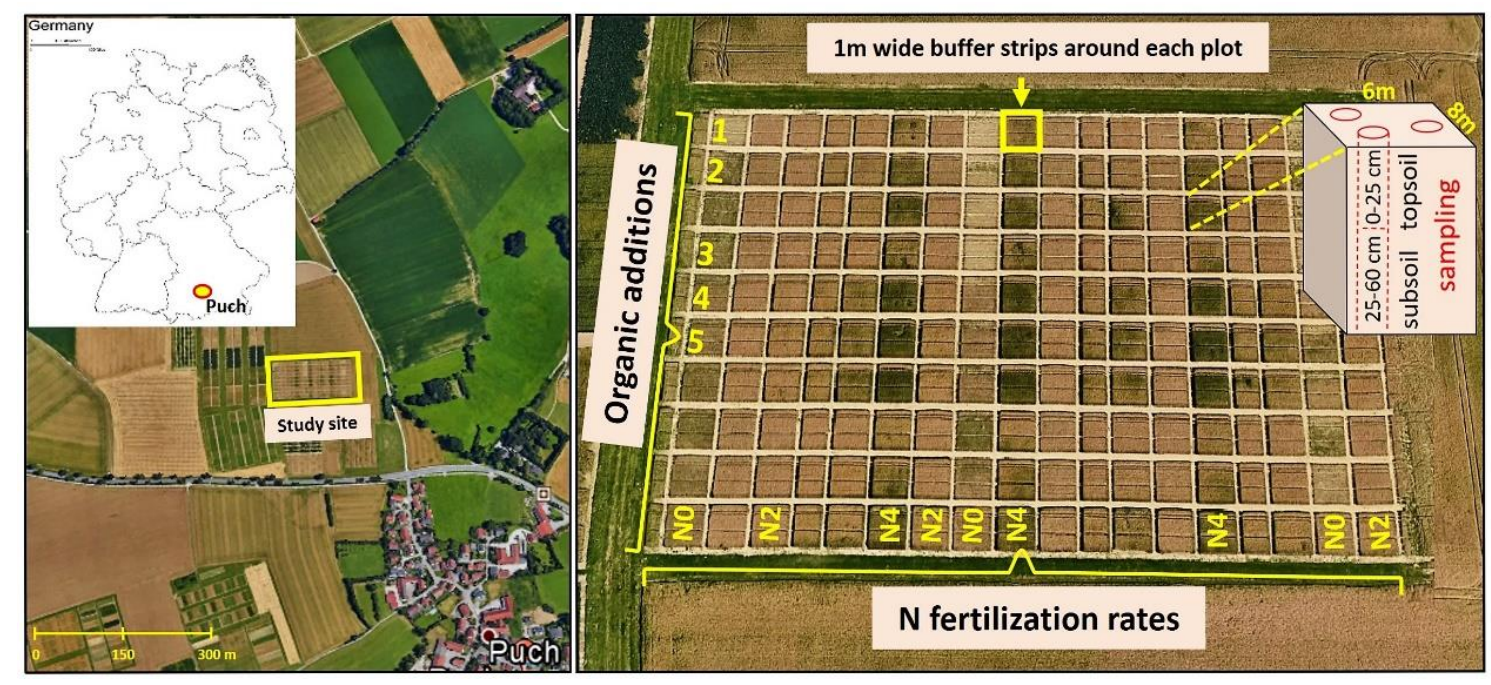

Figure S3-1. Aerial view of the study site $\left(48^{\circ} 11^{\prime} 37.85^{\prime \prime} \mathrm{N}, 9^{\circ} 13^{\prime} 04.55^{\prime \prime}\right.$ E), located at Puch close to Munich (Germany), showing the field experimental design which consists of two factors: organic additions ( 1 - control, 2 - manure, 3 - straw, 4 - slurry, 5 - straw+slurry) and $\mathrm{N}$ fertilization rates (N0, N2 and $\mathrm{N} 4$ represents; no, medium and high $\mathrm{N}$ fertilization, respectively). The expanded box shows random soil sampling points (3 sample which were bulked) for both top- and subsoil of individual plot.

In August and April, before the maize crop, slurry (on average 7.6\% dry matter, 5.8\% OM, 4.4 $\mathrm{kg} \mathrm{N} \mathrm{m}^{-3}, 2.8 \mathrm{~kg} \mathrm{NH}_{4} \mathrm{~N} \mathrm{~m}^{-3}$ ) was applied at rates of $30 \mathrm{~m}^{3} \mathrm{ha}^{-1}$ (corresponds to the regional practices). Since 1999, the slurry application was changed to account for more recent management of the region (Table S3-1): to maize, two applications of $25 \mathrm{~m}^{3}$ (each at sowing time) and additionally (in spring) to winter wheat or winter barley (before sowing), $25 \mathrm{~m}^{3} \mathrm{ha}^{-1}$ 
was applied each time. The manure was spread every third year in August before the maize crop. From 1983 to 1998 , manure was applied on the fresh mass basis of $30 \mathrm{Mg} \mathrm{ha}^{-1}$ (on average $23 \%$ dry matter, $17 \% \mathrm{OM}, 5.5 \mathrm{~kg} \mathrm{~N} \mathrm{Mg}^{-1}$ ) and, from 1998 on, the application rate was increased to $40 \mathrm{Mg} \mathrm{ha}^{-1}$.

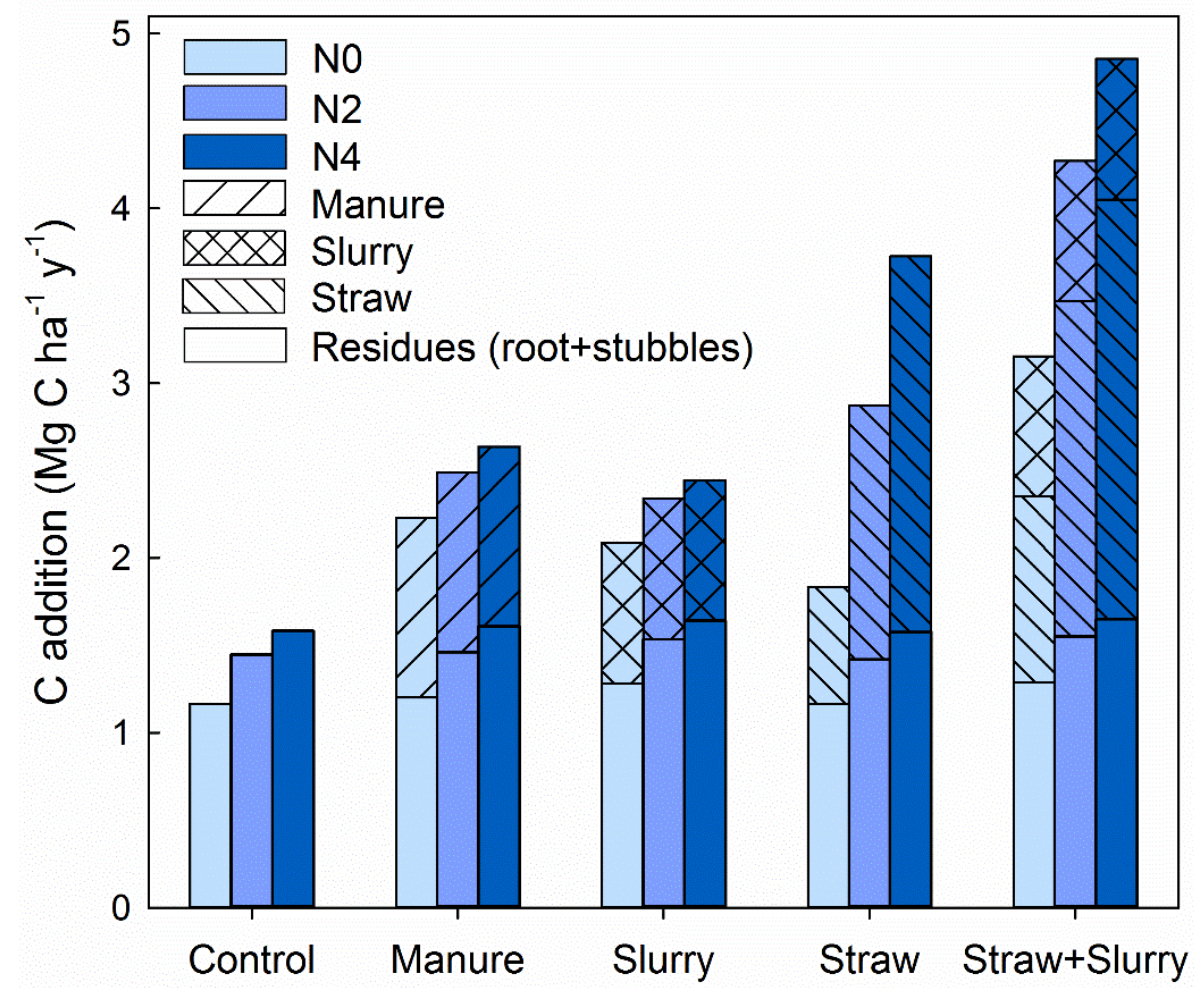

Figure S3-2. The contribution of organic carbon (C) sources to total annual $\mathrm{C}$ additions $\left(\mathrm{Mg} \mathrm{C} \mathrm{ha}{ }^{-1}\right)$ starting from 1984. The $\mathrm{C}$ input by manure, slurry, straw and crop roots (stubbles) was measured and calculated (see detail Heitkamp et al., 2012a). N0, N2 and N4 represents; no, medium and high $\mathrm{N}$ fertilization, respectively. Control: without organic additions; Manure: straw removed, farmyard manure applied every third year; Slurry: cattle slurry application, straw removed; Straw: straw incorporated; Straw+Slurry: straw incorporated combined with slurry application.

The second factor, $\mathrm{N}$ fertilization (three levels, no (N0), medium (N2) and high (N4) fertilization), varied between crops. The amount of $\mathrm{N}$ fertilization rates given to winter wheat and barley was different, because of the specific nutrient demands of the crops (Table S3-1). 
Table S3-1. Mineral N fertilization rates

\begin{tabular}{clll}
\hline $\mathrm{N}-$ fertilization $\left(\mathrm{kg} \mathrm{N} \mathrm{ha}^{-1} \mathrm{y}^{-1}\right)$ & $\mathrm{N} 0$ & $\mathrm{~N} 2$ & $\mathrm{~N} 4$ \\
\hline $\begin{array}{c}\text { 1984-1998 } \\
\text { barley }\end{array}$ & 0 & 60 & $80 / 40$ \\
wheat & 0 & $50 / 30^{*}$ & $70 / 50 / 40$ \\
maize & 0 & 100 & $120 / 80$ \\
since 1999 & & & \\
barley & 0 & $50 / 30$ & $80 / 40 / 40$ \\
wheat & 0 & $50 / 20 / 30$ & $80 / 60 / 60$ \\
maize & 0 & 100 & $120 / 80$ \\
\hline
\end{tabular}

${ }^{*} \mathrm{~N}$-amounts divided by slash indicate split applications.

Until 1993, straw yield was measured in all organic addition plots, and thereafter only for organic additions with straw removal. A C content of $45 \%$ was considered for straw, and the straw yield was estimated based on the mean harvest index (grain to aboveground biomass ratio), which was remarkably stable $(0.49 \pm 0.01)$ through time and among treatments. The straw was incorporated directly into the plot of its origin. This provided realistic on-farm conditions since the amount and chemistry of straw may be directly influenced by the respective treatments. Consequently, the amount of incorporated straw increased with $\mathrm{N}$ fertilizer rate (Fig. S3-2). The amount of manure and slurry was fixed and measured before addition, and their $\mathrm{C}$ contents were calculated by dividing organic matter by 1.92 (Larney et al., 2005). The fraction of crop residues in soil added by roots and crop-stubbles was estimated as described by Heitkamp et al. (2012a). The used regression model of yields with crop residues does not separate between roots and stubbles. Nevertheless, it is reasonable to assume that a major part of the estimated $\mathrm{C}$ input of residues stems from roots. According to estimates of Bolinder et al. (2007), we calculated that ca. $75 \%$ of our estimates may be contributed by roots. Therefore, we argue that the $\mathrm{C}$ input by crop residues in treatments without straw incorporation is clearly dominated by roots. Overall, mean annual $\mathrm{C}$ input for all organic additions ranged from 1.17 to 4.86 $\mathrm{Mg} \mathrm{C} \mathrm{ha}^{-1} \mathrm{y}^{-1}$ and increased with $\mathrm{N}$ fertilization rate (Fig. S3-2). For detailed information about the experiment (i.e., $\mathrm{C}$ input estimation and calculations, crop yields, $\mathrm{N}$ balances) see Hege \& Offenberger (2006) and Heitkamp et al. (2012a).

\subsubsection{Soil sampling}

Following the wheat harvest in August 2015, soil samples were taken from a depth of 0-25 cm (topsoil) and 25-60 cm (subsoil) with the help of a soil auger. The sampled topsoil $(0-25 \mathrm{~cm})$ represents the plough horizon (Ap), which is annually mixed by tillage since 1983 . The subsoil $(25-60 \mathrm{~cm})$ was sampled to estimate the SOM accumulation which is affected due to topsoil 
managements. For each organic addition, the soil was sampled in three field replicates of each selected $\mathrm{N}$ fertilizer rate. Within each selected $\mathrm{N}$ field replicate plot, three random sampling (for both top- and sub-soil) was done and thereafter soil was bulked and represented one composite field replicate of each selected N fertilization level (Fig. S3-1). Three levels of N fertilization were selected: N0, N2 and N4 (Table S3-1). The soil samples were air dried at room temperature, sieved $(<2 \mathrm{~mm})$, and visible parts of large crop residue (e.g. mixed during sampling from recent crop harvest) removed. Additionally, we sampled soil with $100 \mathrm{~cm}^{3}$ cylinders (three replicates per plot, 10-15 cm depths) to determine bulk density. The samples were oven dried $\left(105^{\circ} \mathrm{C}\right)$, left for cooling in a desiccator and weighed.

\subsubsection{Density fractionation}

The SOM density fractionation approach was applied to both top- $(0-25 \mathrm{~cm})$ and subsoil (25$60 \mathrm{~cm}$ ), but the yield of f-LF and o-LF from subsoil was too small to carry out precise measurements. Therefore, the density fractionation was only presented for topsoil and we assumed the subsoil SOM was mainly HF-C.

To isolate the density fractions of topsoil SOM, $20 \mathrm{~g}$ of air-dried soil portioned into two replicates (i.e. $10 \mathrm{~g}$ each) was placed into a centrifugation tube. A $30 \mathrm{~mL}$ of sodium polytungstate solution with a density of $1.6 \mathrm{~g} \mathrm{~cm}^{-3}$ was added to each soil portion in the tube (Cerli et al., 2012). The tube was then gently turned several times by hand, the solution was centrifuged at 4,000 rpm for $40 \mathrm{~min}$, and the supernatant with floating material $\left(\rho>1.6 \mathrm{~g} \mathrm{~cm}^{-3}\right)$ was filtered (cellulose acetate filter, $0.45 \mu \mathrm{m}$; Sartorius, Germany) and washed with ca. $1 \mathrm{~L}$ distilled water to obtain a salt-free f-LF. To isolate o-LF, a similar amount of sodium polytungstate solution ( $\rho=1.6 \mathrm{~g} \mathrm{~cm}^{-3}$ ) was added to the remaining sample after removing of $\mathrm{f}$ LF. The sample was mixed with sodium polytungstate and then the soil-aggregates were dispersed by ultrasound (Retesch, Germany) with a calibrated input energy at $440 \mathrm{~J} \mathrm{ml}^{-1}$. After dispersion, the suspension was left to settle overnight and centrifuged for $40 \mathrm{~min}$ at 4,000 rpm. The supernatant (consist of o-LF) was filtered and washed as described above. To separate sand particles $(>53 \mu \mathrm{m})$ from the remaining sample after the separation of f-LF and o-LF, wet sieving was done with $53 \mu \mathrm{m}$ mesh size. The measured organic $\mathrm{C}$ contents of sand fraction were very low $(<0.01 \%)$ and therefore fraction $<53 \mu \mathrm{m}$ (silt plus clay) was considered as the HF (Breulmann et al., 2016). The HF was washed with distilled water, and suspended particles were precipitated by adding few drops of $0.5 \mathrm{M} \mathrm{AlCl}_{3}$. The clear supernatant was removed and 
the precipitated HF was collected. All the density fractions were dried (at $40^{\circ} \mathrm{C}$, to constant weight) and weighed.

\subsubsection{Analysis of total carbon contents}

Before analysis, all density fractions, topsoil and subsoil samples were dried $\left(40^{\circ} \mathrm{C}\right)$. The soil samples were ball milled (MM2, Fa Retsch, Germany), while density fractions of SOM were homogenously manually ground by using mortar and pestle. The $\mathrm{C}$ contents were measured using an elemental analyzer (Vario EL II, Germany). The soil was carbonate-free, therefore we consider total soil $\mathrm{C}$ as organic $\mathrm{C}$. Further, we reported $\mathrm{C}$ measurements only as contents instead of calculating stocks because there were no significant effects of the tested factors on topsoil bulk density (organic addition $\mathrm{p}=0.310, \mathrm{~N}$ fertilization $\mathrm{p}=0.788$ and their interactions, organic addition $\mathrm{x} \mathrm{N}$ fertilization $\mathrm{p}=0.209$ ).

The $\Delta \mathrm{SOM}$ contents $(\% \mathrm{C})$ of topsoil, in relation to its initial and final $\mathrm{C}$ values were calculated (Johnson et al., 2014) as;

$\Delta \mathrm{SOM}=\left[\left(\mathrm{SOM}_{\mathrm{n}}-\mathrm{SOM}_{\mathrm{i}}\right) / \mathrm{SOM}_{\mathrm{i}}\right] * 100$

Where, $\mathrm{SOM}_{\mathrm{n}}$ is the SOM contents $\left(\mathrm{g} \mathrm{C} \mathrm{kg}^{-1}\right)$ at our sampling time (2015), and SOMi is the initial SOM contents in 1983.

\subsubsection{Statistics}

Statistical analyses were performed using R (version 2.11.1). A linear mixed model (LMM) was used to test the effect of organic additions (factor one, five levels) and $\mathrm{N}$ fertilization (factor 2 , three rates) on top- and subsoil $\mathrm{C}$ and topsoil density fractions. The main two factors were used as fixed effects, while the spatial structure (strip design) was introduced as a random factor. Results are presented as means $(n=3) \pm$ standard error.

To quantify changes of $\mathrm{C}$ contents since the beginning of the experiment, replicate values of $\Delta \mathrm{C}$ were related to the annual $\mathrm{C}$ inputs $\left(\mathrm{Mg} \mathrm{C} \mathrm{ha}^{-1} \mathrm{y}^{-1}\right)$ (Halvorson \& Schlegel, 2012; Johnson et al., 2014). An exponential relationship showed the best fit according to the highest adjusted $\mathrm{R}^{2}$ values. The effect of $\mathrm{C}$ additions on density fractions was additionally quantified. Linear regressions between density fractions and C inputs were applied to the whole dataset $(n=45)$ and within each organic addition among $\mathrm{N}$ fertilizer rates $(n=9)$. Results different at $\mathrm{p}<0.01$ level are considered as significant. 


\subsubsection{Results}

\subsubsection{Soil organic matter contents depending on $C$ inputs and $N$ fertilization}

After 32 years of $\mathrm{C}$ input (1.17 to $\left.4.86 \mathrm{Mg} \mathrm{C} \mathrm{ha}^{-1} \mathrm{y}^{-1}\right)$, the relation of changes in topsoil $\mathrm{C}$ contents (\% change compared to initial $\mathrm{C}$ values) against total $\mathrm{C}$ inputs was best described by an exponential model (Fig. S3-3). The total SOM contents in topsoil were significantly affected by both organic addition and $\mathrm{N}$ fertilizer rates (Fig. S3-4a). The topsoil SOM contents ranged from 9.6 to $12.6 \mathrm{~g} \mathrm{C} \mathrm{kg}^{-1}$ and generally increased with $\mathrm{N}$ fertilization rate. Compared to initial values in 1983, the highest positive change (up to 17\%) of $\mathrm{C}$ along $\mathrm{N}$ fertilization rate over 32 years was recorded under slurry addition, either with straw removal or incorporation (Fig. S33). C contents remained stable under manure additions, which represent the traditional practice in the region. Highest losses of C (12-14\%) were recorded when $\mathrm{N}$ fertilizer was applied alone (control) and or with straw (2-8\%) incorporation.

The $\mathrm{C}$ content in subsoil SOM was also affected by $\mathrm{N}$ fertilization and organic additions (Fig. S3-4a). Contrary to topsoil, however, the subsoil SOM contents decreased with increasing N fertilization rate. The total SOM content in the subsoil ranged from 4.1 to $5.5 \mathrm{~g} \mathrm{C} \mathrm{kg}^{-1}$ soil. Compared to other organic additions, the control had the highest amount of subsoil SOM at each $\mathrm{N}$ fertilization rate (Fig. S3-4). Note that starting conditions in 1983 were not measured for subsoil. The measured C contents in topsoil SOM were highest in the control and, therefore, we assume that the high $\mathrm{C}$ contents in this treatment reflect the heritage of the starting conditions. That this restriction also applies for the $\mathrm{N}$ fertilization is highly unlikely: while organic additions were arranged in strips, plots receiving $\mathrm{N}$ fertilizer rates were randomized. Thus, the highly significant effect of $\mathrm{N}$ fertilization $(\mathrm{p} \leq 0.001)$ strongly indicates a real treatment effect and cannot be explained by spatial heterogeneity. 


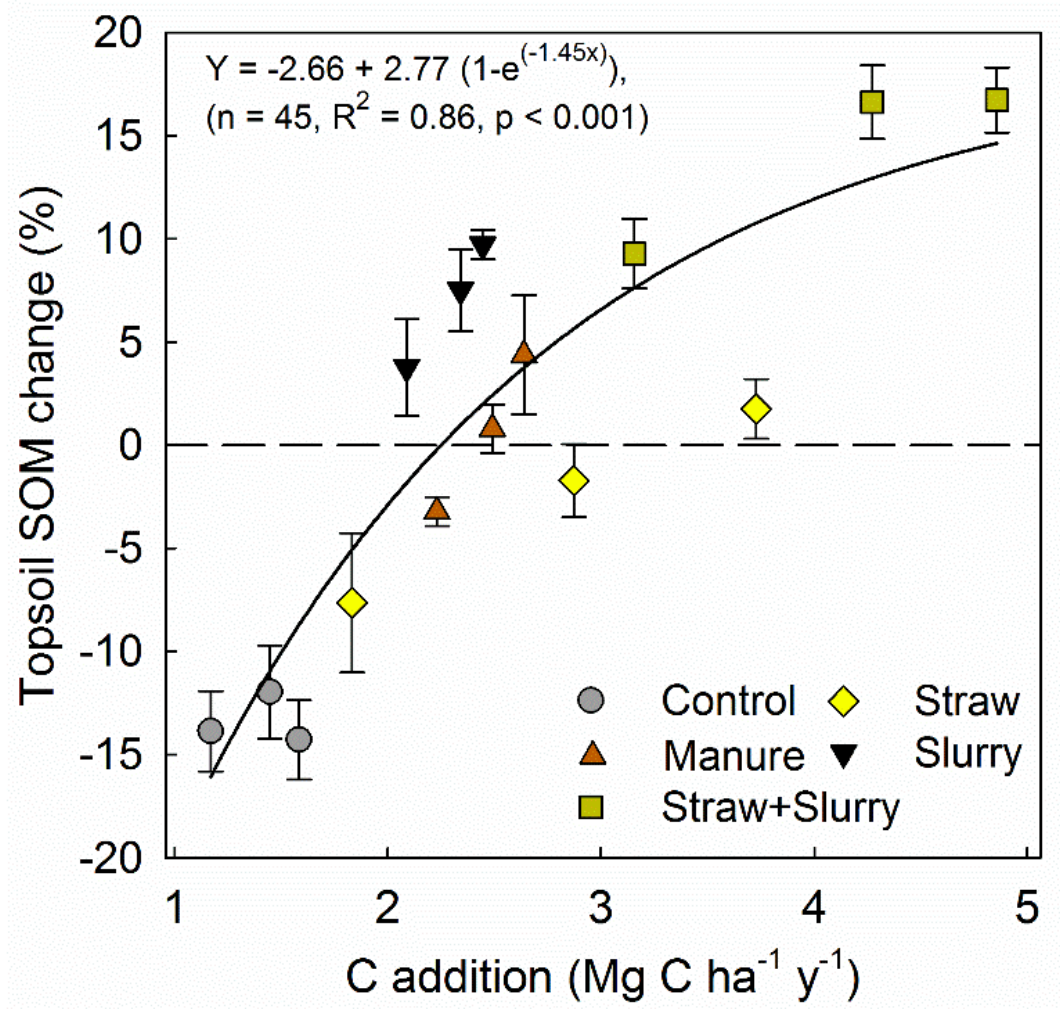

Figure S3-3. The curve represents the exponential relationship between the mean annual C additions and changes of topsoil soil organic matter (SOM) contents (\%, between 1983 and 2015) over 32 years. 0-line corresponds to $C$ content in soil at the start of the experiment (32 years ago). Control: without organic additions; Manure: straw removed, farmyard manure applied every third year; Slurry: cattle slurry application, straw removed; Straw: straw incorporated; Straw+Slurry: straw incorporated combined with slurry application. Bars represent the \pm standard error of the mean $(n=3)$. The probability levels of the linear mixed model describing the effects ( $\mathrm{C}$ addition, $\mathrm{N}$ fertilization, interaction) for accepting the null hypothesis that the factors have no effect for the change of total SOM (\%) are as follows, C addition $\leq 0.001 ; \mathrm{N}$ fertilization $\leq 0.001$ and interactions: $\mathrm{C}$ addition $\times \mathrm{N}$ fertilization $=0.409$.

\subsubsection{Effect of $C$ inputs and $N$ fertilization on SOM fractions}

The total sample recovery after soil density fractionation was ca. 97\%. Total C contents in f-LF ( $p<1.6$ ) ranged from 0.26 to $0.74 \mathrm{~g} \mathrm{C} \mathrm{kg}^{-1}$ and in o-LF from 0.35 to $0.54 \mathrm{~g} \mathrm{C} \mathrm{kg}^{-1}$ of soil (Fig. S3-5a, c). Therefore, both fractions together comprised up to $20 \%$ of total SOM. The C content of the f-LF was affected by both $\mathrm{N}$ fertilization and organic addition. $\mathrm{C}$ contents of the o-LF depended mainly on organic additions. The highest occlusion was found when slurry (alone or in combination with straw) or manure was applied. The effect of $\mathrm{N}$ fertilization on o-LF varied depending on the organic addition (Fig. S3-5c, d), indicated no response (control, slurry), increased (manure, straw) and decreased (slurry+straw). 
The $\mathrm{C}$ contents of the HF ranged from 6.5 to $8.7 \mathrm{~g} \mathrm{C} \mathrm{kg}^{-1}$, thus constituting up to $80 \%$ of total SOM contents. The HF was affected by organic addition, with the highest $\mathrm{C}$ content under slurry+straw and the lowest $\mathrm{C}$ content in the control (Fig. S3-5e, f). Despite the increasing C additions with increasing $\mathrm{N}$ fertilization, the $\mathrm{C}$ contents in $\mathrm{HF}$ decreased across $\mathrm{N}$ fertilizer rates, when straw was removed (Figures 2 and 5e, f). Nonetheless, upon straw incorporation, non-significant slopes (across $\mathrm{N}$ rates) indicated that the $\mathrm{C}$ associated with $\mathrm{HF}$ at least did not decrease with increasing $\mathrm{N}$ fertilization rate (Fig. S3-5f).

\subsubsection{Discussion}

\subsubsection{Effect of $C$ inputs and $N$ fertilization on top- and subsoil SOM}

Compared to the initial $\mathrm{C}$ values, slurry application (alone or with straw) increased topsoil $\mathrm{C}$ contents over 32 years (Fig. S3-3 and S3-4a). This indicated that slurry contained either relatively stable $\mathrm{C}$ and thus was retained in soil (Shahbaz et al., 2014; Weyman-Kaczmarkowa \& Politycka 2002), or that slurry improved root growth (Kandeler et al., 1994). The total SOM changes remained unaffected under manure addition, presumably because this management is closest to the traditional practice and SOM contents were therefore in dynamic equilibrium. The more labile nature of straw explains why its addition did not maintain the $\mathrm{C}$ contents at a similar level as manure or slurry. Other researchers have reported that substantial amounts of straw incorporation did not have marked effects on total SOM contents (Powlson et al., 2011; Poeplau et al., 2015; Novara et al., 2016). C contents increasing with $\mathrm{N}$ fertilizer rates in soils without straw incorporation can be explained by the increasing crop residue return by stubbles and roots. Since straw was removed, roots with their slower decomposition were mainly responsible for the SOM increases (Heitkamp et al., 2012b; Rasse et al., 2005).

The exponential relationship between change in topsoil $\mathrm{C}$ and $\mathrm{C}$ inputs was especially evident with straw incorporation (alone or combined with slurry). This shows a decreasing overall efficiency of $\mathrm{C}$ accumulation with increasing amounts of aboveground biomass. One reason is a closer $\mathrm{C} / \mathrm{N}$ ratio of straw with increasing $\mathrm{N}$ fertilizer rates because litter with closer $\mathrm{C} / \mathrm{N}$ ratios decomposes faster (Ogle et al., 2005). Faster decomposition, however, should also increase the amount of microbial-residues, which form a major part of stable SOM (Cotrufo et al., 2013; Gleixner, 2013). Recently, Castellano et al. (2015) linked the stabilization efficiency of the labile litter with the concept of "C saturation". That concept proposes that effective stabilization of microbial-residues occurs only when mineral surfaces have free capacity for sorption. This 
explanation does not fit to our dataset. Although the shape of the relationship between $\Delta \mathrm{C}$ and C additions (Fig. S3-3) does fit the "C saturation" concept, the data from the subsoil and density fractions contradicts this hypothesis. The subsoil is characterized by low $\mathrm{C}$ contents, and the $\mathrm{C}$ stabilization capacity should be high, resulting in linear relationships with $\mathrm{C}$ input. Instead, we show that $\mathrm{C}$ decreased in subsoils receiving more $\mathrm{C}$ through increased biomass by $\mathrm{N}$ fertilization (Fig. S3-4).
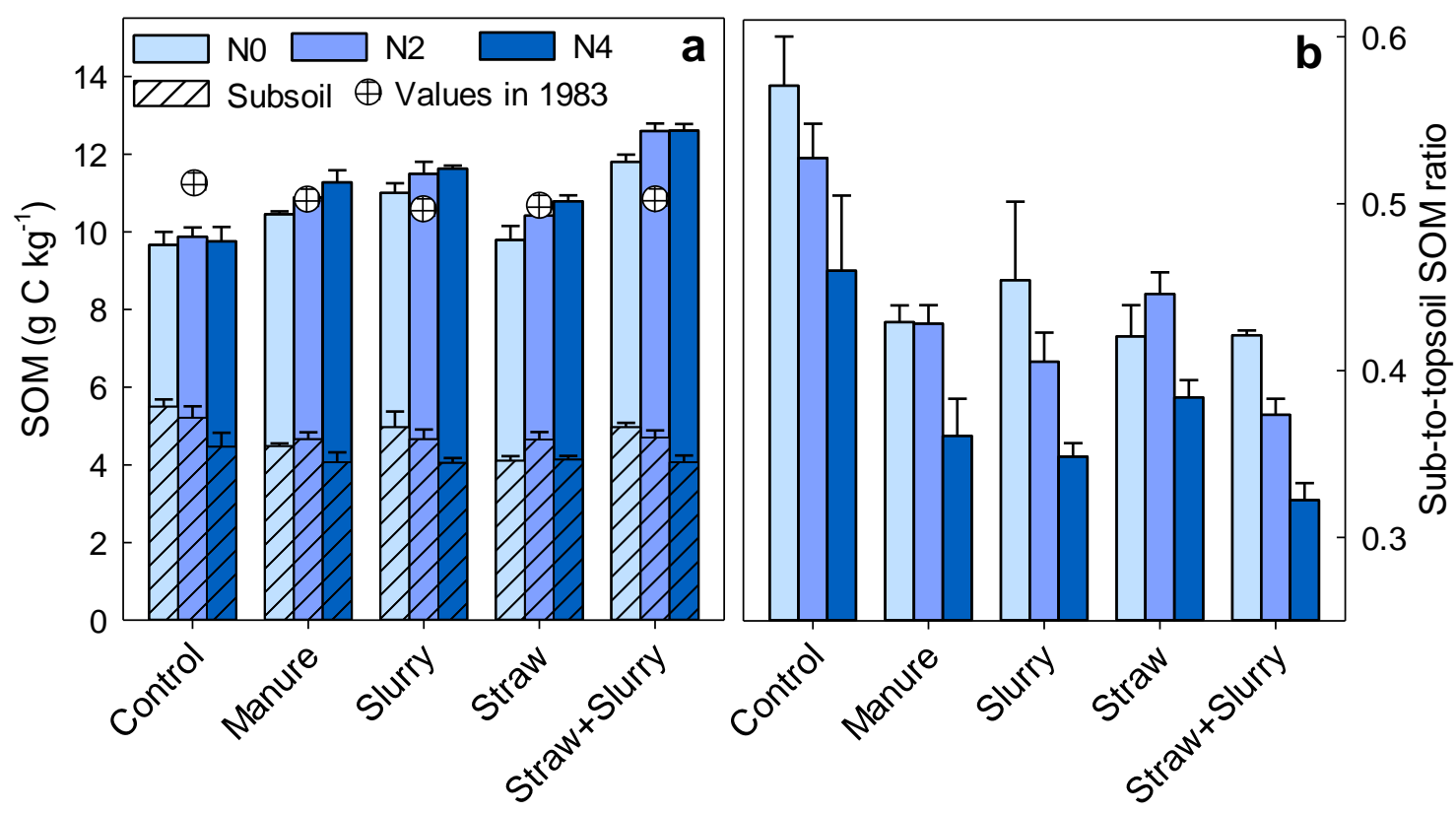

Figure S3-4. Contents of soil organic matter $(\mathrm{SOM})$ in topsoil $(0-25 \mathrm{~cm})$, subsoil $(25-60 \mathrm{~cm})$ and initial topsoil (32 years ago, crossed circle) (a); and the ratio of sub- to topsoil SOM contents (b). N0, N2 and N4 represents; no, medium and high $\mathrm{N}$ fertilization, respectively. Control: without organic additions; Manure: straw removed, farmyard manure applied every third year; Slurry: cattle slurry application, straw removed; Straw: straw incorporated; Straw+Slurry: straw incorporated combined with slurry application. Bars represent the \pm standard error of the mean $(n=3)$. The probability levels of the linear mixed model for accepting the null hypothesis that the factors have no effect are as follows: topsoil SOM (organic addition $\leq 0.001$; $\mathrm{N}$ fertilization $\leq 0.001$; and interactions: organic addition $\times \mathrm{N}$ fertilization $=0.750$ ), subsoil SOM (organic addition $=0.002 ; \mathrm{N}$ fertilization $\leq 0.001$; and interactions: organic addition $\times \mathrm{N}$ fertilization $=$ 0.323 ), sub-to- topsoil $\mathrm{SOM}$ ratio (organic addition $\leq 0.001 ; \mathrm{N}$ fertilization $\leq 0.001$; and interactions: organic addition $\times \mathrm{N}$-fertilization $=0.691$ ).

The decrease of subsoil SOM contents with $\mathrm{N}$ fertilization, probably indicates roots' relocation in Ap horizon with $\mathrm{N}$ fertilization at the surface. However, other studies have shown that the supply of fresh $\mathrm{C}$ and high $\mathrm{N}$ fertilization can destabilize subsoil $\mathrm{C}$ due to priming effects (Fontaine et al., 2007; Khan et al., 2007; da Silva Oliveira et al., 2016). Recent findings also indicate that microbial community composition can strongly change with $\mathrm{N}$ fertilization 
(Kuslien et al., 2014; Fanin et al., 2015) and that microbial activity governs the integration of new C into the soil (Lange et al., 2015). Regardless of the specific mechanism involved, the results show that subsoil $\mathrm{C}$ drops as $\mathrm{N}$ fertilizer rates increase (Fig. S3-4). A similar finding was recently reported by Steinmann et al. (2016) on a large sample set ( $\mathrm{n}=268$, for the Cologne-Bonn region, Germany), where despite increasing topsoil SOM contents, the subsoil $\mathrm{C}$ contents declined over 8 years. This was in contrast to the general notion that subsoil SOM is highly stabilized and insensitive to management. Moreover, fractions that are supposed to be stabilized - such as the organo-mineral HF - can also clearly be affected by management (Hobley et al., 2016).

\subsubsection{Distribution of organic matter in density fractions}

The $\mathrm{C}$ contents of $\mathrm{f}-\mathrm{LF}$ increased with $\mathrm{N}$ fertilizer rates and therefore with $\mathrm{C}$ additions (Fig. S35). However, this increase of $\mathrm{C}$ in $\mathrm{f}-\mathrm{LF}$ was much stronger when straw was removed (in control, manure and slurry), indicating the importance of root-derived C (Fig. S3-5a). The amount of manure and slurry application in our experiments was fixed, and thus any changes in f-LF must be due to residue $\mathrm{C}$ originating mainly from roots (and to a lower degree from crop stubbles). Strongly increasing $C$ contents in the f-LF under straw removal (Fig. S3-5) reflect an enrichment of root C (Schrumpf et al., 2013) due to its slower mineralization rates compared to straw (Rasse et al., 2005; Shahbaz et al., 2016). f-LF is known to be most responsive to C input, especially derived by cattle manure additions (Gregorich et al., 2006; Yagüe et al., 2016). Nonetheless, under straw incorporation (dominant aboveground biomass) the low response of f-LF contents to $\mathrm{C}$ input indicated that straw was rapidly decomposed. The retention of roots and the fast decomposition of straw in the f-LF may explain the behavior of the HF.

The HF-C decreased with increasing $\mathrm{C}$ additions and $\mathrm{N}$ fertilization when straw was removed. This means that root-derived $\mathrm{C}$ was unable to increase, or even sustain, $\mathrm{C}$ contents in the HF under high $\mathrm{N}$ fertilization (Fig. S3-5 and 6). In a meadow ecosystem, $\mathrm{N}$ fertilization increased plant biomass production without changing bulk SOM or its fractions (Neff et al., 2002). This was explained by a substantially increased $\mathrm{C}$ turnover in plant material and f-LF, followed by replacement of $\mathrm{C}$ in the HF by microbial-residues derived from labile substances (Cotrufo et al., 2013; Gleixner, 2013; Gunina \& Kuzyakov, 2014). However, roots or low-quality residue inputs (high $\mathrm{C} / \mathrm{N}$ ) can also contribute markedly to SOM storage (Rasse et al., 2005; Barbera et $a l ., 2010)$. Therefore, we propose that roots and straw fulfilled different functions with regards to SOM storage. On the one hand, root-derived $\mathrm{C}$ was retained in the f-LF and thus directly 


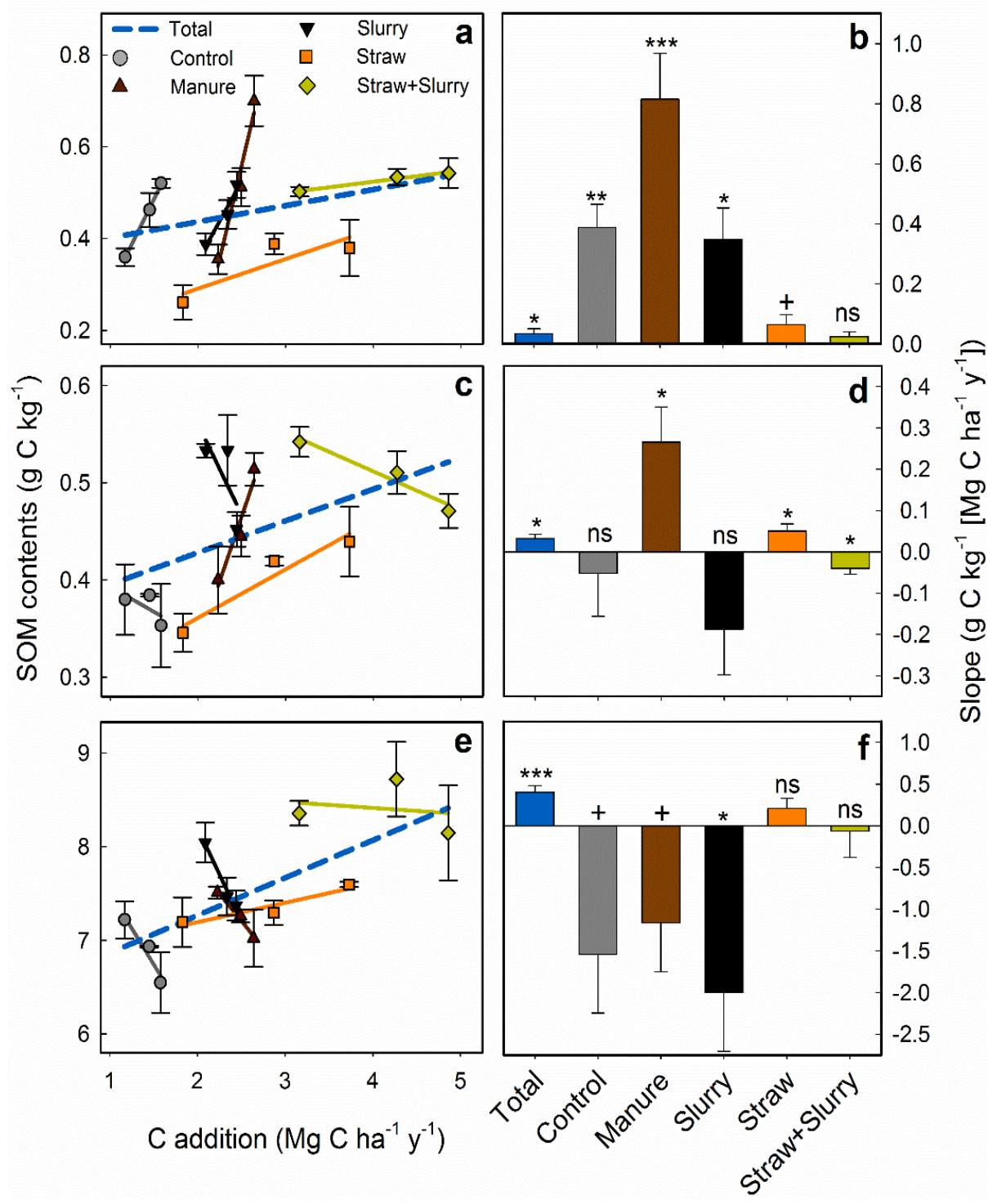

Figure S3-5. Soil organic matter (SOM) contents and their relationships with mean annual $\mathrm{C}$ addition over 32 years. The slopes of the linear regressions ( \pm standard errors) either of the total dataset $(n=45)$ or within individual treatment (organic additions $n=9$ ) along $N$ fertilization rates are given. Free light fractions (f-LF) (a) and their slopes (b), occluded light fractions (o-LF) (c) and their slopes (d), heavy fractions (HF) (e) and their slopes (f). Control: without organic additions; Manure: straw removed, farmyard manure applied every third year; Slurry: cattle slurry application, straw removed; Straw: straw incorporated; Straw+Slurry: straw incorporated combined with slurry application. $* * *: p \leq 0.001 ; * *$ : $\mathrm{p} \leq$ $0.01 ; *: p \leq 0.05 ;+: p \leq 0.1 ; n s: p>0.1$. The probability levels of the linear mixed model for accepting the null hypothesis that the factors have no effect on $\mathrm{C}$ contents are as follows: $\mathrm{f}$ $\mathrm{LF}(\mathrm{C}$ addition $\leq 0.001$; $\mathrm{N}$ fertilization $\leq 0.001$; and interaction: $\mathrm{C}$ addition $\times \mathrm{N}$ fertilization $=0.010), \mathrm{o}-\mathrm{LF}(\mathrm{C}$ addition $\leq 0.001 ; \mathrm{N}$ fertilization $=0.428$; and interaction: $\mathrm{C}$ addition $\times \mathrm{N}$ fertilization $=0.005), \mathrm{HF}(\mathrm{C}$ addition $\leq 0.001 ; \mathrm{N}$ fertilization $=0.0109$; and interaction: $\mathrm{C}$ addition $\times \mathrm{N}$ fertilization $=0.326$ ). 
reflected the amount of $\mathrm{C}$ input and explained the often observed minor increase of SOM with $\mathrm{N}$ fertilization in cropland soils (Lu et al., 2011). On the other hand, straw, exhibiting (relative to roots) faster decomposition, fueled mineral-associated SOM with microbial-residues. The decreasing $\mathrm{C}$ contents in the $\mathrm{HF}$ without straw incorporation indicate that the stimulating effect of $\mathrm{N}$ on SOM turnover (Neff et al., 2002; Qiao et al., 2016) could not be counteracted by remaining $\mathrm{C}$ inputs. Importantly, this discussion centers around the effect of $\mathrm{N}$ fertilization solely within one type of organic addition. Accordingly, our finding is sensu strictu valid only for $\mathrm{C}$ inputs, which are stimulated by $\mathrm{N}$ fertilization.

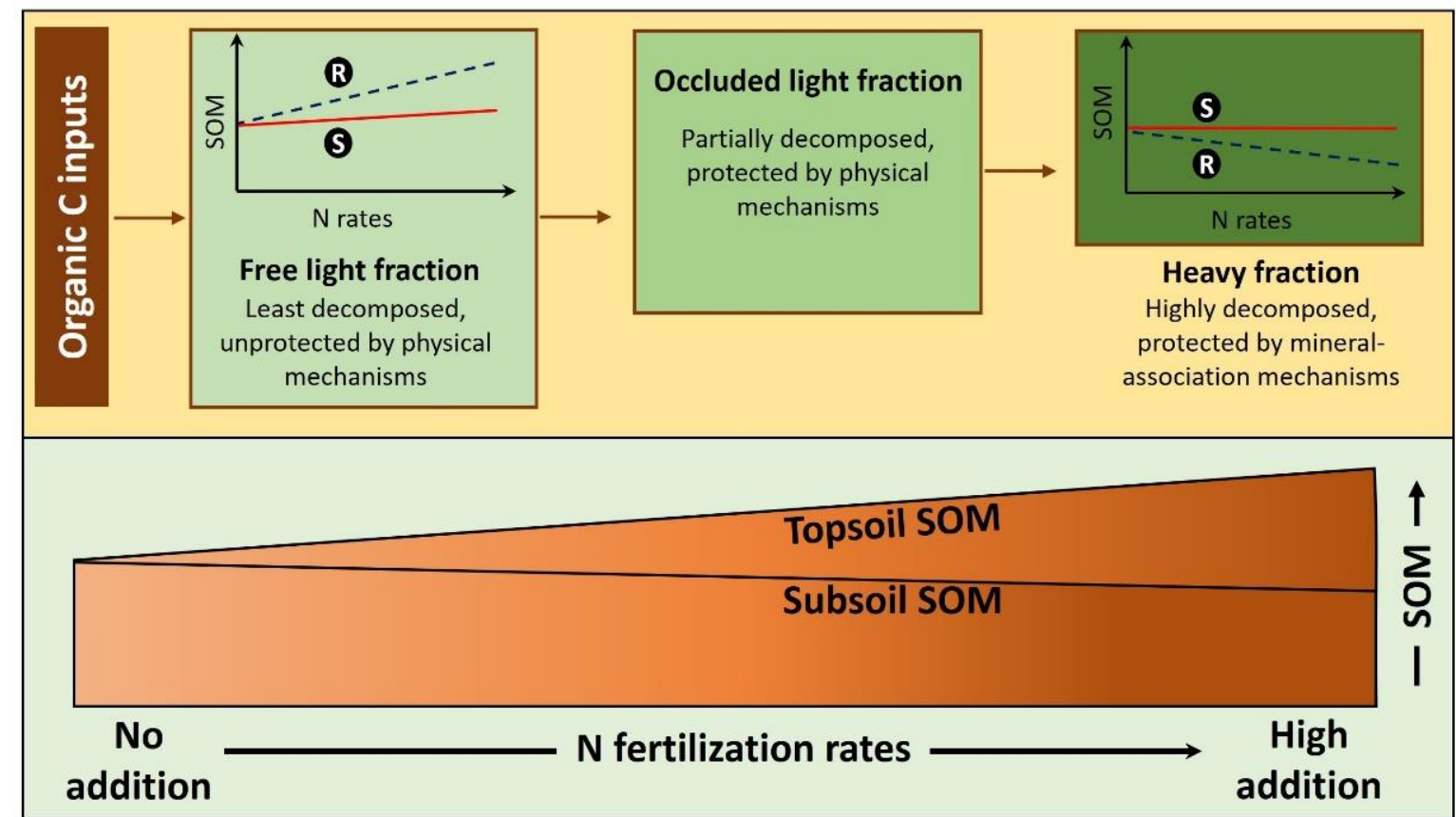

Figure S3-6. The stabilization of top- and subsoil soil organic matter (SOM) under longterm organic $\mathrm{C}$ inputs and $\mathrm{N}$ fertilization rates (lower part). The upper part represents the partitioning and stabilization (by different mechanisms) of added organic $\mathrm{C}$ into topsoil SOM fractions. The inset on free light fraction and heavy fraction shows the contribution of root dominated ( $\mathrm{R}$ in circle) or straw dominated ( $\mathrm{S}$ in circle) $\mathrm{C}$ inputs in $\mathrm{C}$ storage within $\mathrm{SOM}$ fraction along $\mathrm{N}$ fertilization rates.

The $\mathrm{C}$ contents in o-LF showed inconsistent results and were mainly affected by organic additions (Fig. S3-5c, d). The increase of C contents in o-LF with manure additions is consistent with other findings, where high aggregates formation to animal manure additions attributed to the increase of occlusion. The addition of manure along $\mathrm{N}$ fertilization can increase favorably 
root biomass (Hati et al., 2006) which are important for aggregate formation during growth (Denef et al., 2002) and decomposition (Majumder \& Kuzyakov, 2010; Shahbaz et al., 2016). The results, however, indicated that straw incorporation resists, while slurry addition favored the decreases of occluded $\mathrm{C}$ under increasing $\mathrm{N}$ fertilizer rates.

Overall, the SOM fractions (f-LF, o-LF and HF) are a sensitive indicator for evaluating changes in the soil quality, due to their vital role in nutrient cycling, SOM formation and soil structural development (Brevik et al., 2015; Schrumpf et al., 2013; Six et al., 2002). In our study, the C content of f-LF increased and of HF decreased with $\mathrm{N}$ fertilization, particularly when straw was absent (Fig. S3-5 and S3-6). In contrast, straw incorporation with $\mathrm{N}$ fertilization did not improve $\mathrm{C}$ contents of $\mathrm{f}-\mathrm{LF}$ but prevented the loss of $\mathrm{C}$ in $\mathrm{HF}$, which is less responsive to environmental changes. HF is considered the most important principal component for long-term SOM stabilization and it plays a pivotal role in soil structural development due to its strong bindings effect (Six et al., 2002). It has been shown that soil mineral particles (HF) with low SOM content exhibit faster dispersal in soil water compared with SOM-rich mineral fractions (Dexter and Czyz, 2000; Schjønning et al., 2009). Under low HF-associated SOM contents (as without straw additions, Fig. S3-5e), therefore, the prevalence of erosion-induced land degradation may increase possibly due to decrease of soil stability (Jiménez et al., 2016; Keesstra et al., 2016; Schjønning et al., 2009). In addition to the positive impact on mineral-associated SOM fraction, straw incorporation also provides soil physical protection against raindrop impact, resulting in reduced sediment detachment (Auerswald et al., 2009; Cerdà et al., 2016; Prosdocimi et al., 2016). Although, the overall effect of straw removal on bulk SOM (at our low-erosion study site) was minor, our findings however, support the potential benefits of straw incorporation (to protect decadal mineral-associated SOM from loss, and so may improve soil quality e.g. by mulching effect and improving soil structure) at exposed site suffering from high rates of erosion (Auerswald et al., 2009; Rodrigo Comino et al., 2016a, 2016b; Prosdocimi et al., 2016).

\subsubsection{Conclusions}

Nitrogen fertilization substantially increased $\mathrm{C}$ input by roots and straw into the soil because of higher plant productivity. Therefore, total SOM increased with $\mathrm{N}$ fertilizer rates during the 32 years in the Ap horizon (0-25 cm). Subsoil $(25-60 \mathrm{~cm})$ SOM, however, decreased with increasing $\mathrm{C}$ additions and $\mathrm{N}$ fertilization, probably because roots are relocated to the topsoil as the $\mathrm{N}$ supply increased. The increase of total SOM in the topsoil was driven mainly by the 
light fraction. Mineral-associated $\mathrm{C}$, however, decreased with increasing $\mathrm{C}$ input induced by $\mathrm{N}$ fertilization. Straw contributed little to the f-LF but prevented C losses from the mineralassociated HF. We ascribe this finding to different functions of roots (dominating crop residue input when straw was removed) and straw: Whereas under root-dominated residue input, light SOM fraction increased linearly with $\mathrm{N}$ fertilization, more easily decomposable straw was transformed (from f-LF) by microorganisms and stabilized on minerals thereafter. Accordingly, the often described minor increase of SOM with $\mathrm{N}$ fertilization reflects the opposite response of functionally variable SOM fractions to root and aboveground residues. This calls for caution when recommending removal of aboveground crop residues, such as straw, e.g. for bioenergy or other purposes. Although the overall effect of straw removals on bulk SOM can be minor, the SOM stabilized on mineral fractions, which are less responsive to environmental changes, could be lost over decades. In conclusion, organic residues increase the SOM level, but their effects strongly depend not only on their quantity (e.g. regulated by management and $\mathrm{N}$ fertilization) but also on the quality and functions of plant residues remaining and added on and in soil.

\subsubsection{Acknowledgements}

We acknowledge the financial support provided by German Academic Exchange Service (DAAD) to MS. We are thankful to Florian Hackmann for helping in field sampling. We also acknowledge the assistance of Ms. Karin Schmidt and Ms. Anita Krieger for C analysis. This study was funded by the Deutsche Forschungsgemeinschaft (DFG, projects HE 6726/6 and KU 1184/29). The field experiment is maintained by the Bayerische Landesanstalt für Landwirtschaft, Germany.

\subsubsection{References}

Auerswald K, Fiener P, Dikau R. 2009. Rates of sheet and rill erosion in Germany - A metaanalysis. Geomorphology 111: 182-193. DOI:10.1016/j.geomorph.2009.04.018

Barbera V, Poma I, Gristina L, Novara A, Egli M. 2010. Long-term cropping systems and tillage management effects on soil organic carbon stock and steady state level of C sequestration rates in a semiarid environment. Land degradation \& Development 23: 82-

91. DOI: 10.1002/ldr.1055.

Bolinder MA, Janzen HH, Gregorich EG, Angers DA, VandenBygaart AJ. 2007. An approach 
for estimating net primary productivity and annual carbon inputs to soil for common agricultural crops in Canada. Agriculture, Ecosystems \& Environment 118: 29-42. DOI: org/10.1016/j.agee.2006.05.013

Breulmann M, Boettger T, Buscot F, Gruendling R, Schulz E. 2016. Carbon storage potential in size-density fractions from semi-natural grassland ecosystems with different productivities over varying soil depths. Science of Total Environment 545: 30-39. DOI: 10.1016/j.scitotenv.2015.12.050.

Brevik EC, Cerdà A, Mataix-Solera J, Pereg L, Quinton JN, Six J, Van Oost K. 2015. The interdisciplinary nature of SOIL. SOIL 1: 117-129. DOI:10.5194/soil-1-117-2015

Castellano MJ, Mueller KE, Olk DC, Sawyer JE, Six J. 2015. Integrating plant litter quality, soil organic matter stabilization, and the carbon saturation concept. Global Change Biology 21: 3200-3209. DOI: 10.1111/gcb.12982.

Cerdà A, González-Pelayo Ó, Giménez-Morera A, Jordán A, Pereira P, Novara A, Brevik EC, Prosdocimi M, Mahmoodabadi M, Keesstra S, Orenes FG, Ritsema CJ. 2016. Use of barley straw residues to avoid high erosion and runoff rates on persimmon plantations in Eastern Spain under low frequency-high magnitude simulated rainfall events. Soil Research 54: 154-165. DOI: 10.1071/SR15092

Cerdà A, Lavee H, Romero-Díaz A, Hooke J, Montanarella L. 2010. Soil erosion and degradation in mediterranean-type ecosystem. Preface. Land Degradation \& Development 21: 71-74. DOI: 10.1002/ldr.968.

Cerli C, Celi L, Kalbitz K, Guggenberger G, Kaiser K. 2012. Separation of light and heavy organic matter fractions in soil - Testing for proper density cut-off and dispersion level. Geoderma 170: 403-416. DOI: 10.1016/j.geoderma.2011.10.009.

Cotrufo MF, Soong JL, Horton AJ, Campbell EE, Haddix ML, Wall DH, Parton WJ. 2015. Formation of soil organic matter via biochemical and physical pathways of litter mass loss. Nature Geoscience 8: 776-779. DOI: 10.1038/ngeo2520.

Cotrufo MF, Wallenstein MD, Boot CM, Denef K, Paul E. 2013. The Microbial EfficiencyMatrix Stabilization (MEMS) framework integrates plant litter decomposition with soil organic matter stabilization: Do labile plant inputs form stable soil organic matter? Global Change Biology 19: 988-995. DOI: 10.1111/gcb.12113. 
da Silva Oliveira DM, da Silva IR, de Oliveira Mendes G, de Almeida Vasconcelos A, Mayrink GCV, Verburg EEJ. 2016. Carbon fluxes from different pools in a mined area under reclamation in Minas Gerais state, Brazil. Land Degradation \& Development. DOI: $10.1002 /$ ldr.2601.

De Almeida RF, Silveira CH, Mota RP, Moitinho M, Arruda EM, De Sá Mendonça E, Scala NL, Wendling B. 2016. For how long does the quality and quantity of residues in the soil affect the carbon compartments and $\mathrm{CO}_{2}-\mathrm{C}$ emissions? Journal of Soils Sediments 1-11. DOI: $10.1007 / \mathrm{s} 11368-016-1432-3$.

Denef K, Six J, Merckx R, Paustian K. 2002. Short-term effects of biological and physical forces on aggregate formation in soils with different clay mineralogy. Plant \& Soil 246: 185-200. DOI: 10.1023/A:1020668013524.

Dexter AR, Czyz EA. 2000. Effects of soil management on the dispersibility of clay in a sandy soil. International Agrophysics 14: 269-272

Don A, Scholten T, Schulze E-D. 2009. Conversion of cropland into grassland: Implications for soil organic-carbon stocks in two soils with different texture. Journal of Plant Nutrition \& Soil Science 172: 53-62. DOI: 10.1002/jpln.200700158.

Dou X, He P, Cheng X, Zhou W. 2016. Long-term fertilization alters chemically-separated soil organic carbon pools: Based on stable C isotope analyses. Scientific Reports 6: 19061. DOI: 10.1038/srep19061.

Fanin N, Hättenschwiler S, Schimann H, Fromin N. 2015. Interactive effects of C, N and P fertilization on soil microbial community structure and function in an Amazonian rain forest. Functional Ecology 29: 140-150. DOI: 10.1111/1365-2435.12329.

Fontaine S, Barot S, Barré P, Bdioui N, Mary B, Rumpel C. 2007. Stability of organic carbon in deep soil layers controlled by fresh carbon supply. Nature 450: 277-80. DOI: 10.1038 /nature06275.

García-Orenes F, Roldán A, Morugán-Coronado A, Linares C, Cerdà A, Caravaca F. 2016. Organic fertilization in traditional mediterranean grapevine orchards mediates changes in soil microbial community structure and enhances soil fertility. Land Degradation \& Development 27: 1622-1628. DOI: 10.1002/ldr.2496.

Gleixner G. 2013. Soil organic matter dynamics: a biological perspective derived from the use 
of compound-specific isotopes studies. Ecological Research 28: 683-695. DOI: 10.1007/s11284-012-1022-9.

Gregorich EG, Beare MH, McKim UF, Skjemstad JO. 2006. Chemical and biological characteristics of physically uncomplexed organic matter. Soil Science Society of America Journal 70: 975. DOI: 10.2136/sssaj2005.0116.

Gregory AS, Kirk GJD, Keay CA, Rawlins BG, Wallace P, Whitmore AP. 2014. An assessment of subsoil organic carbon stocks in England and Wales. Soil Use \& Management 30: 10-22. DOI: 10.1111/sum.12085.

Gunina A, Kuzyakov Y. 2014. Pathways of litter C by formation of aggregates and SOM density fractions: Implications from 13C natural abundance. Soil Biology \& Biochemistry 71: 95-104. DOI: 10.1016/j.soilbio.2014.01.011.

Halvorson AD, Schlegel AJ. 2012. Crop rotation effect on soil carbon and nitrogen stocks under limited irrigation. Agronomy Journal 104: 1265-1273. DOI: 10.2134/agronj2012.0113.

Hati KM, Mandal KG, Misra AK, Ghosh PK, Bandyopadhyay KK.2006. Effect of inorganic fertilizer and farmyard manure on soil physical properties, root distribution, and wateruse efficiency of soybean in Vertisols of central India. Bioresource Technology 97: 2182-2188. DOI: 10.1016/j.biortech.2005.09.033.

Hege U, Offenberger K. 2006. Effect of differentiated mineral fertilization and organic manuring on yield, product quality and $\mathrm{N}$ balances in the international permanent organic nitrogen experiment (IOSDV) Puch. Archives of Agronomy \& Soil Science 52: 535-550. DOI: $10.1080 / 03650340600931650$.

Heitkamp F, Jäger N, Flessa H, Raupp J, Ludwig B. 2012b. Effect of fertilization on respiration from different sources in a sandy soil of an agricultural long-term experiment. Archives of Agronomy \& Soil Science 58: 933-944.

DOI:10.1080/03650340.2011.555762.

Heitkamp F, Wendland M, Offenberger K, Gerold G. 2012a. Implications of input estimation, residue quality and carbon saturation on the predictive power of the Rothamsted Carbon Model. Geoderma 170: 168-175. DOI: 10.1016/j.geoderma.2011.11.005.

Hobley E, Baldock J, Hua Q, Wilson B. 2016. Land-use contrasts reveal instability of subsoil 
organic carbon. Global Change Biology. DOI: 10.1111/gcb.13379.

Hobley EU, Wilson B. 2016. The depth distribution of organic carbon in the soils of eastern Australia. Ecosphere. DOI: 10.1002/ecs2.1214.

Jiménez MN, Fernández-Ondoño E, Ripoll MÁ, Castro-Rodríguez J, Huntsinger L, Navarro FB. 2016. Stones and Organic Mulches Improve the Quercus Ilex L. Afforestation Success Under Mediterranean Climatic Conditions. Land Degradation and Development 27: 357-365. DOI:10.1002/ldr.2250.

IUSS Working Group WRB. 2015. World Reference Base for Soil Resources 2014, update 2015 International soil classification system for naming soils and creating legends for soil maps. World Soil Resources Reports No. 106. FAO, Rome.

Johnson JMF, Novak JM, Varvel GE, Stott DE, Osborne SL, Karlen DL, Lamb JA, Baker J, Adler PR. 2014. Crop residue mass needed to maintain soil organic carbon levels: can it be determined? BioEnergy Research 7: 481-490. DOI: 10.1007/s12155-013-9402-8.

Kandeler E, Eder G, Sobotik M. 1994. Microbial biomass, N mineralization, and the activities of various enzymes in relation to nitrate leaching and root distribution in a slurryamended grassland. Biology \& Fertility of Soils 18: 7-12. DOI: 10.1007/BF00336437.

Keesstra S, Pereira P, Novara A, Brevik EC, Azorin-Molina C, Parras-Alcántara, L, Jordán A, Cerdà A. 2016. Effects of soil management techniques on soil water erosion in apricot orchards. Science of the Total Environment 551-552: 357-366.

DOI:10.1016/j.scitotenv.2016.01.182.

Khan SA, Mulvaney RL, Ellsworth TR, Boast CW. 2007. The myth of nitrogen fertilization for soil carbon sequestration. Journal of Environmental Quality 36: 1821-1832. DOI: 10.2134/jeq2007.0099.

Kuslien G, Rasmussen J, Kuzyakov Y, Eriksen J. 2014. Medium-term response of microbial community to rhizodeposits of white clover and ryegrass and tracing of active processes induced by $13 \mathrm{C}$ and $15 \mathrm{~N}$ labelled exudates. Soil Biology \& Biochemistry 76: 22-33. DOI: 10.1016/j.soilbio.2014.05.003.

Kuzyakov Y, Friedel J., Stahr K. 2000. Review of mechanisms and quantification of priming effects. Soil Biology \& Biochemistry 32: 1485-1498. DOI: 10.1016/S00380717(00)00084-5. 
Lange M, Eisenhauer N, Sierra CA, Bessler H, Engels C, Griffiths RI, Mellado-Vázquez PG, Malik AA, Roy J, Scheu S, Steinbeiss S, Thomson BC, Trumbore SE, Gleixner G. 2015. Plant diversity increases soil microbial activity and soil carbon storage. Nature Communication 6: 1-8. DOI: 10.1038/ncomms7707.

Larney FJ, Ellert BH, Olson AF. 2005. Carbon, ash and organic matter relationships for feedlot manures and composts. Canadian Journal of Soil Science 85: 261-264. DOI: 10.4141/S04-060.

Laudicina VA, Novara A, Barbera V, Egli M, Badalucco L. 2015. Long-term tillage and cropping system effects on chemical and biochemical characteristics of soil organic matter in a mediterranean semiarid environment. Land Degradation \& Development 26: 45-53. DOI: 10.1002/ldr.2293.

Lehmann J, Kleber M. 2015. The contentious nature of soil organic matter. Nature 528: 6068. DOI: $10.1038 /$ nature16069.

Lu M, Zhou X, Luo Y, Yang Y, Fang C, Chen J, Li B. 2011. Minor stimulation of soil carbon storage by nitrogen addition: A meta-analysis. Agriculture, Ecosystem \& Environment 140: 234-244. DOI: 10.1016/j.agee.2010.12.010.

Majumder B, Kuzyakov Y. 2010. Effect of fertilization on decomposition of ${ }^{14} \mathrm{C}$ labelled plant residues and their incorporation into soil aggregates. Soil \& Tillage Research 109: 94-102. DOI: 10.1016/j.still.2010.05.003.

Neff JC, Townsend AR, Gleixner G, Lehman SJ, Turnbull J, Bowman WD. 2002. Variable effects of nitrogen additions on the stability and turnover of soil carbon. Nature 419: 915-917. DOI: 10.1038/nature01136.

Novara A, Gristina L, Guaitoli F, Santoro A, Cerdà A. 2013. Managing soil nitrate with cover crops and buffer strips in Sicilian vineyards. Solid Earth 4: 255-262. DOI: 10.5194/se-4255-2013.

Novara A, Poma I, Sarno M, Venezia G, Gristina L. 2016. Long-term durum wheat-based cropping systems result in the rapid saturation of soil carbon in the mediterranean semiarid environment. Land degradation \& Development 27: 612-619. DOI: 10.1002/ldr.2468.

Ogle SM, Breidt FJ, Paustian K. 2005. Agricultural management impacts on soil organic 
carbon storage under moist and dry climatic conditions of temperate and tropical regions. Biogeochemistry 72: 87-121. DOI: 10.1007/s10533-004-0360-2.

Pabst H, Gerschlauer F, Kiese R, Kuzyakov Y. 2016. Land use and precipitation affect organic and microbial carbon stocks and the specific metabolic quotient in soils of eleven ecosystems of Mt. Kilimanjaro, Tanzania. Land Degradation \& Development 27: 592602. DOI: 10.1002/ldr.2406.

Poeplau C, Kätterer T, Bolinder MA. Börjesson G, Bertid A, Lugato E. 2015. Low stabilization of aboveground crop residue carbon in sandy soils of Swedish long-term experiments. Geoderma 237-238: 246-255. DOI: org/10.1016/j.geoderma.2014.09.010.

Powlson D, Glendining MJ, Coleman K, Whitmore AP. 2011. Implications for soil properties of removing cereal straw: results from long-term studies. Agronomy Journal 103: 279288. DOI:10.2134/agronj2010.0146s.

Prosdocimi M, Tarolli P, Cerdà A. 2016. Mulching practices for reducing soil water erosion: A review. In press, Earth-Science Reviews. DOI:10.1016/j.earscirev.2016.08.006

Qiao N, Xu X, Hu Y, Blagodatskaya E, Liu Y, Schaefer D, Kuzyakov Y. 2016. Carbon and nitrogen additions induce distinct priming effects along an organic-matter decay continuum. Scientific Reports 6: 1-8. DOI: 10.1038/srep19865.

Rasse DP, Rumpel C, Dignac M-F. 2005. Is soil carbon mostly root carbon? Mechanisms for a specific stabilisation. Plant \& Soil 269: 341-356. DOI: 10.1007/s11104-004-0907-y.

Rodrigo Comino J, Iserloh T, Lassu T, Cerdà A, Keestra SD, Prosdocimi M, Brings C, Marzen M, Ramos MC, Senciales JM, Ruiz Sinoga JD, Seeger M, Ries JB. 2016 a. Quantitative comparison of initial soil erosion processes and runoff generation in Spanish and German vineyards. Science of the Total Environment 565: 1165-1174. DOI:10.1016/j.scitotenv.2016.05.163.

Rodrigo Comino J, Quiquerez A, Follain S, Raclot D, Le Bissonnais Y, Casalí J, Giménez R, Cerdà A, Keesstra SD, Brevik EC, Pereira P, Senciales JM, Seeger M, Ruiz Sinoga JD, Ries JB. 2016b. Soil erosion in sloping vineyards assessed by using botanical indicators and sediment collectors in the Ruwer-Mosel valley. Agriculture Ecosystem and Environment 233: 158-170. DOI:10.1016/j.agee.2016.09.009

Rumpel C, Kögel-Knabner I. 2011. Deep soil organic matter-a key but poorly understood 
component of terrestrial C cycle. Plant \& Soil 338: 143-158. DOI: 10.1007/s11104-0100391-5.

Schjønning P, de Jonge LW, Olsen JE. Greve MH. 2009. Organic farming effects on clay dispersion in carbon-exhausted soils. ICROFS news, November/2009. Archived at http: //orgprints.org/18442.

Schrumpf M, Kaiser K, Guggenberger G, Persson T, Kögel-Knabner I, Schulze E-D. 2013. Storage and stability of organic carbon in soils as related to depth, occlusion within aggregates, and attachment to minerals. Biogeosciences 10: 1675-1691. DOI: 10.5194/bg-10-1675-2013.

Shahbaz M, Akhtar MJ, Ahmed W, Wakeel A. 2014. Integrated effect of different N-fertilizer rates and bioslurry application on growth and $\mathrm{N}$-use efficiency of okra (Hibiscus esculentus L.). Turkish Journal of Agriculture \& Forestory 38: 311-319. DOI: 10.3906/tar-1303-65.

Shahbaz M, Kuzyakov Y, Heitkamp F. 2016. Decrease of soil organic matter stabilization with increasing inputs: Mechanisms and controls. Geoderma. DOI: 10.1016/j.geoderma.2016.05.019.

Six J, Conant RT, Paul EA, Paustian K. 2002. Stabilization mechanisms of soil organic matter: Implications for C-saturation of soils. Plant \& Soil 241: 155-176. DOI: 10.1023/A:1016125726789.

Steinmann T, Welp G, Wolf A, Holbeck B, Große-Rüschkamp T, Amelung W. 2016. Repeated monitoring of organic carbon stocks after eight years reveals carbon losses from intensively managed agricultural soils in Western Germany. Journal of Plant Nutrition \& Soil Science 179: 355-366. DOI: 10.1002/jpln.201500503.

Stewart CE, Plante AF, Paustian K, Conant RT, Six J. 2008. Soil Carbon Saturation: Linking Concept and Measurable Carbon Pools. Soil Science Society of America Journal 72: 379-392. DOI: 10.2136/sssaj2007.0104.

Weyman-Kaczmarkowa W, Politycka B. 2002. Greenhouse medium enrichment with composted pig slurry: Effect on the rooting of pelargonium peltatum hort. cuttings and development of rhizosphere microflora. Polish Journal of Environmental Study 11: 6770. 
Withers PJA, Hodgkinson RA, Barberis E, Presta M, Hartikainen H, Quinton J, Miller N, Sisák I, Strauss P, Mentler A. 2007. An environmental soil test to estimate the intrinsic risk of sediment and phosphorus mobilization from European soils. Soil Use and Management 23: 57-70. DOI:10.1111/j.1475-2743.2007.00117.x

Yagüe MR, Domingo-Olivé F, Bosch-Serra AD, Poch RM, Boixadera J. 2016. Dairy cattle manure effects on soil quality: porosity, earthworms, aggregates and soil organic carbon fractions. Land Degradation \& Development 27: 1753-1762. DOI: 10.1002/ldr.2477

Zhang L, Unteregelsbacher S, Hafner S, Xu X, Schleuss P-M, Miehe G, Kuzyakov Y. 2016. Fate of organic and inorganic nitrogen in crusted and non-crusted kobresia grasslands. Land Degradation \& Development. DOI: 10.1002/ldr.2582. 


\section{Additional Study}

This chapter presents a study that is completed but the writing is still in progress. The goal is to present the short description of the work that has been done and that still needs to be done before submitting a manuscript. The presented results are not exhaustive but are selected because they enhance the understanding of SOM stabilization when crop residues are partially decomposed and labile $\mathrm{C}$ (such as root exudates) is available. The results present the potential of the future manuscript.

\section{Study 4 (in preparation)}

\section{Interactive effect of glucose and partially decomposed plant residues priming: A three} source partitioning study

\subsection{Background}

Crop residue return to the soil is aimed to improve SOM levels and soil physical properties. The pool size of SOM depends on the balance between SOM formation from added plant residue and roots decomposition and its mineralization to inorganic $\mathrm{C}$. Much is known about factors controlling residue and SOM decomposition rates, information related to how labile C inputs (e.g. exudates released by roots) can alter residues as well as then SOM stabilization is scare. Under natural conditions, labile $\mathrm{C}$ is usually released into the soil through root exudation. Glucose is an organic component that resembles the root exudates and it represents simple monosaccharides which are produced during cellulose decomposition. The availability of such labile substrate influence the microbial growth and activities (due to rapid $\mathrm{C}$ assimilation by microbes) which can affect decomposition of already degrading crop residues (present is soil) and SOM. The impact of contrasting substrates quality, separately i.e. less labile plant residues or labile C (such as glucose) additions on SOM is mostly studied. It has been reported that glucose and plant residues can prime the decomposition of SOM. However, we lack the knowledge about the simultaneous effects of glucose on SOM versus plant residue mineralization. Further, information related to combined effect of these substrates: labile $\mathrm{C}$ and especially partially decomposed residues (as under field conditions), on SOM is need to be investigated. 


\subsection{Objectives and hypotheses}

The aim of this study is to explore the responses of SOM versus residue mineralization in response to labile $\mathrm{C}$ (glucose) addition in a soil having partially decomposed wheat residues (leaves, root), over an incubation period of 3 months. The combined effect of residues plus glucose on SOM stabilization is also studied. We followed a three-source partitioning approach using dual isotopic labeling $\left({ }^{13} \mathrm{C}\right.$ and $\left.{ }^{14} \mathrm{C}\right)$ to partition the decomposition of glucose, residues and SOM. Specific objectives of this study were: (1) to compare the priming effects of glucose versus residues on SOM decomposition when they were added separately, (2) to differentiate the effects of glucose addition on SOM versus residue in soil-residue mixtures, (3) to provide insights into the possible consequences of glucose amendment on different $\mathrm{C}$ pools.

Two type of wheat residues are used representing contrasting quality i.e. easily decomposable leaves and recalcitrant to decomposition roots. To meet the study objectives, we hypothesized that: regardless of the type of plant residues glucose will be mineralized at the same rate, and therefore the magnitude of priming will increase at the same rate between glucose+leaves and glucose+roots treated soils. The base of this hypothesis is that priming of SOM mineralization is facilitated by increased availability of labile $\mathrm{C}$ for microbial activity. That means the rate of priming is constrained by the maximum potential activity of microorganisms and that microbial biomass composition/size and residues/SOM recalcitrance are soil-specific limitations on SOM mineralization.

\subsection{Methods}

We used dual ${ }^{13} \mathrm{C} /{ }^{14} \mathrm{C}$ isotopic labeling approach to partition soil $\mathrm{CO}_{2}$ efflux and $\mathrm{C}$ pools into three sources: glucose $\left({ }^{14} \mathrm{C}\right)$, plant residues $\left({ }^{13} \mathrm{C}\right)$ and SOM. To obtain partially decomposed plant residues, ${ }^{13} \mathrm{C}$ labeled wheat residue (leaves, stems separately) were preincubated in the soil for 30 days, to reach a constant residue mineralization rate (Fig. 4-1). This was done because under natural conditions during residues decomposition (partial degradation) labile substrate (such as root exudates) are released to the soil. After partial degradation of residue, soil alone or with residues was amended with or not with ${ }^{14} \mathrm{C}$-labeled glucose solution $(160 \mu \mathrm{g}$ $\mathrm{C} \mathrm{g} \mathrm{g}^{-1}$ ) over a period of 3 months at $22{ }^{\circ} \mathrm{C}$ (Fig. 4-1). Accordingly, six treatments were established (Soil alone, Soil+glucose, Soil+leaves, Soil+leaves+glucose, Soil+roots, Soil+roots+glucose) with three replicates. To see the changes in microbial biomass over the 
incubation period, the microbial biomass $\mathrm{C}$ contents were estimated before the glucose additions (at day 30 of pre-incubation) and at the end of incubation.

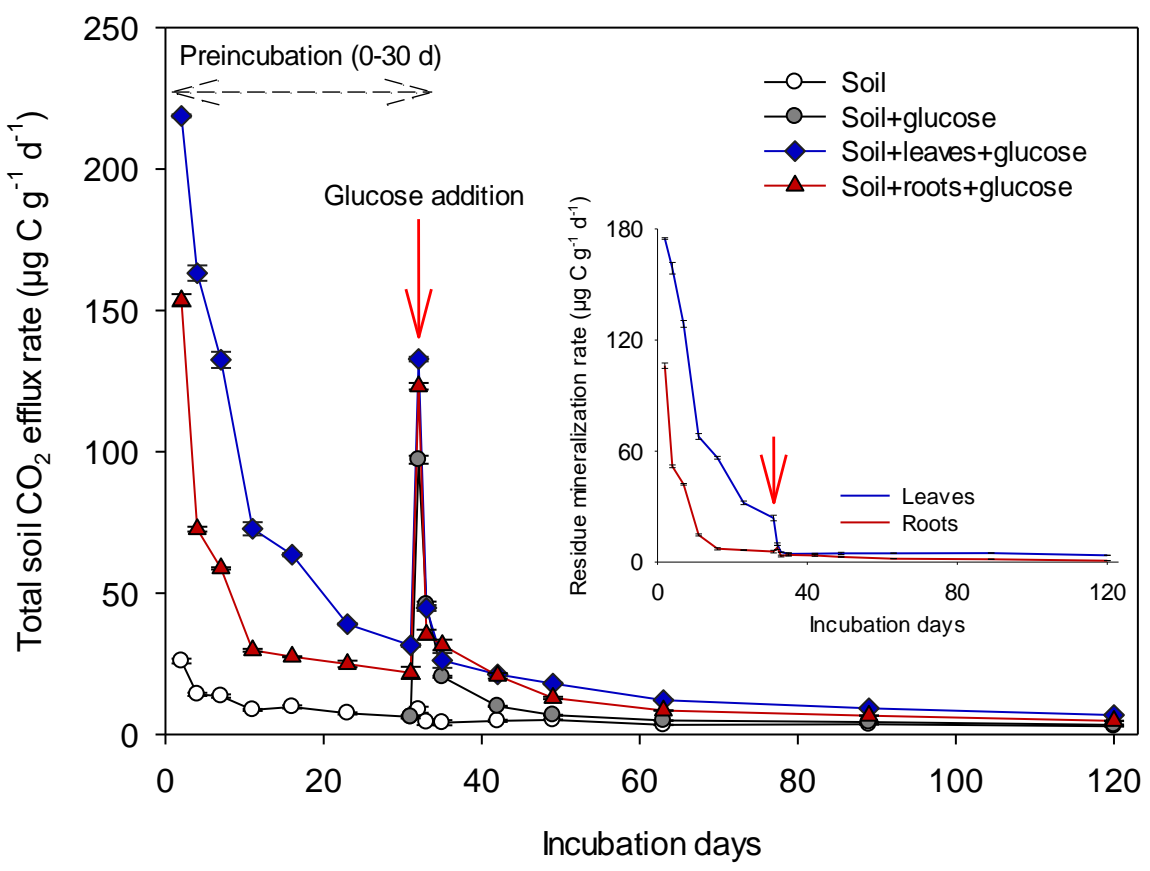

Figure 4-1: Mineralization rate of total soil $\mathrm{CO}_{2}$ efflux, before (during 30 day preincubation period) and after glucose additions. The inset represent the mineralization rate of wheat residues (leaves and stems). Error bar represents standard error $(n=3)$

\section{Results and discussion}

\subsubsection{Glucose and residue mineralization}

Glucose decomposition was calculated based on the ${ }^{14} \mathrm{CO}_{2}$ efflux. The results show that glucose mineralization rate was dependent on the residue quality. Glucose mineralization rate was highest during the initial days (up to 11 days) and remained similar between with roots and alone soil additions. Adding with leaves, glucose mineralization increased by $17 \%$ than with roots or alone soil (Fig. 4-2).

After glucose addition, mineralization rate of leaves declined up to $65 \%$ and of roots remained unaffected (Fig. 4-1). However, at the end of incubation, the cumulative leaves mineralization under glucose addition also reached to the similar level as without glucose additions. A fast 
decline in leaves residues but high glucose mineralization indicated a strong shift of residue decomposing microorganism toward added glucose C. Root mineralization rate remained unaffected after glucose additions. This indicates that roots decomposition was already reached to a stable conditions (i.e. slow-growing) and the glucose mineralization was not mainly due to the root decomposing microorganisms.

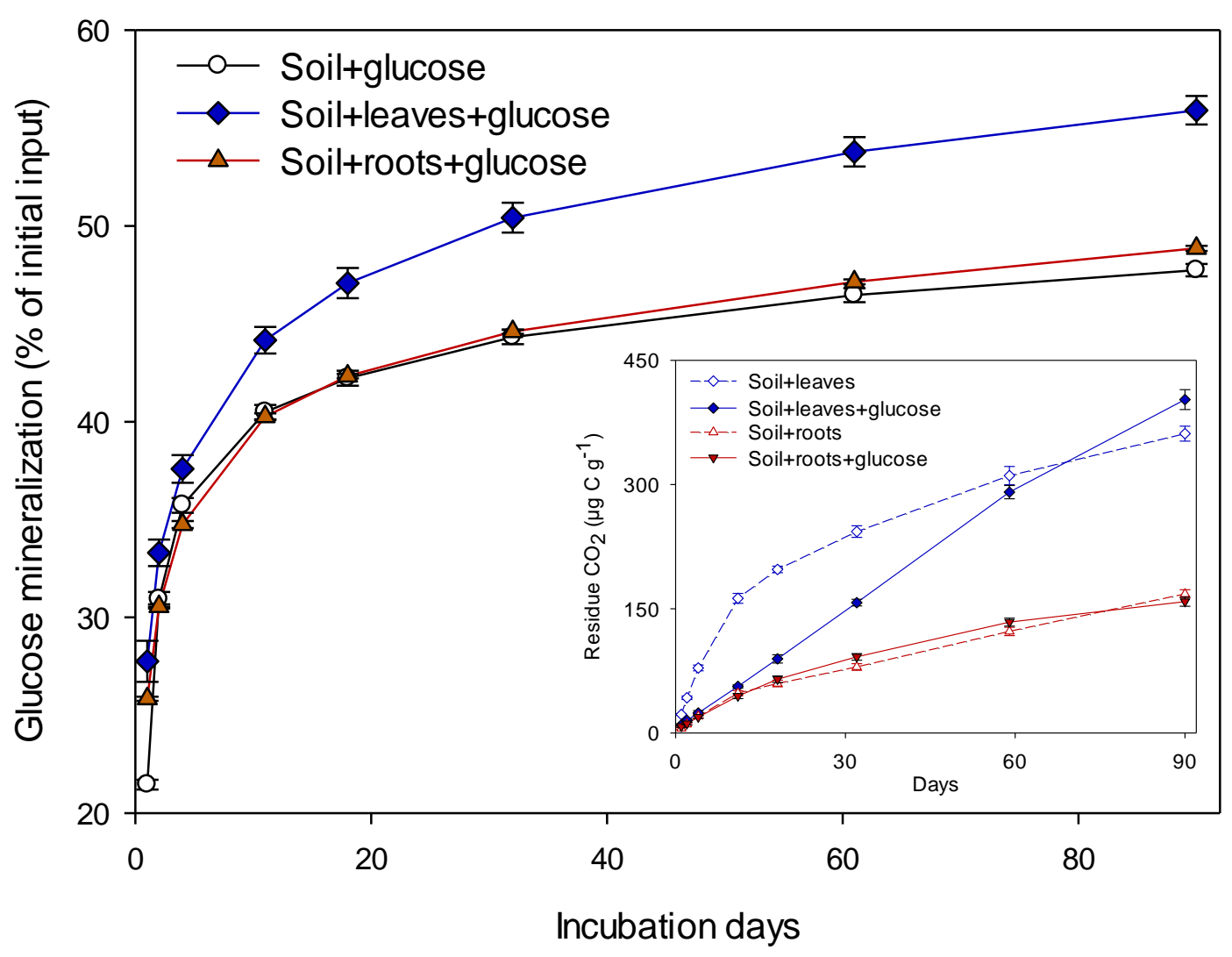

Figure 4-2: Cumulative glucose mineralization over the incubation period depending on plant residue type. The inset shows cumulative residue derived $\mathrm{CO}_{2}$ with or without glucose additions. Error bar represents standard error of mean $(n=3)$

\subsubsection{Priming effect}

The addition of glucose to the alone soil induced a cumulative positive priming effect $(0.19 \mathrm{mg}$ $\mathrm{C}^{-1}$ ) on SOM over 90 days, a much higher (42\%) effect than residue-induced priming in the presence of glucose. Compared to soils with only residue amended, glucose and residue added in combination increased SOM mineralization by $44 \%$. This increase in priming effect was solely due to the contribution of primed SOM during the initial (up to 11 days) period of glucose 
mineralization (Fig. 4-3). Meaning that microbial activation after glucose addition caused mainly SOM mineralization.

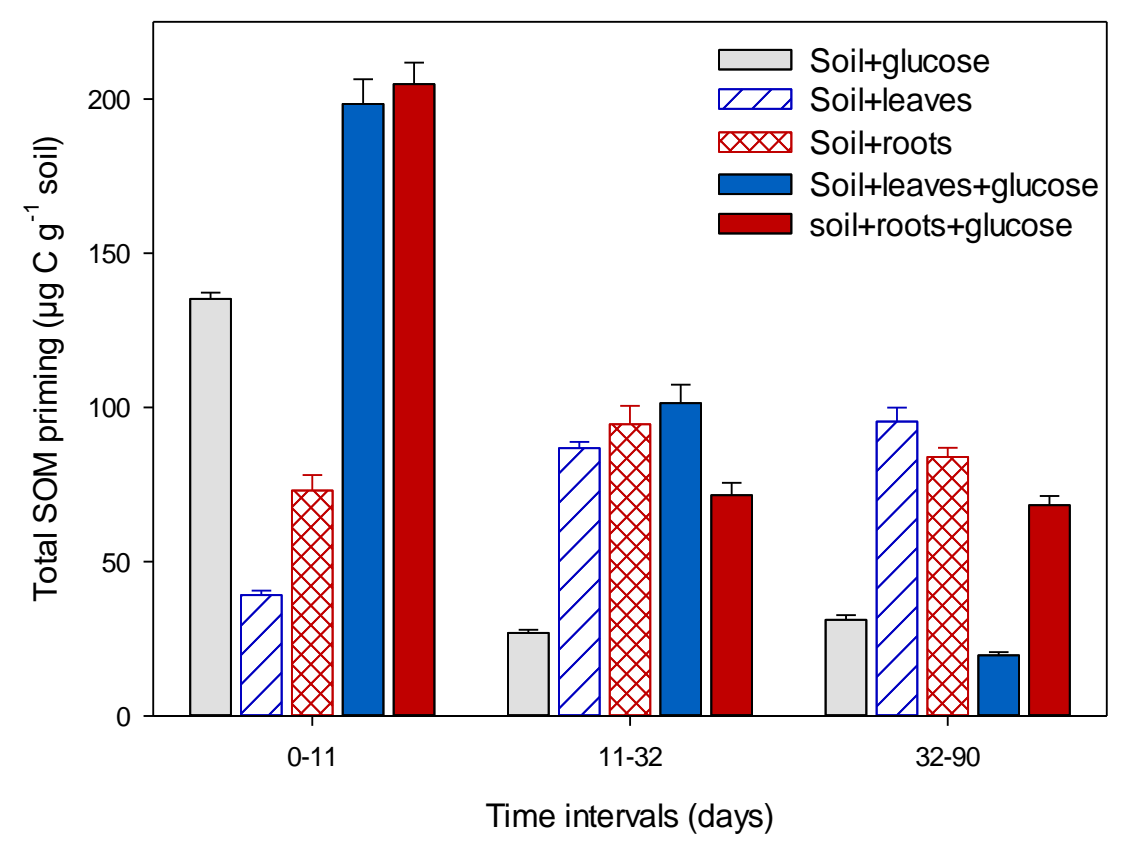

Figure 4-3: Cumulative soil organic matter (SOM) priming effect at different time intervals, depending on: time, glucose and residue addition, type of residue and combination of glucose and residues. Error bar represents standard error of mean $(n=3)$

To assess the priming effects of glucose on residue (i.e. leaves and roots) versus SOM in the soil-residue mixture, the residue- and SOM-derived $\mathrm{CO}_{2}$ effluxes from the Soil+residue+glucose amendments were compared to those with soil+residue treatments. The results showed that glucose had opposite priming effect on residue and SOM decomposition. During the initial period (up to 11 days of addition), glucose caused a strong priming effect on SOM (higher when added with leaves than roots), but thereafter cumulative priming effect was decreased (Fig. 4-4). The total SOM priming effect due to glucose addition in residue treatments was up to $120 \mu \mathrm{g} \mathrm{C} \mathrm{g}^{-1}$ soil. In contrast, the priming effect of glucose on residue mineralization was negative (slightly for roots and strongly for leaves) in the initial 2 weeks but then became positive. Accordingly, residue mineralization with glucose gradually reached to the level without glucose additions after 90 days (Inset Fig. 4-2, Fig. 4-4). 


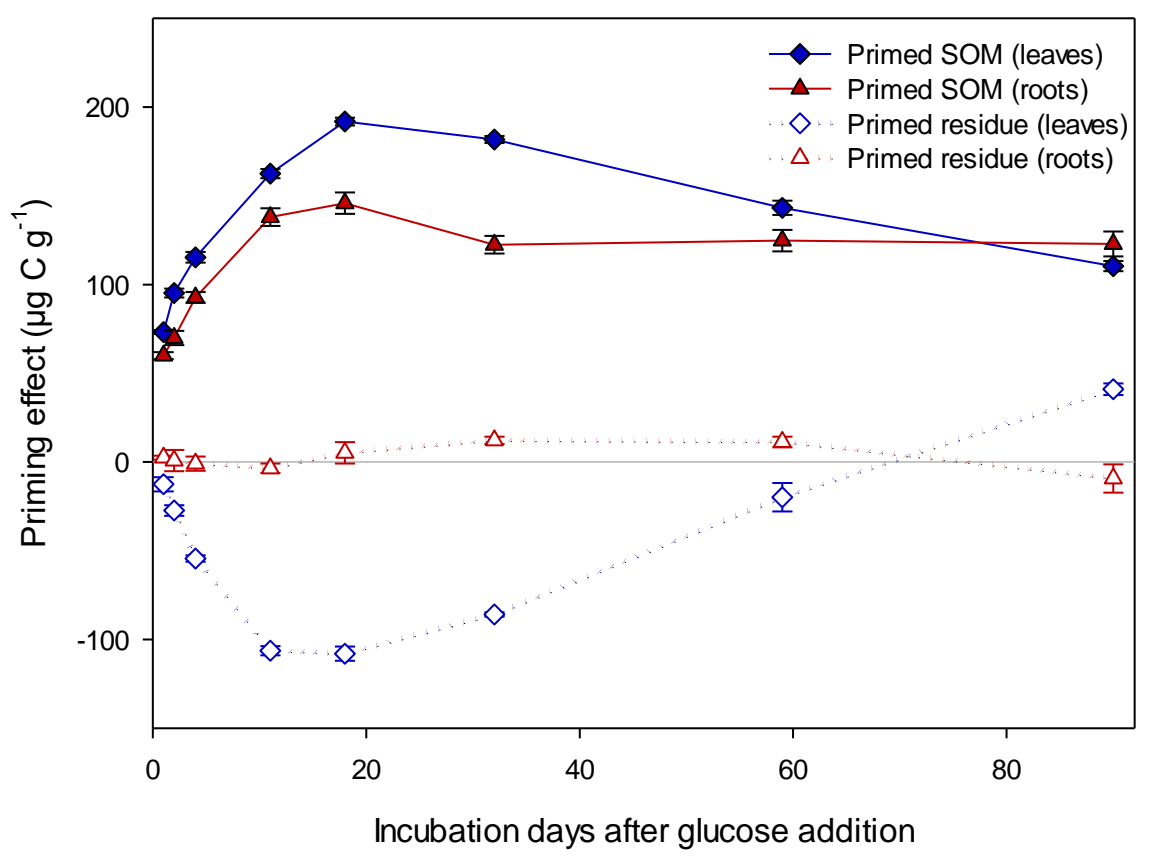

Figure 4-4: Priming effects of glucose on the mineralization of residues (leaves and roots) versus soil organic matter (SOM) in soil-residue mixtures. The priming effects are differences in SOM mineralization between the Soil+residue+glucose and soil+residue amendments. Error bars represent standard error of mean $(n=3)$.

\subsubsection{Microbial biomass}

To assess the changes in residue and SOM feeding microorganisms, the microbial biomass $\mathrm{C}$ were estimated at the time of glucose additions and at the end of incubation. At the end of incubation, a higher amount of microbial biomass was recorded under leaves addition followed by root additions than alone soil control. Partitioning of microbial biomass $\mathrm{C}$ into various sources revealed that a remarkable amount of SOM originated $\mathrm{C}$ caused an increase in microbial biomass $\mathrm{C}$ either with alone residues, or the combination of glucose and residues. Glucose increased microbial biomass $\mathrm{C}$, which was mainly due to SOM decomposing microorganisms. However, a significant portion of residue decomposing microorganism was lost after glucose addition (Fig. 4-5). 


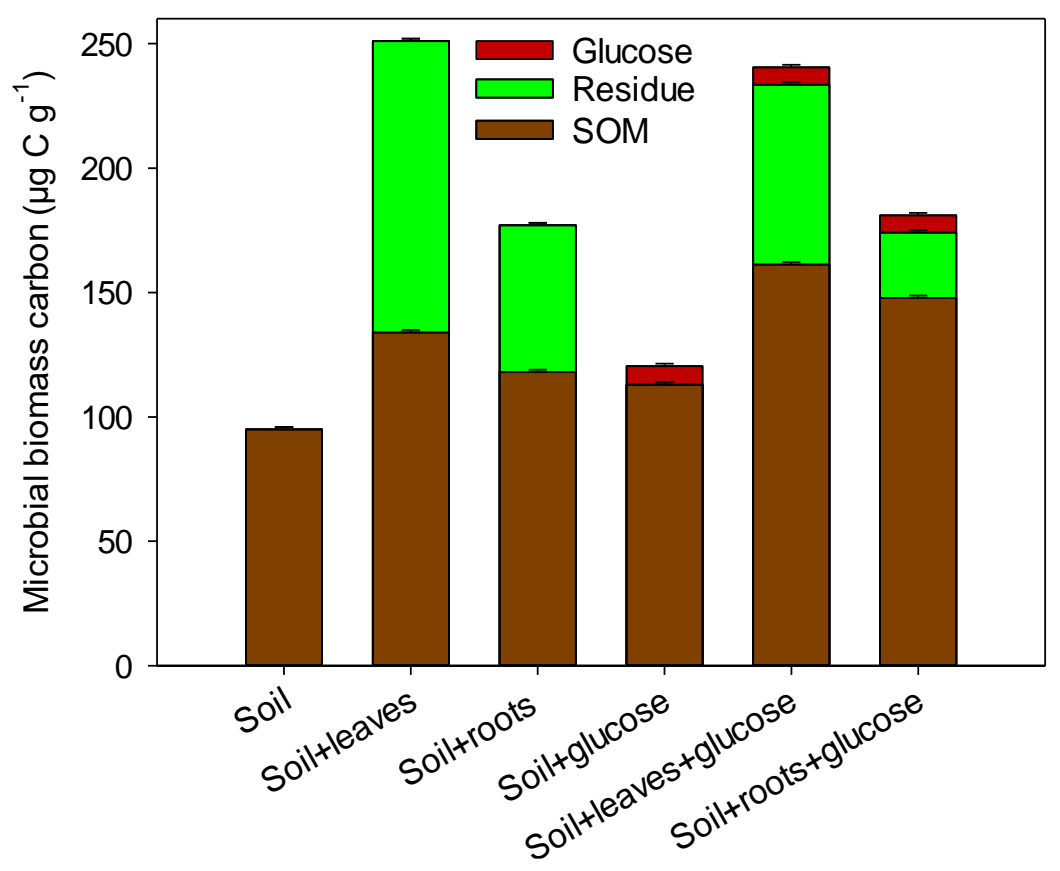

Figure 4-5: Microbial biomass carbon originating from three sources: soil organic matter $(\mathrm{SOM})$, residue and glucose following incubation. Error bars represent standard error of mean $(n=3)$.

\subsubsection{Conclusions}

Increased SOM- but not residue-derived $\mathrm{C}$ in microbial biomass suggested that glucose caused a preferential microbial utilization of SOM over crop residues. This was evident by high SOM priming under glucose addition. Glucose additions caused contrasting priming effect on residues and SOM. Residue mineralization rates decreased (strongly of leaves) but SOM decomposition strongly increased after glucose addition. Thereafter (after ca. 2 weeks), residue mineralization gradually reached to the residue mineralization levels without glucose addition. Overall, addition of glucose after residues preincubation (30 days of decomposition) enhanced the SOM priming significantly, either glucose was added alone or in combination with residues. Glucose induced priming effect was mainly evident by SOM decomposing microorganisms. Further, the priming effects of residue on SOM are changed by the presence of glucose. 


\section{General conclusions}

A combined approach of controlled laboratory experiments and a less controlled long-term (32 year) field experiment enhanced the understanding of SOM formation and stabilization. SOM stabilization is related to soil physical properties, source and amount of crop residue inputs (root or straw dominated), priming effects and residue C partitioning between SOM fractions. Addition of large amounts of crop residues improved soil physical structure, but efficiency of residue $\mathrm{C}$ stabilization in SOM was lower than for smaller additions. Increased C input was associated with a low percentage of residues physically protected within aggregates and a high rate of SOM mineralization. This explained the reduced long-term C stabilization in SOM with increasing residue additions.

A more precise effect of crop residue quality and quantity on SOM stabilization was investigated, especially in terms of SOM priming. An increased level of addition led to a disproportionate increase in the residue mineralization rate for aboveground residues, but not for roots (belowground). SOM priming decreased with greater residue additions for all residue types. However, we demonstrated that root residues induced faster and stronger SOM priming than aboveground residues. This was attributed to the recalcitrance of roots to decomposition, which causes microorganisms to decompose SOM for nutritional needs by increasing their enzyme activities. Remarkably, the amount of primed $\mathrm{C}$ and enzyme activities were mainly correlated with the residue-feeding microorganisms, indicating a possible link between the residue-feeding microbial fraction and priming. To describe this link, we suggested a unifying logistic model for all residue types describing SOM priming as a function of residue mineralization. We recorded threshold levels for the onset of strong priming in terms of the fraction of mineralized residues at high additions: ca. 20, 44 and 51\% mineralization of roots, stems and leaves, respectively. Therefore, we concluded that the quality of added substrate is crucial for microbe-mediated SOM decomposition.

The density fractionation approach revealed the importance of crop residue quality in $\mathrm{C}$ partitioning between SOM fractions and role of these fractions in determining SOM contents in the field experiment. The $\mathrm{C}$ input in the field experiment was mainly ascribed from two main sources: root- or straw, which were both increased by $\mathrm{N}$ fertilization. The topsoil SOM contents increased with higher input ( $\mathrm{N}$ induced) to only a limited extent, and was mainly accounted for by the free light fraction of SOM. Mineral-associated C, however, decreased with the increasing 
$\mathrm{C}$ input induced by $\mathrm{N}$ fertilization. The aboveground residue (straw) contributed little to the free light fraction, but prevented C losses from the mineral-associated SOM fraction. We ascribed this finding to the different behaviors of roots (the dominant crop residue input when straw is removed) and straw: Under root-dominated residue input, the light SOM fraction increased linearly with $\mathrm{N}$ fertilization, whereas the more easily decomposable straw was transformed (from the light SOM fraction) by microorganisms and stabilized in the mineralassociated fraction thereafter. Although the overall effect of straw addition on bulk SOM was minor, it prevented the loss of mineral-associated SOM fractions (observed when straw removed), which are stable over decades. In contrast to topsoil, the subsoil $(25-60 \mathrm{~cm}) \mathrm{SOM}$ contents decreased with increasing $\mathrm{C}$ additions (along with $\mathrm{N}$ fertilization), probably because roots were more localized in the topsoil as $\mathrm{N}$ supply increased. This was contrary to our hypothesis, i.e. high $\mathrm{C}$ inputs at the surface may cause high subsoil SOM accumulation.

In conclusion, organic residues improve soil structure and SOM levels, but their effects strongly depend on not only their quantity (which can be managed through additions) but also on the quality and behavior of plant residues added to the soil. Roots and aboveground residues exhibit variable effects and functions for SOM stabilization. Root-dominated C inputs contribute greatly to the unprotected or less decomposed SOM fractions (free light fraction) for a longer period than aboveground plant residues. Although roots are more recalcitrant to decomposition than aboveground residues, they have a lower mineralization threshold at which SOM priming increases. Therefore, in addition to SOM destabilization through priming, root additions may result in lower levels of microbially-mediated stable SOM formation following residue decomposition, which is necessary for mineral-associated stable SOM formation. Although larger aboveground residue additions (leaves, stems) improve soil aggregation and protect the mineral-associated SOM fraction, low physical protection and high mineralization decreases the efficiency of their stabilization in SOM. The often-described minor increase of SOM with high crop residue inputs emerges from the opposing responses of functionally variable SOM fractions to root and aboveground residues.

Overall, our findings connect the quantity and quality of crop residues for better prediction and understanding of the mineralization and stabilization of SOM. In order to sustain sufficient SOM levels, efficient crop residue management under specific field conditions is required. This is important when recommending removal of aboveground crop residues, such as straw, e.g. for bioenergy purposes. 


\section{References}

Abiven, S., Menasseri, S., Chenu, C., 2009. The effects of organic inputs over time on soil aggregate stability-A literature analysis. Soil Biol. Biochem. 41, 1-12. http://dx.doi.org/10.1016/j.soilbio.2008.09.015

Adair, E.C., Parton, W.J., Del Grosso, S.J., Silver, W.L., Harmon, M.E., Hall, S.A., Burke, I.C., Hart, S.C., 2008. Simple three-pool model accurately describes patterns of longterm litter decomposition in diverse climates. Glob. Chang. Biol. 14, 2636-2660. doi:10.1111/j.1365-2486.2008.01674.x

Andruschkewitsch, R., Geisseler, D., Dultz, S., Joergensen, R., Ludwig, B., 2014. Rate of soil-aggregate formation under different organic matter amendments - a short-term incubation experiment. J. Plant Nutr. Soil Sci. 177, 297-306. doi:10.1002/JPLN.201200628

Angers, D.A., Recous, S., Aita, C., 1997. Fate of carbon and nitrogen in water-stable aggregates during decomposition of $13 \mathrm{C} 15 \mathrm{~N}$-labelled wheat straw in situ. Eur. J. Soil Sci. 48, 295-300. doi:10.1111/j.1365-2389.1997.tb00549.x

Bertrand, I., Chabbert, B., Kurek, B., Recous, S., 2006. Can the biochemical features and histology of wheat residues explain their decomposition in soil? Plant Soil. 281, 291307. doi:10.1007/s11104-005-4628-7

Berg B, McClaugherty C (2003) Plant litter - Decomposition, Humus Formation, Carbon Sequestration. Springer, Berlin

Blagodatskaya, E., Khomyakov, N., Myachina, O., Bogomolova, I., Blagodatsky, S., Kuzyakov, Y., 2014. Microbial interactions affect sources of priming induced by cellulose. Soil Biol. Biochem. 74, 39-49. doi:10.1016/j.soilbio.2014.02.017

Blagodatskaya, E., Yuyukina, T., Blagodatsky, S., Kuzyakov, Y., 2011. Three-sourcepartitioning of microbial biomass and of $\mathrm{CO}_{2}$ efflux from soil to evaluate mechanisms of priming effects. Soil Biol. Biochem. 43, 778-786. doi:10.1016/j.soilbio.2010.12.011

Blagodatskaya, E., Kuzyakov, Y., 2008. Mechanisms of real and apparent priming effects and their dependence on soil microbial biomass and community structure: critical review. Biol. Fertil. Soils. 45, 115-131. doi:10.1007/s00374-008-0334-y 
Bronick, C.J, Lal, R., 2005. Soil structure and management: a review. Geoderma 124:3-22. http://dx.doi.org/10.1016/j.geoderma.2004.03.005

Castellano, M.J., Mueller, K.E., Olk, D.C., Sawyer, J.E., Six, J., 2015. Integrating plant litter quality, soil organic matter stabilization, and the carbon saturation concept. Glob. Chang. Biol. 21, 3200-3209. doi:10.1111/gcb.12982

Chen, R., Senbayram, M., Blagodatsky, S., Myachina, O., Dittert, K., Lin, X., Blagodatskaya, E., Kuzyakov, Y., 2014. Soil C and N availability determine the priming effect: Microbial N mining and stoichiometric decomposition theories. Glob. Chang. Biol. 20, 2356-2367. doi:10.1111/gcb.12475

Christensen, B. T., 1996. Matching measurable soil organic matter fractions with conceptual pools in simulation models of carbon turnover: revision of model structure. In Evaluation of soil organic matter models (pp. 143-159). Springer Berlin Heidelberg.

Cotrufo, M.F., Wallenstein, M.D., Boot, C.M., Denef, K., Paul, E., 2013. The Microbial Efficiency-Matrix Stabilization (MEMS) framework integrates plant litter decomposition with soil organic matter stabilization: Do labile plant inputs form stable soil organic matter? Glob. Chang. Biol. 19, 988-995. doi:10.1111/gcb.12113

Don, A., Scholten, T., Schulze, E.-D., 2009. Conversion of cropland into grassland: Implications for soil organic-carbon stocks in two soils with different texture. J. Plant Nutr. Soil Sci. 172, 53-62. doi:10.1002/jpln.200700158

Elliott, E.T., 1986. Aggregate structure and carbon, nitrogen, and phosphorus in native and cultivated soils. Soil Sci. Soc. Am. J. 50, 627-633. doi:10.2136/sssaj1986.03615995005000030017x

Fontaine, S., Barot, S., Barré, P., Bdioui, N., Mary, B., Rumpel, C., 2007. Stability of organic carbon in deep soil layers controlled by fresh carbon supply. Nature 450, 277-80. doi:10.1038/nature06275

Fontaine, S., Mariotti, A., Abbadie, L., 2003. The priming effect of organic matter: a question of microbial competition? Soil Biol. Biochem. 35, 837-843. doi:10.1016/S00380717(03)00123-8

Freibauer, A., Rounsevell, M., Smith, P., Verhagen, J., 2004. Carbon sequestration in the agricultural soils of Europe. Geoderma. 122, 1-23. 
http://dx.doi.org/10.1016/j.geoderma.2004.01.021

Garnett, T., Appleby, M.C., Balmford, A., Bateman, I.J., Benton, T.G., Bloomer, P., Burlingame, B., Dawkins, M., Dolan, L. et al., 2013. Sustainable intensification in agriculture: premises and policies. Science 341, 33-34. doi:10.1126/science.1234485

Gong, W., Yan, X., Wang, J., Hu, T., Gong, Y., 2009. Long-term manure and fertilizer effects on soil organic matter fractions and microbes under a wheat-maize cropping system in northern China. Geoderma 149, 318-324. doi:10.1016/j.geoderma.2008.12.010

Gregory, A.S., Kirk, G.J.D., Keay, C.A., Rawlins, B.G., Wallace, P., Whitmore, A.P., 2014. An assessment of subsoil organic carbon stocks in England and Wales. Soil Use Manag. 30, 10-22. doi:10.1111/sum.12085

Guenet, B., Neill, C., Bardoux, G., Abbadie, L., 2010. Is there a linear relationship between priming effect intensity and the amount of organic matter input? Appl. Soil Ecol. 46, 436-442. http://dx.doi.org/10.1016/j.apsoil.2010.09.006

Gulde, S., Chung, H., Amelung, W., Chang, C., Six, J., 2008. Soil Carbon Saturation Controls Labile and Stable Carbon Pool Dynamics. Soil Sci. Soc. Am. J. 72, 605-612. doi:10.2136/sssaj2007.0251

Gunina, A., Kuzyakov, Y., 2015. Sugars in soil and sweets for microorganisms: Review of origin, content, composition and fate. Soil Biol. Biochem. 90, 87-100. http://dx.doi.org/10.1016/j.soilbio.2015.07.021

Hassink, J., Whitmore, A.P., 1997. A Model of the Physical Protection of Organic Matter in Soils. Soil Sci. Soc. Am. J. 61, 131-139. doi:10.2136/sssaj1997.03615995006100010020x

Haynes, R.J., Naidu, R., 1998. Influence of lime, fertilizer and manure applications on soil organic matter content and soil physical conditions: a review. Nutr. Cycl. Agroecosys. 51, 123-137. doi: 10.1023/A:1009738307837

Hege, U., Offenberger, K., 2006. Effect of differentiated mineral fertilization and organic manuring on yield, product quality and $\mathrm{N}$ balances in the international permanent organic nitrogen experiment (IOSDV) Puch. Arch. Agron. Soil Sci. 52, 535-550. doi:10.1080/03650340600931650

Heitkamp, F., Raupp, J., Ludwig, B., 2011. Effects of fertilizer type and rate on labile soil 
fractions of a sandy Cambisol-long-term and short-term dynamics. J. Plant Nutr. Soil Sci. 174, 121-127. doi:10.1002/jpln.201000121

Heitkamp, F., Wendland, M., Offenberger, K., Gerold, G., 2012. Implications of input estimation, residue quality and carbon saturation on the predictive power of the Rothamsted Carbon Model. Geoderma 170, 168-175.

doi:10.1016/j.geoderma.2011.11.005

Hobley, E., Baldock, J., Hua, Q., Wilson, B., 2016. Land-use contrasts reveal instability of subsoil organic carbon. Glob. Chang. Biol. doi:10.1111/gcb.13379

Hobley, E.U., Wilson, B., 2016. The depth distribution of organic carbon in the soils of eastern Australia. Ecosphere 7. doi:10.1002/ecs2.1214

Houghton, R., 2012. Historic changes in terrestrial carbon storage. Recarbonization Biosph. 51-55. doi:10.1007/978-94-007-4159-1

IPCC - Intergovernmental Panel on Climate Change [WWW Document], 2007. URL https://www.ipcc.ch/publications_and_data/publications_ipcc_fourth_assessment_report _synthesis_report.htm

IUSS Working Group WRB. 2015. World Reference Base for Soil Resources 2014, update 2015 International soil classification system for naming soils and creating legends for soil maps. World Soil Resources Reports No. 106. FAO, Rome.

Jäger, N., Stange, C.F., Ludwig, B., Flessa, H., 2011. Emission rates of N2O and CO2 from soils with different organic matter content from three long-term fertilization experiments—a laboratory study. Biol. Fertil. Soils 47, 483-494. doi:10.1007/s00374011-0553-5

Johnson, J.M.F., Novak, J.M., Varvel, G.E., Stott, D.E., Osborne, S.L., Karlen, D.L., Lamb, J.A., Baker, J., Adler, P.R., 2014. Crop Residue Mass Needed to Maintain Soil Organic Carbon Levels: Can It Be Determined? BioEnergy Res. 7, 481-490. doi:10.1007/s12155013-9402-8

Keating, B.A., Herrero, M., Carberry, P.S., Gardner, J., Cole, M.B., 2014. Food wedges: Framing the global food demand and supply challenge towards 2050. Glob. Food Sec. 3, 125-132. doi:10.1016/j.gfs.2014.08.004

Khan, S., Mulvaney, R.L., Ellsworth, T.R., Boast, C.W., 2007. The myth of nitrogen 
fertilization for soil carbon sequestration. J. Environ. Qual. 36, 1821-32.

doi:10.2134/jeq2007.0099

Kögel-Knabner, I., Guggenberger, G., Kleber, M., Kandeler, E., Kalbitz, K., Scheu, S.,

Eusterhues, K., Leinweber, P., 2008. Organo-mineral associations in temperate soils:

Integrating biology, mineralogy, and organic matter chemistry. J. Plant Nutr. Soil Sci.

171, 61-82. doi:10.1002/jpln.200700048

Krull, E.S., Baldock, J.A., Skjemstad, J.O., 2003. Importance of mechanisms and processes of the stabilisation of soil organic matter for modelling carbon turnover. Funct. Plant Biol. 30, 207-222. doi:10.1071/FP02085

Kuzyakov, Y., Friedel, J.., Stahr, K., 2000. Review of mechanisms and quantification of priming effects. Soil Biol. Biochem. 32, 1485-1498. doi:10.1016/S0038-0717(00)000845

Lal, R., 2004. Soil carbon sequestration impacts on global climate change and food security. Science 304, 1623-1627. DOI: 10.1126/science.1097396

Lal, R., Lorenz, K., Hüttl, R.F., Schneider, B.U., von Braun, J. (Eds.), 2012. Recarbonization of the Biosphere. Springer Netherlands, Dordrecht. doi:10.1007/978-94-007-4159-1

Lehmann, J., Kleber, M., 2015. The contentious nature of soil organic matter. Nature 528, 6068. doi:10.1038/nature16069

Lian, T., Wang, G., Yu, Z., Li, Y., Liu, X., Jin, J., 2016. Carbon input from 13C-labelled soybean residues in particulate organic carbon fractions in a Mollisol. Biol. Fertil. Soils 52, 331-339. doi: 10.1007/s00374-015-1080-6

Lorenz, K., Lal, R., 2012. Cropland Soil Carbon Dynamics, in: Recarbonization of the Biosphere. Springer Netherlands, Dordrecht, pp. 303-346. doi:10.1007/978-94-0074159-1_14

Majumder, B., Kuzyakov, Y., 2010. Effect of fertilization on decomposition of 14C labelled plant residues and their incorporation into soil aggregates. Soil Tillage Res. 109, 94-102. doi:10.1016/j.still.2010.05.003

Miltner, A., Bombach, P., Schmidt-Brücken, B., Kästner, M,. 21012. SOM genesis: microbial biomass as a significant source. Biogeochemistry 111, 41-55. doi: 10.1007/s10533-0119658-z 
Moreno-Cornejo, J., Zornoza, R., Doane, T.A., Faz, Á., Horwath, W.R., 2015. Influence of cropping system management and crop residue addition on soil carbon turnover through the microbial biomass. Biol. Fertil. Soils 51, 839-845. doi:10.1007/s00374-015-1030-3

Ogle, S.M., Breidt, F.J., Paustian, K., 2005. Agricultural management impacts on soil organic carbon storage under moist and dry climatic conditions of temperate and tropical regions. Biogeochemistry 72, 87-121. doi:10.1007/s10533-004-0360-2

Paustian, K., Six, J., Elliott, E.T., Hunt, H.W., 2000. Management options for reducing CO2 emissions from agricultural soils. Biogeochemistry 48, 147-163. doi:10.1023/A:1006271331703

Post, W.M., Kwon, K.C., 2000. Soil Carbon Sequestration and Land-Use Change: Processes and Potential. Glob. Chang. Biol. 6, 317-328.

Powlson, D., Glendining, M., 2011. Implications for soil properties of removing cereal straw: results from long-term studies. Agron. J. 103, 279-287. doi:10.2134/agronj2010.0146s

Rasse, D.P., Rumpel, C., Dignac, M.-F., 2005. Is soil carbon mostly root carbon? Mechanisms for a specific stabilisation. Plant Soil 269, 341-356. doi:10.1007/s11104004-0907-y

Rumpel, C., Kögel-Knabner, I., 2011. Deep soil organic matter-a key but poorly understood component of terrestrial C cycle. Plant Soil 338, 143-158. doi:10.1007/s11104-0100391-5

Sauerbeck, D., 2001. $\mathrm{CO}_{2}$ emissions and $\mathrm{C}$ sequestration by agriculture-perspectives and limitations. Nutr. Cycl. Agroecosys. 60, 253-266. doi:10.1023/A:1012617516477

Scharlemann, J.P., Tanner, E.V., Hiederer, R. and Kapos, V., 2014. Global soil carbon: understanding and managing the largest terrestrial carbon pool. Carbon Manag. 5, 81-91. doi:10.4155/CMT.13.77

Schlesinger, W.H., 1984. The Role of Terrestrial Vegetation in the Global Carbon Cycle: Measurement by Remote Sensing Edited Soil Organic Matter: a Source of Atmospheric CO2. Woodwell GM (Ed.). John Wiley Sons, Chichester, UK 111-130 (1984).

Schmidt, J., Schulz, E., Michalzik, B., Buscot, F., Gutknecht, J.L.M., 2015. Carbon input and crop-related changes in microbial biomarker levels strongly affect the turnover and composition of soil organic carbon. Soil Biol. Biochem. 85, 39-50. 
doi:10.1016/j.soilbio.2015.02.024

Schrumpf, M., Kaiser, K., Guggenberger, G., Persson, T., Kögel-Knabner, I., Schulze, E.D., 2013. Storage and stability of organic carbon in soils as related to depth, occlusion within aggregates, and attachment to minerals. Biogeosciences 10, 1675-1691. doi:10.5194/bg-10-1675-2013

Schjønning, P., Thomsen, I.K., Moberg, J.P., de Jonge, H., Kristensen, K., Christensen, B.T., 1999. Turnover of organic matter in differently textured soils - I. Physical characteristics of structurally disturbed and intact soils. Geoderma 89:177-198. http://dx.doi.org/10.1016/S0016-7061(98)00083-4

Shahbaz, M., Kuzyakov, Y., Heitkamp, F., 2016. Decrease of soil organic matter stabilization with increasing inputs: Mechanisms and controls. Geoderma. doi:10.1016/j.geoderma.2016.05.019

Silveira, M.L., Liu, K., Sollenberger, L.E., Follett, R.F., Vendramini, J.M.B., 2013. Shortterm effects of grazing intensity and nitrogen fertilization on soil organic carbon pools under perennial grass pastures in the southeastern USA. Soil Biol. Biochem. 58, 42-49. doi:10.1016/j.soilbio.2012.11.003

Six, J., Conant, R.T., Paul, E. a, Paustian, K., 2002. Stabilization mechanisms of soil organic matter: Implications for C-saturatin of soils. Plant Soil 241, 155-176. doi:10.1023/A:1016125726789

Six, J., Elliott, E.T., Paustian, K., 2000. Soil macroaggregate turnover and microaggregate formation: a mechanism for $\mathrm{C}$ sequestration under no-tillage agriculture. Soil Biol. Biochem. 32, 2099-2103. http://dx.doi.org/10.1016/S0038-0717(00)00179-6

Six, J., Paustian, K., 2014. Aggregate-associated soil organic matter as an ecosystem property and a measurement tool. Soil Biol. Biochem. 68, A4-A9. doi:10.1016/j.soilbio.2013.06.014

Smith, P., Haberl, H., Popp, A., Erb, K., Lauk, C., Harper, R., Tubiello, F.N., de Siqueira Pinto, A., Jafari, M., 2013. How much land-based greenhouse gas mitigation can be achieved without compromising food security and environmental goals? Glob. Chang. Biol. 19, 2285-2302. doi:10.1111/gcb.12160

Steinmann, T., Welp, G., Wolf, A., Holbeck, B., Große-Rüschkamp, T., Amelung, W., 2016. 
Repeated monitoring of organic carbon stocks after eight years reveals carbon losses from intensively managed agricultural soils in Western Germany. J. Plant Nutr. Soil Sci. 179, 355-366. doi:10.1002/jpln.201500503

Stewart, C.C.E., Plante, A.A.F., Paustian, K., Conant, R.T., Six, J., 2008. Soil carbon saturation: linking concept and measurable carbon pools. Soil Sci. Soc. Am. J. 72, 379392. doi:10.2136/sssaj2007.0104

Stewart, C.E., Moturi, P., Follett, R.F., Halvorson, A.D., 2015. Lignin biochemistry and soil $\mathrm{N}$ determine crop residue decomposition and soil priming. Biogeochemistry 124, 335351. doi:10.1007/s10533-015-0101-8

Stewart, C.E., Paustian, K., Conant, R.T., Plante, A.F., Six, J., 2007. Soil carbon saturation: Concept, evidence and evaluation. Biogeochemistry 86, 19-31. doi:10.1007/s10533-0079140-0

Stockmann, U., Adams, M.A., Crawford, J.W., Field, D.J., Henakaarchchi, N., Jenkins, M., 2013. The knowns, known unknowns and unknowns of sequestration of soil organic carbon. Agric. Ecosyst. Environ. 164, 80-99. doi:10.1016/j.agee.2012.10.001

Tisdall, J.M., Oades, J.M., 1982. Organic matter and water-stable aggregates in soils. J. Soil Sci. 33, 141-163. doi:10.1111/j.1365-2389.1982.tb01755.x

Wang, H., Boutton, T., Xu, W., Hu, G., Jiang, P., Bai, E., 2015a. Quality of fresh organic matter affects priming of soil organic matter and substrate utilization patterns of microbes. Sci. Rep. 5, 10102. doi:10.1038/srep10102

Wang, H., Xu, W., Hu, G., Dai, W., Jiang, P., Bai, E., 2015b. The priming effect of soluble carbon inputs in organic and mineral soils from a temperate forest. Oecologia 178, 12391250. doi:10.1007/s00442-015-3290-x

Xiao, C., Guenet, B., Zhou, Y., Su, J., Janssens, I.A., 2015. Priming of soil organic matter decomposition scales linearly with microbial biomass response to litter input in steppe vegetation. Oikos 124, 649-657. doi:10.1111/oik.01728 


\section{Appendix}

\subsection{Supplementary material Study 3.2}

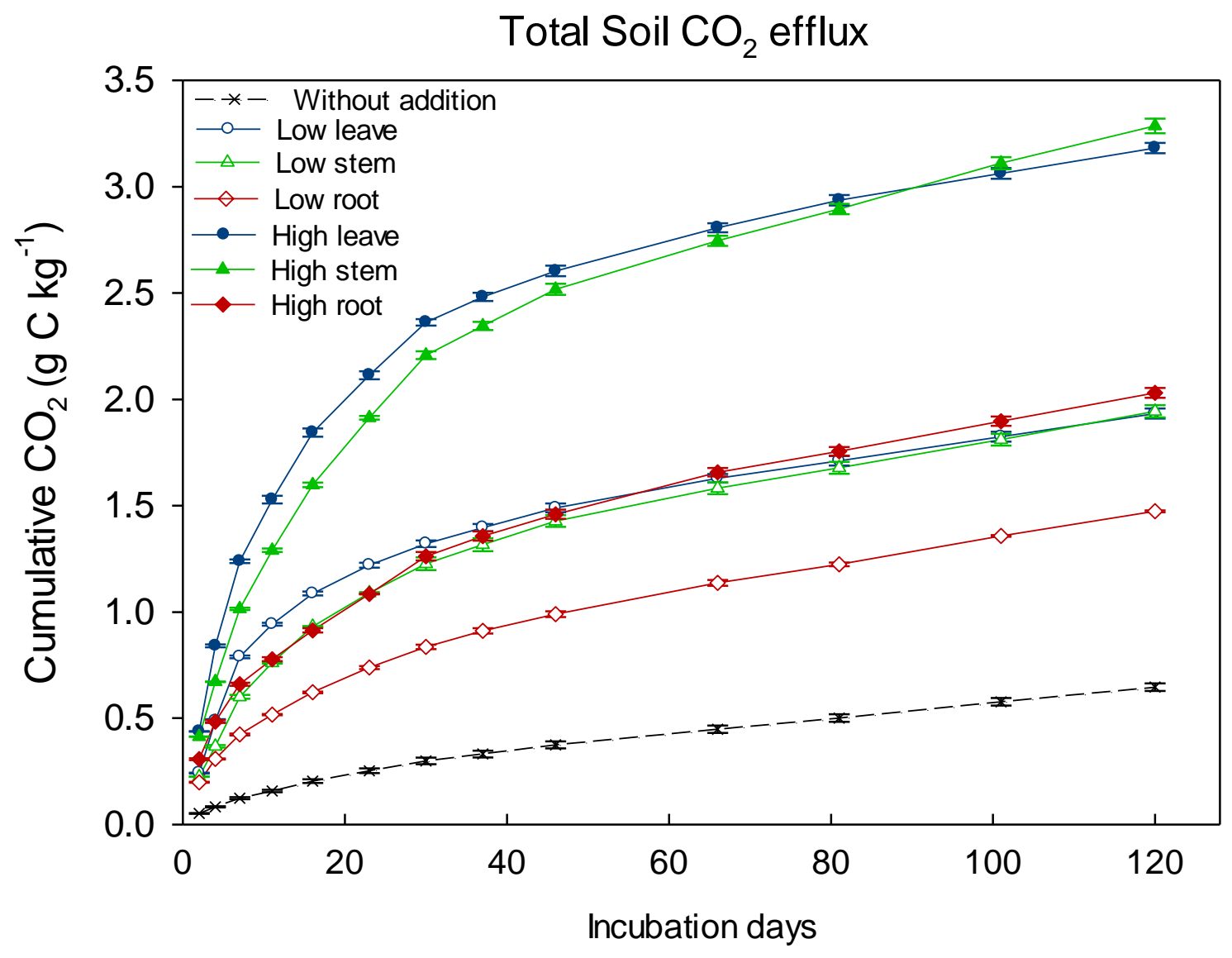

Figure S2-S1. Cumulative total soil $\mathrm{CO}_{2}$ efflux over 120 days of incubation, depending on type and level of crop residue additions. Mean values with standard errors $(n=3)$. 


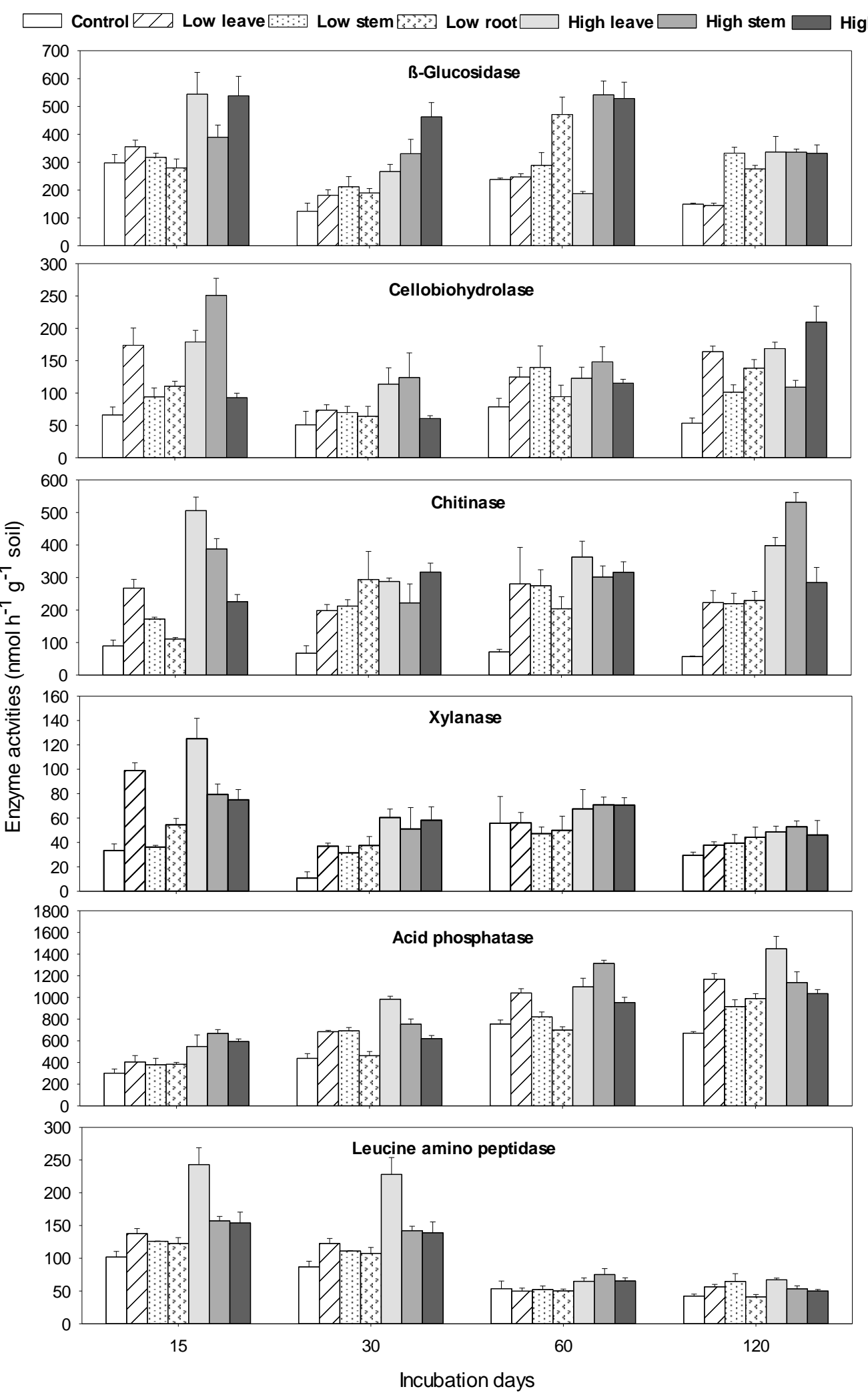

Figure S2-S2. The effect of residue type and level of addition on potential soil enzymes activities over the incubation period of 120 days. Mean values with standard errors $(n=3)$. 
Table S2-S1: The Pearson correlations (r) of residue and soil organic matter (SOM) derived microbial biomass carbon (MBC) with total and residue originated $\mathrm{CO}_{2}$ efflux, and with the values of the potential activities of hydrolytic enzymes in soils amended with residues at incubation day 15 , 30 , 60 and 120 .

\begin{tabular}{|c|c|c|c|c|c|c|c|c|}
\hline & Total $\mathrm{CO}_{2}$ & Residue $\mathrm{CO}_{2}$ & ß-Glucosidase & Acid Phosphatase & Chitinase & Xylanase & Cellubiohydrolase & LAP $^{*}$ \\
\hline 30 day & 0.54 & 0.64 & 0.08 & 0.90 & 0.02 & 0.40 & 0.40 & 0.85 \\
\hline 120 day & 0.76 & 0.78 & 0.27 & 0.53 & 0.86 & 0.29 & -0.25 & 0.33 \\
\hline \multicolumn{9}{|c|}{ SOM MBC } \\
\hline 60 day & 0.39 & 0.40 & 0.07 & 0.35 & 0.02 & 0.13 & 0.11 & 0.17 \\
\hline 120 day & 0.48 & 0.53 & -0.09 & 0.50 & 0.65 & 0.11 & -0.05 & 0.14 \\
\hline
\end{tabular}

*Leucine aminopeptidase 


\subsection{Contribution to the studies}

Names order corresponds to the estimated importance of the each contribution

Study 1 (chapter 3.1): Decrease of soil organic matter stabilization with increasing inputs: mechanisms and controls

Study design: Felix Heitkamp, Muhammad Shahbaz, Yakov Kuzyakov

Sample collection: Muhammad Shahbaz

Sample preparation, incubation and analysis: Muhammad Shahbaz

Data interpretation: Muhammad Shahbaz, Felix Heitkamp

Manuscript writing: Muhammad Shahbaz

Comments on manuscript: Felix Heitkamp, Yakov Kuzyakov

Study 2 (chapter 3.2): Microbial decomposition of soil organic matter is mediated by quality and quantity of crop residues: mechanisms and thresholds

Study design: Muhammad Shahbaz, Felix Heitkamp, Yakov Kuzyakov

Sample collection: Muhammad Shahbaz, Muhammad Sanaullah

Sample preparation, incubation and analysis: Muhammad Shahbaz, Amit Kumar,

Muhammad Sanaullah

Data interpretation: Muhammad Shahbaz, Evgenia Blagodatskaya

Logistic model development: Vladimir Zelenev, Evgenia Blagodatskaya, Muhammad Shahbaz, Felix Heitkamp

Manuscript writing: Muhammad Shahbaz

Comments on manuscript: Evgenia Blagodatskaya, Yakov Kuzyakov, Muhammad Sanaullah, Felix Heitkamp 
Study 3 (chapter 3.3): Decadal nitrogen fertilization decreases mineral-associated and subsoil carbon: a 32 year study

Field experiment maintenance: Matthias Wendland

Sample collection: Muhammad Shahbaz, Shafique Maqsood, Felix Heitkamp

Sample preparation and analysis: Muhammad Shahbaz, Shafique Maqsood

Data interpretation: Muhammad Shahbaz, Felix Heitkamp, Yakov Kuzyakov

Manuscript writing: Muhammad Shahbaz

Comments on manuscript: Felix Heitkamp, Yakov Kuzyakov

Study 4 (chapter 4, in preparation): Interactive effect of glucose and partially decomposed plant residues priming: A three source partitioning study

Study design: Muhammad Shahbaz, Yakov Kuzyakov, Felix Heitkamp

Sample collection: Muhammad Shahbaz

Sample preparation, incubation and analysis: Muhammad Shahbaz

Data interpretation: Muhammad Shahbaz, Evgenia Blagodatskaya

Preliminarily results writing: Muhammad Shahbaz 


\subsection{Declarations}

1. I, hereby, declare that this Ph.D. dissertation has not been presented to any other examining body either in its present or a similar form.

Furthermore, I also affirm that I have not applied for a Ph.D. at any other higher school of education.

Göttingen,

(Signature)

MUHAMMAD SHAHBAZ

(Name in block capitals)

2. I, hereby, solemnly declare that this dissertation was undertaken independently and without any unauthorized aid.

Göttingen,

(Signature)

MUHAMMAD SHAHBAZ

(Name in block capitals) 


\title{
7.4 Curriculum vitae
}

Georg-August-Universität Göttingen

Department of agricultural soil sciences Büsgenweg 2, Göttingen, 37077

Germany shahbazmu@yahoo.com

Phone: 0049 (0) 5513920502

Mobile: 0049 (0) 17641737599

http://www.uni-goettingen.de/de/544112.html

\section{Muhammad Shahbaz}

(born on 30.08.1986)

\section{Education}

\author{
July 2014 - Dec 2016 PhD, Agricultural Soil Science \\ Georg-August-Universität Göttingen, Göttingen, Germany \\ Sep 2009 - Jun 2011 M.Sc. (Hons) Agricultural Soil Sciences \\ University of Agriculture Faisalabad, Faisalabad, Pakistan \\ Aug 2005 - Sep 2009 B.Sc.(Hons), Agricultural Soil Science \\ University of Agriculture Faisalabad, Faisalabad, Pakistan
}

\section{Research Work Experience}

Oct 2012 - Justus-Liebig University of Gießen,

April 2014 Institute of plant nutrition, Gießen, Hessen, Germany

May 2009 - University of Agriculture Faisalabad,

Oct 2011 Institute of Soil and Environmental Sciences, Faisalabad, Punjab, Pakistan

\section{Training/Workshops}

2014 - 2016 Georg-August-Universität Göttingen, Germany: Modules:

\footnotetext{
2013 (7 days) DAAD-Berlin (Wandlitz), Germany

2010 (4 University of Agriculture weeks) Faisalabad, Pakistan

2010 (8 Fauji Fertilizer Company (Pvt. Ltd) weeks) Pakistan
}

Research project: Role of abscisic acid and auxin in acid invertase activity and kernel setting of various maize hybrids under salt stress

Research project: Investigating the role of foliar feeding of micronutrients for crop yield maximization in Punjab

- Linear statistical models with R

- Systematic review and metaanalysis in ecology

- Isotopes in ecosystems sciences and environment

- Scientific writing and publishing in crop sciences

- Soil biogeochemistry discussions

Making sustainability internationally

Remote sensing and digital image processing

Assessment of farmer field problems and provision of fertilizer recommendations 
Awards \& Grants

Oct 2012 PhD Scholarship: German Academic Exchange Service (DAAD), Germany

Oct 2011 Award: master thesis research funding from International Center for Development and Decent work (ICDD), University of Kassel, Germany

Sep 2011 Award: Highest CGPA (4.00/4.00) award in M.Sc. (Hons); institute of soil and environmental Sciences, University of Agriculture, Faisalabad, Faisalabad Pakistan

Aug 2009 Award: Highest CGPA (3.98/4.00) award in B.Sc. (Hons); institute of soil and environmental Sciences, University of Agriculture, Faisalabad, Faisalabad Pakistan

\title{
Research Interests and Skills
}

\author{
Research interests Soil organic matter, Soil structure, Carbon sequestration, Priming effects, \\ Partitioning of $\mathrm{CO}_{2}$ fluxes, Stable and radioactive isotopic applications \\ $\left({ }^{13} \mathrm{C},{ }^{14} \mathrm{C}\right.$ and $\left.{ }^{15} \mathrm{~N}\right)$, Soil organic matter dynamics, Crop residue quality \\ effects, Soil fertility, Sustainable agriculture \\ Languages English (fluent), German (medium), Urdu (mother tongue) \\ Scientific European Geosciences Union (EGU), Vienna, Austria \\ Memberships \\ Softwares MS-office, SigmaPlot, Statistix 8.1, Linear statistical model R (basic), \\ Mendeley
}

\section{Journal Publications}

Shahbaz M, Kuzyakov Y, Maqsood S, Weendlad M, Heitkamp F: Decadal nitrogen fertilization decreases mineral-associated and subsoil carbon. Land Degradation \& Development 11/2016. DOI: $10.1002 / \mathrm{ldr} .2667$

Shahbaz M, Kuzyakov Y, Heitkamp F: Decrease of soil organic matter stabilization with increasing inputs: Mechanisms and controls. Geoderma 06/2016. DOI:10.1016/j.geoderma.2016.05.019

Shahbaz M, Kuzyakov Y, Sanaullah M, Heitkamp F, Zelenev V, Kumar A, Blagodatskaya E: Microbial decomposition of soil organic matter is mediated by quality and quantity of crop residues: mechanisms and thresholds. Biology and Fertility of soils 12/2016. DOI: 10.1007/s00374-016-1174-9

Shahbaz M, Akhtar MJ, Ahmed W, Wakeel A: Integrated effect of different N-fertilizer rates and bioslurry application on growth and N-use efficiency of okra (Hibiscus esculentus L.). Turkish Journal of Agriculture and Forestry 03/2014. DOI:10.3906/tar-1303-65

Yaseen M, Ahmed W, Shahbaz M: Role of foliar feeding of micronutrients in yield maximization of cotton in Punjab. Turkish Journal of Agriculture and Forestry 07/2013. DOI:10.3906/tar-120656 


\section{Conference Proceedings}

Shahbaz M, Sanaullah M, Kuzyakov Y, Heitkamp F, Zelenev V, Blagodatskaya E: Microbial residues accelerate decomposition of Soil Organic Matter: new mechanism, actors and thresholds. Workshop "SOMmic - Microbial Contribution and Impact on Soil Organic Matter, Structure and Genesis“. Leipzig, Germany, November 9-11, 2016 (Oral presentation)

Stelmach, W, Shahbaz M, Bieganowski A, Kuzyakov Y: Sludge C stabilization and mineralization in soil as assessed by ${ }^{13} \mathrm{C}$ natural abundance. $11^{\text {th }}$ International Conference on Agrophysics, September 26-28 2016, Lublin (Poland)

Stelmach W, Shahbaz M, Bieganowski A, kuzyakov Y: Sequestration of sludge C in soil as assessed by ${ }^{13} \mathrm{C}$ abundance and ${ }^{14} \mathrm{C}$ labeling. $15^{\text {th }}$ International Workshop for Young Scientists, BioPhys Spring 2016, 05/2016, Prague (Czech Republic)

Shahbaz M, Kuzyakov Y, Heitkamp F: Mineral-associated and aggregate-occluded soil carbon decreased with increasing nitrogen and residue input for three decades. EGU General Assembly 2016, Vienna (Austria); 04/2016 (Oral presentation)

Shahbaz M, Kuzyakov Y, Heitkamp F: High rate of residue addition decreases stabilization efficiency due to priming and low physical protection. $5^{\text {th }}$ International Symposium on Soil Organic Matter; Göttingen (Germany); 09/2015 (Poster presentation)

Shahbaz M, Kuzyakov Y, Heitkamp F: Dynamics of soil organic matter and residue addition.

Colloquium of the Regulation of soil organic matter and nutrient turnover in organic agriculture, Witzenhausen-university of Kassel (Germany) 11/2015 (Oral + Poster presentation) 